\title{
ROBERTO RATZKE
}

Avaliação da confiabilidade e validade da versão em português ( $\mathrm{SCl}$ MOODS - VP) de uma entrevista estruturada para o espectro do humor , a Structured Clinical Interview for Mood Spectrum (SCI-MOODS)

Dissertação apresentada à Faculdade de Medicina da Universidade de São Paulo para obtenção do título Mestre em Ciências

Área de Concentração: Psiquiatria

Orientador: Prof. Dr. Ricardo Alberto Moreno

SÃO PAULO

2007 
Ao meu filho Bernardo 


\section{Agradecimentos}

Agradeço a todas as pessoas que contribuíram de alguma forma neste projeto, principalmente:

Ao Dr. Ricardo Alberto Moreno, por aceitar ser meu orientador, pelo seu estímulo ao raciocínio e importantes contribuições na sua orientação.

Aos estudantes de medicina, residentes e ex-residentes da Clínica Heidelberg que me auxiliaram nas minhas atividades habituais, permitindo minha dedicação à pós-graduação.

Aos colegas do Grupo de Doenças Afetivas (GRUDA), que auxiliaram com sugestões e críticas a este estudo e na seleção de pacientes.

Á Dra. Doris Moreno, por despertar em mim o interesse pelo espectro bipolar.

Aos Drs. Clarice Gorenstein, Laura Helena Guerra de Andrade, Frederico Navas Demétrio pelas sugestões durante a minha qualificação.

Aos meus pais,Osmar e Clarice, e à minha irmã Karin que nunca deixaram de me incentivar e me apoiar em meus projetos pessoais e profissionais. 
A minha esposa Adriane, pela paciência que sempre demonstrou comigo durante este período especial em nossas vidas. 
Esta dissertação encontra-se de acordo com as seguintes normas, em vigência atualmente:

Referências: International Committee of Medical Journal Editors (Vancouver)

Serviço de Biblioteca e Documentação, Faculdade de Medicina da Universidade de São Paulo. Guia de apresentação de dissertações, teses e monografias. $2^{\mathrm{a}}$ ed. São Paulo: 2005.

Universidade de São Paulo, Sistema Integrado de Bibliotecas-SIBi. Diretrizes para a apresentação de dissertações e teses da USP: documento eletrônico e impresso. Grupo DiTeses (compilação). São Paulo: 2004.

Abreviatura dos títulos dos periódicos de acordo com o List of Journals Indexed in Index Medicus 


\section{SUMÁRIO}

DEDICATÓRIA

AGRADECIMENTOS

LISTA DE ILUSTRAÇÕES

LISTA DE TABELAS

LISTA DE SIGLAS

RESUMO

SUMMARY

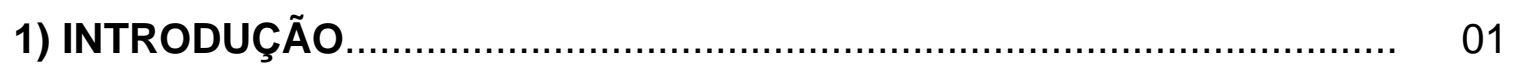

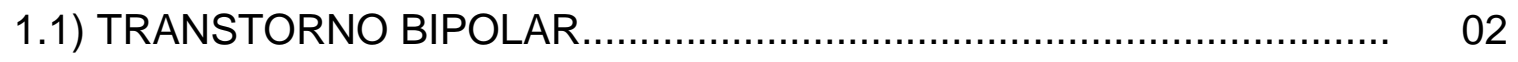

1.1.1) Uma breve história do transtorno bipolar.......................................... 02

1.1.2) Diagnóstico e classificação.............................................................. 04

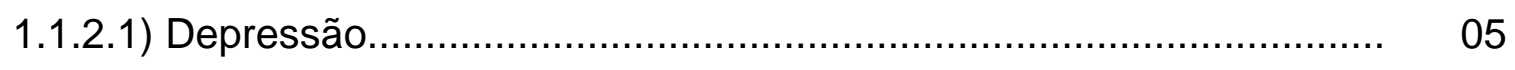

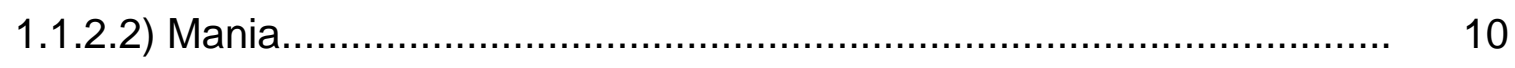

1.1.2.3) Episódio misto..................................................................... 12

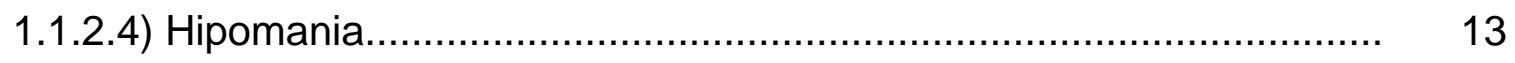

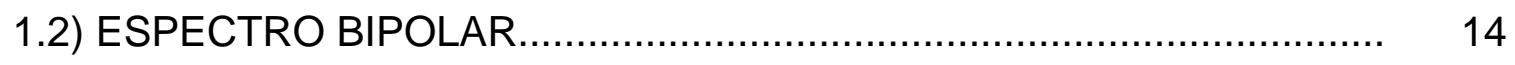

1.2.1) Instrumentos para avaliação do espectro bipolar............................. 18

1.2.2) O projeto Spectrum e a SCI-MOODS............................................. 20

1.3) VALIDADE E CONFIABILIDADE ................................................ 25

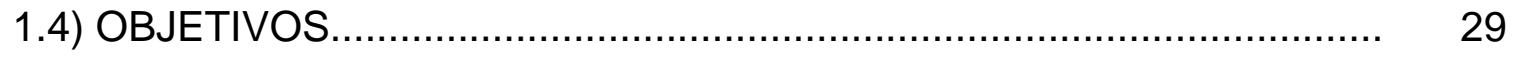

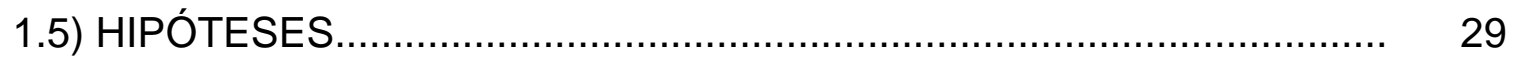

2) CASUÍSTICA E MÉTODOS........................................................... 30 


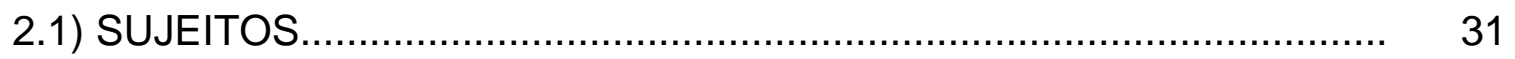

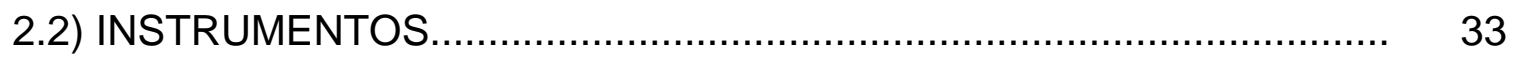

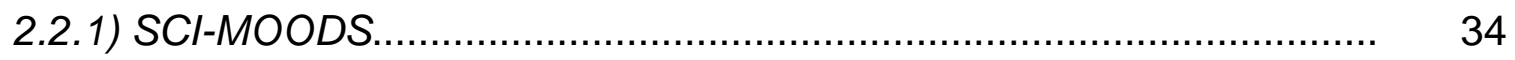

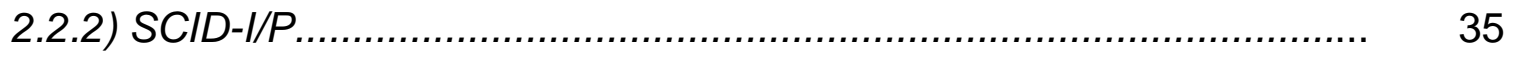

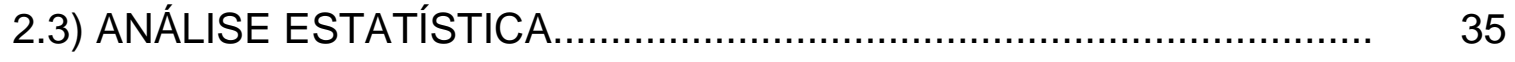

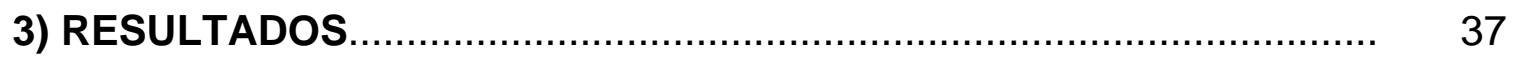

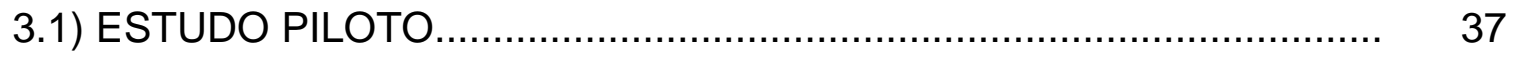

3.2) ESTUDO PRINCIPAL............................................................. 39

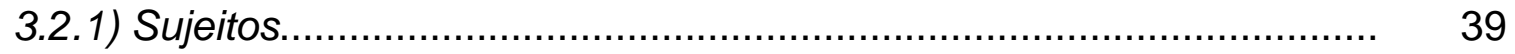

3.2.2) Resultados da SCID-I/P........................................................... 40

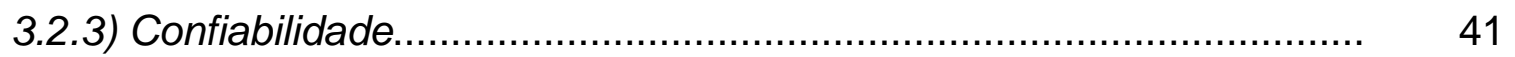

3.2.4) Correlação parcial..........................................................................

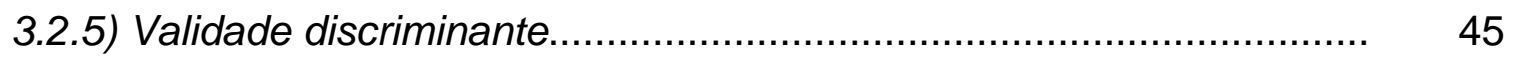

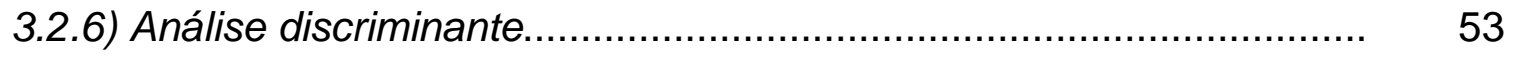

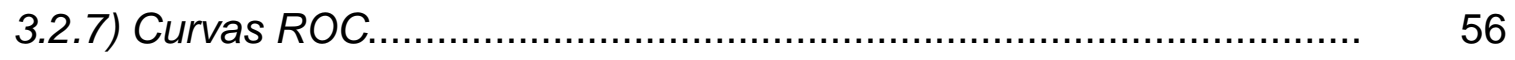

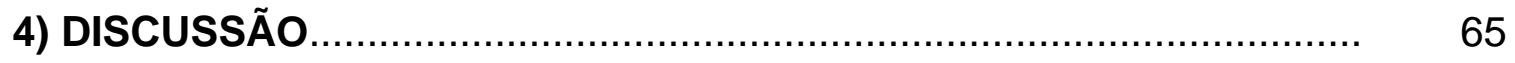

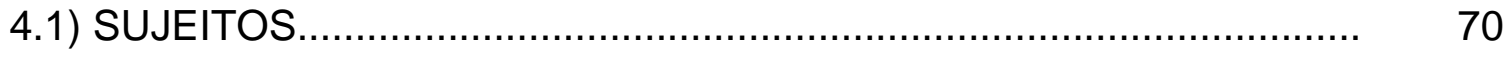

4.2) RESULTADOS DA SCID-I/P..........................................................

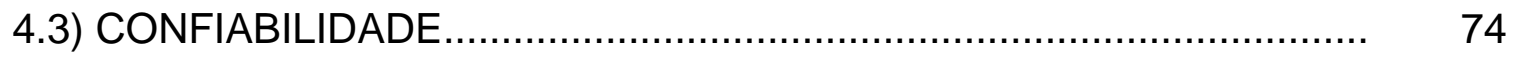

4.4) TIPOS DE VALIDADE E A SCI-MOODS........................................

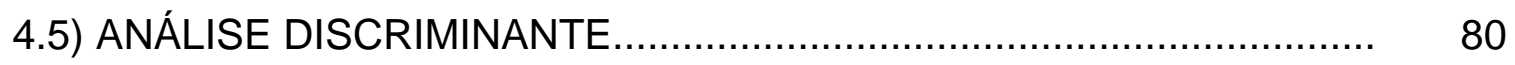

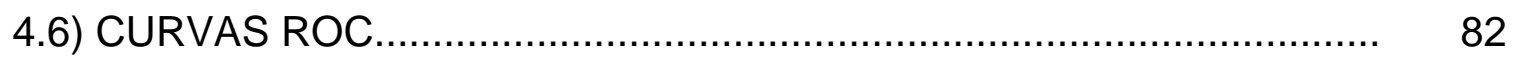

4.7) A IMPORTÂNCIA DA SCI-MOODS-VP.............................................. 83 


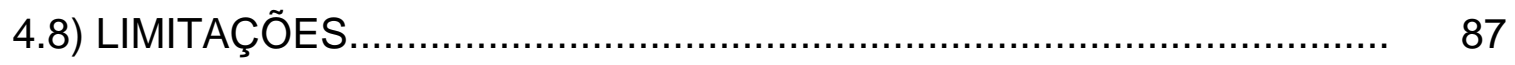

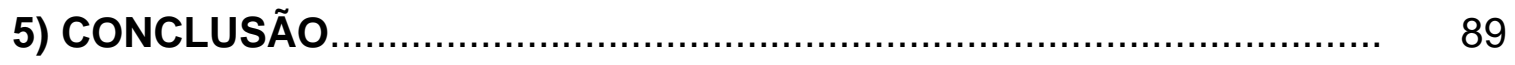

6) ANEXOS

6.1)ANEXO A. VERSÃO EM INGLÊS AMERICANO DA SCI-MOODS......... 91

6.2)ANEXO B. VERSÃO FINAL DA SCI-MOODS-VP.............................. 106

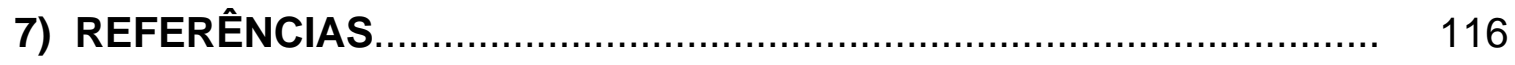




\section{LISTA DE ILUSTRAÇÕES}

Quadro 1. Critérios diagnósticos de Ghaemi e colaboradores para o

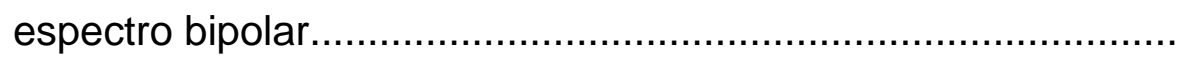

Gráfico 1. Curva ROC (sensibilidade x 1-especificidade) de escore total, maníaco e depressivo entre bipolares $(n=47)$ e unipolares

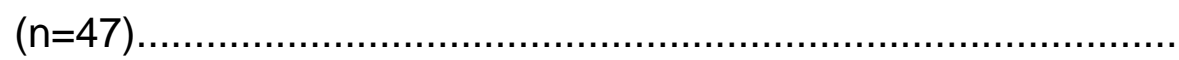

Gráfico 2. Curva ROC (sensibilidade x 1 - especificidade) de escores total, maníaco e depressivo entre pacientes portadores de transtornos afetivos $(n=94)$ e controles $(n=40)$ 


\section{LISTA DE TABELAS}

Tabela 1- Principais resultados de estudos de validação do Projeto

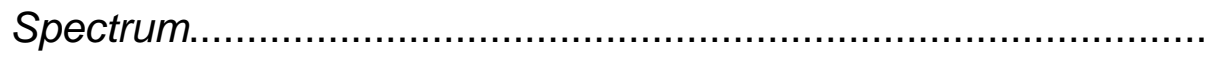

Tabela 2- Características demográficas e pontuações da SCI-MOODS-VP dos primeiro vinte sujeitos do estudo piloto

Tabela 3- Características demográficas dos sujeitos.

Tabela 4- Resultados da SCID-I/P

Tabela 5- Consistência interna (Cl) da SCI-MOODS-VP.

Tabela 6-Características dos sujeitos do estudo de confiabilidade entre examinadores.

Tabela 7- Comparação entre a amostra original de bipolares e unipolares $(n=94)$ e da do estudo de confiabilidade entre examinadores $(n=20)$

Tabela 8- Correlação parcial entre domínios e subdomínios da SClMOODS-VP, controlada por idade e sexo....................................

Tabela 9- Escore médio ( \pm desvio padrão) dos domínios e subdomínios da SCIMOODS-VP em bipolares, unipolares, esquizofrenia, normais e amostra total

Tabela 10-ANOVA de escores depressivo, maníaco, total, de domínios e subdomínios da SCI-MOODS-VP

Tabela 11-Diferenças entre escores de domínios e subdomínios da SClMOODS-VP de sujeitos no Post Hoc Dunnett C de ANOVA........ 
Tabela 12-Teste de Kruskal-Wallis -Rank de escores maníaco, depressivo, total, subdomínios domínios da SCI-MOODS-VP... 52

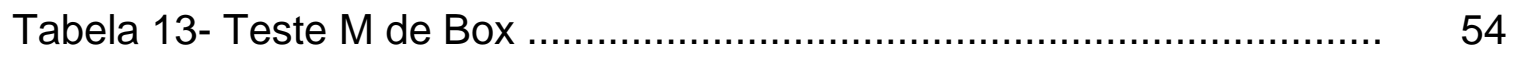

Tabela 14- Determinantes log do teste $\mathrm{M}$ de Box.............................. 54

Tabela 15-Análise discriminante passo a passo (forward stepwise) progressiva dos subdomínios da SCI-MOODS-VP em

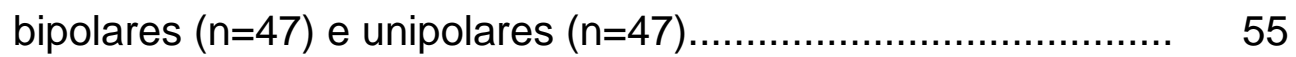

Tabela 16- Função discriminante canônica...................................... 55

Tabela 17- Coeficientes da função discriminante canônica......................... 56

Tabela 18- AUC dos escores maníaco, depressivo e total da curva ROC

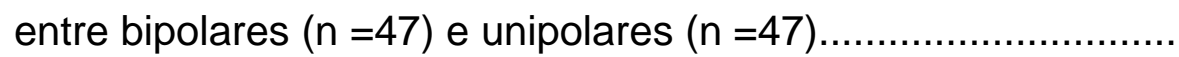

Tabela 19-Coordenadas da curva ROC do escore maníaco entre bipolares $(n=47)$ e unipolares $(n=47)$

Tabela 20- Propriedades do escore maníaco da SCI-MOODS-VP maior ou igual a 30 (em \%)

Tabela 21- AUC da curva ROC, escore maníaco, depressivo e total entre sujeitos com transtornos afetivos $(n=94)$ e controles $(n=40) \ldots$

Tabela 22- Coordenadas da curva ROC do escore depressivo entre sujeitos com transtornos afetivos $(n=94)$ e controles $(n=40)$.. 63

Tabela 23- Propriedades do escore depressivo da SCI-MOODS-VP maior ou igual a 35 (em \%). 
Tabela 24 -Internações públicas por esquizofrenia e transtorno bipolar no 85 estado de São Paulo entre novembro de 2005 e Outubro de

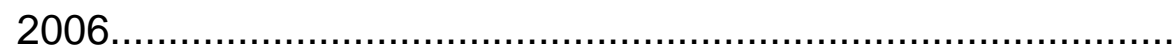




\section{LISTA DE SIGLAS}

$\begin{array}{ll}\text { ABS-SR } & \text { Anorexic-Bulimic Spectrum, Self-Report } \\ \text { ANOVA } & \text { Análise de variância } \\ \text { APA } & \text { Associação Psiquiátrica Americana } \\ \text { AUC } & \text { Área abaixo da curva } \\ \text { BDI } & \text { Inventário de Depressão de Beck } \\ \text { BPRS } & \text { Escala Breve de Avaliação Psiquiátrica } \\ \text { BRMS } & \text { Bech-Rafaelsen Mania Scale } \\ \text { BSDS } & \text { Bipolar Spectrum Diagnostic Scale } \\ \text { CARS-M } & \text { Clinician Administered Rating Scale for Mania } \\ \text { CID-10 } & \text { Classificação Internacional de Doenças, 10a. Edição } \\ \text { CIDI } & \text { Composite International Diagnostic Interview } \\ \text { DIS } & \text { Diagnostic Interview Schedule } \\ \text { DSM-IV } & \text { Manual Diagnóstico e Estatístico, 4a. Edição } \\ \text { ECA } & \text { Epidemiological Catchment Area } \\ \text { FHS } & \text { Family History Screen } \\ \text { GAEM } & \text { Guia para Avaliação do Estado Maníaco } \\ \text { GRUDA } & \text { Grupo de Estudos de Doenças Afetivas } \\ \text { HAM-A } & \text { Correlação intra-classe } \\ \text { HAM-D } & \text { Escala de Depressão de Hamilton } \\ \text { HCL-32 } & \text { ICC }\end{array}$


IMC Índice de massa corporal

IPq HC FMUSP Instituto de Psiquiatria do Hospital das Clínicas da Faculdade de Medicina da Universidade de São Paulo

MADRS Escala de Depressão de Montgomery-Asberg

MANOVA Análise de variância multivariável

MDQ Mood Disorder Questionnaire

MINI Mini-International Neuropsychiatric Interview

MOODS-SR Mood Spectrum, Self-Report

MRS Mania Rating Scale

OBS-SR Obsessive -Compulsive Spectrum, Self-Report

OMS Organização Mundial da Saúde

PAS-SR Panic-Agoraphobic Spectrum, Self-Report

PSY-SR Psychotic Spectrum, Self-Report

RDC Research Diagnostic Criteria

ROC Receiver operating characteristic

SAS-SR Separation Anxiety Symptoms, Self-Report

SCAN Schedules for Clinical Assessment in Neuropsychiatry

SCl-ABS Structured Clinical Interview for Anorexic - Bulimic Spectrum,

Self -Report

SCID-I/P Entrevista Clínica Estruturada para o DSM-IV Transtornos do

Eixo I, Versão de Pacientes

SCI-MOODS Structured Clinical Interview for Mood Spectrum

SCI-MOODS-VP Entrevista Clínica Esruturada para o Espectro do Humor Versão em Portguês 
SCI-OBS

SCI-PAS

SCI-PSY

SCI-SAS

SCl-SHY

SCI-SUBS

SHY-SR

SRQ-20

STAI

STEP-BD

SUBS -SR

$\mathrm{TCl}$

WMHS
Structured Clinical Interview for Obsessive-Compulsive

Spectrum

Structured Clinical Interview for Panic-Agoraphobic Spectrum

Structured Clinical Interview for the Psychotic Spectrum

Structured Clinical Interview for Separation Anxiety

Symptoms

Structured Clinical Interview for Social Phobia Spectrum

Structured Clinical Interview for the Spectrum of Substance

Use

Social Phobia Spectrum, Self-Report

Self-Report Questionnaire

Inventário de Ansiedade Traço-Estado

Systematic Treatment Enhancement Program for Bipolar

Disorder

Spectrum of Substance Use, Self-Report

Inventário de Temperamento e Caráter

World Mental Health Survey 


\section{RESUMO}

Ratzke R. Avaliação da confiabilidade e validade da versão em português (SCIMOODS - VP) de uma entrevista estruturada para o espectro do humor , a Structured Clinical Interview for Mood Spectrum (SCI-MOODS) [dissertação]. São Paulo: Faculdade de Medicina, Universidade de São Paulo; p.131.

A SCI-MOODS (Entrevista Clínica Estruturada para o Espectro do Humor) é uma entrevista de 161 itens com sete subdomínios (humor depressivo e maníaco, energia depressiva e maníaca, cognição depressiva e maníaca e ritmicidade) que avalia o humor de forma dimensional, permitindo um diagnóstico mais preciso de transtornos afetivos. O objetivo deste estudo é desenvolver uma versão em português, a SCI-MOODS -VP, determinando sua confiabilidade, validade e uma linha de corte entre pacientes bipolares e unipolares e portadores de transtornos do humor e controles (normais e esquizofrênicos). A SCI-MOODS, versão 3.0, foi traduzida do inglês para o português brasileiro e posteriormente retro-traduzida. Foram selecionados, bipolares $(n=47)$, unipolares $(n=47)$, esquizofrênicos ( $n=18)$, e sujeitos sem transtorno psiquiátrico $(n=22)$, de acordo com o SCID-I/P. Uma análise discriminante progressiva passo a passo foi feita entre os subdomínios de bipolares e unipolares além de uma curva ROC para determinar o melhor ponto de corte. A consistência interna de domínios e subdomínios da SCI-MOODS-VP variou entre 0.86 to 0.94 . A confiabilidade entre examinadores de uma amostra de 10 bipolares e 10 unipolares apresentou coeficiente de correlação intra-classe de 0,956. Os sujeitos bipolares apresentaram escores total e maníaco da SCI-MOODS - VP maiores que os 
outros grupos. A curva receiver operating characteristic (ROC) do escore maníaco entre bipolares e unipolares apresentou área abaixo da curva (AUC) de 0,909. O escore maníaco igual ou acima de 30 demonstrou sensibilidade de 91 , $49 \%$ e especificidade de $74,47 \%$. Outra curva entre pacientes com transtornos afetivos e controles apresentou escore depressivo com AUC de 0,869. O escore depressivo acima de 35 teve sensibilidade de $82.98 \%$ e especificidade de $75 \%$. A energia maníaca e o humor maníaco foram os subdominios que melhor distinguiram os bipolares de unipolares através de uma análise discriminante passo a passo progressiva. A correlação parcial entre domínios e subdomínios, controlados por sexo e idade, medida pelo alfa de Cronbach, variou entre 0.472 to 0.937.Concluímos que a SCI-MOODS - VP apresenta boa validade discriminante e confiabilidade.

Descritores: 1-TRANSTORNO BIPOLAR 2- VALIDADE 3- DIAGNÓSTICO 4-ENTREVISTA 


\section{SUMMARY}

Ratzke R. Reliability and Validity of a Brazilian Portuguese mood spectrum interview (SCI-MOODS-VP), the Structured Clinical Interview for Mood Spectrum (SCI-MOODS) [dissertation]. São Paulo: Faculdade de Medicina, Universidade de São Paulo; p. 131.

The SCI-MOODS (Structured Clinical Interview for Mood Spectrum) is a 161 questions questionnaire with seven sub domains (depressive and manic mood, depressive and manic energy, depressive and manic cognitive functioning and rhythmicity) that evaluates mood as a dimensional construct allowing a more precise mood disorder diagnosis. We developed the SCI-MOODS-VP, a Brazilian Portuguese version, and established its validity and reliability, and determined a threshold score for differentiation between bipolar from unipolar and affective patients from non-affective controls. The English 3.0 version of SCl-MOODS was translated to Brazilian Portuguese and back-translated. Bipolars $(n=47)$, unipolars $(n=47)$ and schizophrenics $(n=18)$ patients, and 22 subjects without psychiatric diagnostic according to SCID-I/P were selected. A forward stepwise discriminant analysis among bipolars and unipolars sub domains and two ROC curves to determine the bipolar threshold were done. The internal consistency of SClMOODS-VP domains and sub domains was 0,86 to 0,94 . The interater reliability among 10 bipolar and 10 unipolar subjects had an intraclass coefficient of 0,956. The bipolar subjects had total and manic scores higher than other groups. A receiver operating characteristic (ROC) curve of manic score between bipolar and unipolar subjects had an area under curve (AUC) of 0,909. The manic score equal 
or above 30 had a $91,49 \%$ sensibility and $74,47 \%$ specificity. Other ROC curve between patients with affective disorders and controls (without psychiatric diagnostic and schizophrenics) had a depressive score with AUC of 0,869 . The depressive score equal or above 35 had an $82,98 \%$ sensibility and a $75 \%$ specificity. The manic energy and mood were the sub domains that best distinguished bipolar and unipolar subjects by discriminant analysis. The partial correlation among domains and subdomains, controlled by age and gender, measured by Cronbach's alpha, was 0,472 to 0,93 . SCI-MOODS-VP has good reliability and discriminant validity.

Descriptors: 1-BIPOLAR DISORDER 2-REPRODUCIBILITY OF RESULTS 3-DIAGNOSIS 4-MENTAL STATUS SCHEDULE 


\section{1) INTRODUÇÃO}

O diagnóstico correto do transtorno bipolar (TB) muitas vezes pode demorar até 10 anos desde o início dos sintomas (Hirschfeld et al., 2003). Ele é diagnosticado com freqüência como depressão unipolar ou transtornos de personalidade e nas suas formas mais graves (psicóticas) pode ser confundido com a esquizofrenia (Pope Jr e Lipinski,1978). É caracterizado por episódios de depressão, estados mistos e mania ou hipomania, estes dois últimos porém muitas vezes não são relatados durante a consulta clínica ou não são vistos como patológicos por pacientes e familiares (Cassano et al., 1999).

O TB tipo I é a forma clássica da doença. Sua prevalência na população geral varia entre 1 e 2 \% (Kessler et al., 1994; Grant et al., 2005). O TB tipo II é caracterizado por hipomania e depressão (APA,1994). As formas mais leves do TB podem afetar até $11 \%$ da população (Angst et al., 2003a). Estas incluem o espectro bipolar. Provavelmente, no Brasil este número seja em torno de $8 \%$ (Moreno \& Andrade, 2005).

O TB apresenta alta recorrência. Cerca de $90 \%$ dos pacientes irão apresentar uma recorrência sem tratamento, sendo metade destas nos primeiros 2 anos (Sajatovic, 2005). Gitlin e colaboradores demonstraram uma taxa de recorrência de 73 \% em 5 anos mesmo com o tratamento adequado (Gitlin et al, 1995). Em um seguimento de 10 anos cerca de $50 \%$ dos pacientes melhoraram 
com o tratamento e 30 a 40 \% têm um declínio funcional (Goldberg e Harrow, 2004). Cerca de $60 \%$ dos bipolares estavam desempregados e $88 \%$ referiam dificuldades ocupacionais em um estudo americano mesmo estando em tratamento (Hirschfeld et al., 2003). Outro estudo demonstrou $65 \%$ dos bipolares em tratamento com dificuldade de manter relacionamentos com parceiros a longo prazo e $64 \%$ com problemas de relacionamento com os seus filhos (Kupfer et al., 2002). É a doença com maior risco de suicídios entre as doenças clínicas ou psiquiátricas (Woods, 2000). Ela apresenta altas taxas de comorbidade. Um estudo populacional mostrou que dentre os pacientes com TB, $46 \%$ tinham abuso ou dependência de álcool, 41 \% abuso ou dependência de outras substâncias, 21 \% transtorno de pânico e 21 \% transtorno obsessivo-compulsivo (Sajatovic, 2005).

Os pacientes bipolares geralmente buscam o tratamento durante a depressão. Os médicos, por outro lado, não dispõem de instrumentos adequados para o diagnóstico diferencial. Há, por exemplo, mais entrevistas estruturadas e escalas para avaliação de depressão e esquizofrenia do que para mania ou hipomania (Vilela e Loureiro, 2000).

\section{1) TRANSTORNO BIPOLAR}

\subsection{1) Uma breve história do transtorno bipolar}

Dado o aumento do interesse e prevalência do TB nos últimos anos (Angst et al., 2003a), há a impressão desta ser uma doença moderna. A sua primeira descrição ocorreu no primeiro século antes de Cristo, na Capadócia, por Areteu 
(Goodwin e Ghaemi, 2003; Wang, 2005). A melancolia, hoje um subtipo da depressão, já era conhecida à época pelos gregos, tendo sido descrita por Hipócrates de Cós, entre o século quarto e quinto antes de Cristo. Areteu acreditava que a mania evoluía a partir da melancolia (Marneros,2001).

No final do século XIX, Kraepelin separou as psicoses endógenas entre "insanidade maníaco-depressiva" e dementia praecox acreditando que na primeira o prognóstico seria bom e a segunda evoluiria com deterioração. A primeira englobava tanto a depressão unipolar quanto o TB. A segunda é a que posteriormente foi conhecida como esquizofrenia.

Em 1957, Leonhard foi o primeiro a separar a depressão unipolar, chamada por ele de monopolar, do TB, por ele separado em duas entidades: a bipolar propriamente dita e a mania monopolar. Em 1966, Perris e Angst, trabalhando de forma independente, confirmaram a distinção unipolar-bipolar entre as psicoses endógenas (Wang e Demetrio, 2005). Posteriormente, Winokur também chegou a resultados semelhantes através de estudos familiares genéticos. Dunner et al. (1976) distinguiram dois tipos de TB: o tipo I, com episódios de mania, e o tipo II, com episódios de hipomania. Esta distinção encontra-se presente na classificação diagnóstica da Associação Psiquiátrica Americana (APA), o Manual Diagnóstico e Estatístico, 4a . edição (DSM-IV; APA,1994). A classificação da Organização Mundial da Saúde (OMS), conhecida como Classificação Internacional de Doenças, $10^{\mathrm{a}}$. edição (CID-10), apesar de todas as evidências validando o diagnóstico de TB tipo II (Coryell,1999), ainda não incorporou este conceito (WHO,1992). Outros subtipos bipolares foram descritos, como o tipo III, que pode significar, dependendo do autor, um episódio depressivo sem episódios maníacos 
ou hipomaníacos em pessoas com familiar de primeiro grau com TB tipo I (Depue e Monroe, 1978) ou virada maníaca ou hipomaníaca após tratamento somático (ex: luz, antidepressivos, eletroconvulsoterapia) para depressão em pacientes que nunca tiveram mania ou hipomanias espontâneas (Klerman, 1981). Recentemente, há uma tendência ao retorno do conceito amplo de Emil Kraepelin, com o espectro bipolar englobando características temperamentais (Cassano et al., 1999; Akiskal e Pinto, 1999).

\subsection{2) Diagnóstico e Classificação}

O TB clássico anteriormente conhecido como psicose maníaco-depressiva é hoje o bipolar tipo I, caracterizado por episódios de mania. Na maioria das vezes, estes vêm acompanhados por episódios de depressão. O TB tipo II é caracterizado pela presença de episódios de hipomania sem nunca a pessoa ter apresentado crises de mania. Ao contrário da visão de Kraepelin de bom prognóstico e recuperação plena, são transtornos caracterizados pela presença de sintomas residuais inter episódicos, que na maioria das vezes são depressivos. Além disso, apresentam importante morbidade e mortalidade a longo prazo.

O DSM-IV coloca nos seus critérios para bipolar I a obrigatoriedade do episódio maníaco ou misto e para o II do hipomaníaco. Os episódios não são melhor explicados por esquizofrenia, transtorno esquizoafetivo, esquizofreniforme, delirante ou psicótico sem outra especificação. Ele especifica no TB I se há episódio maníaco único ou mais recente maníaco, hipomaníaco, misto, depressivo ou inespecificado (APA,1994). O inespecificado é caracterizado por sintomas 
preenchendo critérios para episódio maníaco, depressivo maior, hipomaníaco ou misto, exceto pela duração. Os demais episódios são descritos a seguir.

\subsubsection{1) Depressão}

Apesar dos sintomas maníacos ou hipomaníacos do TB serem mais característicos, os sintomas depressivos costumam ser mais freqüentes (Judd et al., 2002; Judd et al., 2003), o que torna o diagnóstico diferencial com depressão unipolar difícil. O episódio depressivo bipolar é praticamente indistinguível do unipolar. O sintoma ou sinal primário é uma alteração de humor, que costuma estar depressivo, triste, desanimado, ansioso ou irritável. Outro sintoma muito importante, que costuma diferenciar os quadros depressivos de quadros primariamente ansiosos, é a anedonia ou perda da capacidade de sentir prazer. Ela é o fator ausência de afetos positivos nas pesquisas de Clark e Watson (Clark e Watson, 1991). Há uma diminuição da energia e motivação, lentificação de processos psíquicos, referida pelo paciente como cansaço, preguiça, maior dificuldade de iniciar ou concluir tarefas (Moreno e Almeida, 2005).

A depressão afeta também o pensamento. Seu conteúdo se torna negativo, com preocupações excessivas, visão pessimista do ambiente, futuro e de si, com desesperança, niilismo, idéias de culpa inapropriadas, de que talvez fosse melhor desaparecer, sumir, morrer, de suicídio. As idéias de suicídio podem evoluir para um planejamento ou tentativa de suicídio. O diagnóstico com maior freqüência associado a tentativas ou mortes por suicídio é o TB, principalmente em episódios mistos ou depressivos e do tipo II (Leverich et al., 2003; Rihmer e 
Pestality, 1999). Em casos mais graves de depressão, sintomas psicóticos como idéias delirantes ou crenças resistentes a argumentação, que costumam não corresponder a realidade, aparecem, dominando a vida mental do paciente. Estes costumam ser de ruína, niilistas, podendo ser somáticos, hipocondríacos ou paranóides também. Por exemplo, um senhor de grandes posses recusa-se a contratar uma empregada doméstica pagando salário mínimo pois acredita estar falido. Além do conteúdo, o curso do pensamento também é afetado, com lentificação, aumento de latência de respostas, diminuição da fluência verbal. A tonalidade da voz torna-se mais baixa, sendo até difícil compreender o que é dito pelo paciente. Nestes casos mais graves, alucinações podem aparecer, em geral auditivas, com vozes chamando o nome do sujeito, ofendendo-o ou diminuindo-o, dizendo que este irá morrer.

A psicomotricidade também é afetada. Em geral há lentificação dos movimentos e prejuízo da conação e vontade, diminuição da expressividade facial, fala, de impulsos e retraimento social. Muitos pacientes ficam deitados o dia todo, sem levantar-se. Em casos graves, esta lentificação leva à catatonia.

Sintomas físicos também são comuns na depressão. Pode haver diminuição de apetite, com emagrecimento ou aumento de apetite, em geral para carboidratos, e ganho de peso. O sono torna-se insuficiente, pouco repousante, podendo haver insônia ou hipersonia. A insônia pode ser inicial, quando há associação com ansiedade, além de intermediária ou terminal, esta última com o paciente acordando horas (geralmente duas ou mais) antes do habitual, a mais característica da depressão. A presença de quadros dolorosos, como a enxaqueca 
(Mclntyre et al., 2006), além de dores inexplicáveis, é comum nos estados depressivos bipolares.

A classificação mais utilizada hoje em pesquisas, o DSM-IV coloca o humor depressivo e a anedonia como sintomas mais importantes que os demais sintomas do episódio depressivo maior (APA,1994). Um destes sintomas tem de estar presente a maior parte do tempo por pelo menos duas semanas para o diagnóstico ser possível. Além deste primeiro sintoma fundamental, quatro dentre sete grupos de sintomas são necessários para o diagnóstico: perda ou aumento de apetite ou peso, insônia ou excesso de sono, agitação ou retardo psicomotor, fadiga ou perda de energia, sentimentos de inutilidade ou culpa excessiva, diminuição da capacidade de pensar ou concentrar-se ou indecisão, pensamentos recorrentes de morte, idéias, planejamento, ou tentativas de suicídio. Estes sintomas devem ser freqüentes, isto é, quase todos os dias e causarem prejuízo social ou ocupacional. Não podem ser causados por uso, abuso ou abstinência de substâncias químicas ou serem causados por uma condição médica geral, como hipotireoidismo. Além disso, não podem ser causados por luto, durando mais de dois meses após o falecimento e sendo de maior intensidade que o luto normal, por exemplo, com prejuízo significativo de funções sociais e ocupacionais, idéias de suicídio, sintomas psicóticos ou retardo psicomotor.

A classificação utilizada para propósitos de documentação, médico-legais, administrativos é a CID-10 (WHO,1992). Ela separa o episódio depressivo em leve, moderado ou grave com ou sem sintomas psicóticos. Como sintomas fundamentais da depressão, além do humor depressivo e anedonia do DSM-IV, a CID-10 coloca em seus critérios de pesquisa a energia diminuída ou fatigabilidade, 
exigindo dois entre três sintomas (WHO ,1993). Posteriormente, são citados como sintomas a perda de confiança ou auto-estima, culpa excessiva ou autoreprovação, pensamentos recorrentes de morte ou suicídio, diminuição da capacidade de pensar, agitação ou retardo psicomotor, alteração significativa no sono e no apetite ou peso. No episódio depressivo leve, a soma dos sintomas fundamentais e dos anteriormente citados deve ser de quatro; no moderado, seis; no grave, oito; no grave com sintomas psicóticos, além dos oito, delírios, alucinações ou estupor depressivo devem estar presente. A duração do episódio depressivo pela CID-10 também é de no mínimo duas semanas.

A maioria dos estudos compararam depressivos unipolares com bipolares tipo I em depressão. Por exemplo, Mitchell et al.(2001) parearam 39 unipolares quanto a idade, sexo e presença ou ausência de subtipo melancólico do DSM-IV com 39 bipolares tipo I. Os últimos apresentavam mais retardo psicomotor e sintomas atípicos que os primeiros, além de histórico de depressões psicóticas, apesar de não haver diferença entre a gravidade dos dois grupos. Um grupo de 1143 depressivos em clínica de atendimento básico foi separado em unipolar e bipolar de acordo com pontuação pré-definida do instrumento de rastreamento Mood Disorder Questionnaire (MDQ), melhor para a detecção de TB tipo I que para o II. Os bipolares apresentavam maior chance de apresentar alucinações, ideação suicida atual e baixa auto-estima, transtorno de abuso ou dependência de álcool, histórico de internações psiquiátricas, e tratamento com antipsicóticos no último mês. Os unipolares, por outro lado, apresentavam maior alteração de apetite que os bipolares (Olfson et al., 2005). Perlis et al. (2006) compararam a fenomenologia de 477 sujeitos com depressão bipolar e 1074 com unipolar, 
ambulatoriais, não-psicóticos provenientes de três estudos clínicos multicêntricos. Os primeiros apresentaram maior probabilidade de apresentar história familiar para o TB, menor idade de início, maior número de episódios depressivos prévios. Em relação a itens das escalas Montgomery-Asberg Depression Rating Scale (MADRS) e Hamilton Anxiety Rating Scale (HAM-A), a tristeza, insônia, comportamento depressivo, sintomas musculares, cognitivos, respiratórios e genito-urinários foram mais freqüentes em unipolares e medos, em bipolares. Solomon et al. (2006) estudaram as diferenças clínicas e demográficas entre 91 bipolares tipo I, 52 tipo II e 338 unipolares durante um episódio depressivo, que posteriormente foram seguidos por até 20 anos. Os bipolares apresentaram delírios durante o episódio índice com maior freqüência que unipolares, além da história familiar para depressão ou TB e maior número de episódios depressivos. Recentemente, dois estudos diferenciaram bipolares tipo II em depressão com unipolares. Em pacientes privados ambulatoriais depressivos melancólicos, Benazzi (2004) comparou 39 depressivos bipolares tipo II e 34 unipolares. Ao contrário dos bipolares tipo I, os tipo II apresentaram maior chance de agitação psicomotora e os unipolares retardo psicomotor, apesar dos sintomas psicomotores serem pouco freqüentes nos dois grupos. Hantouche e Akiskal (2005) compararam a sintomatologia de 196 bipolares tipo II e 256 unipolares de uma amostra nacional francesa. Não houve diferença em relação à gravidade da depressão dos dois grupos. Os unipolares apresentaram mais retardo psicomotor, perda de interesse e insônia e os bipolares, hipersônia.

Em resumo a depressão bipolar costuma se iniciar mais cedo, apresentar maior recorrência (Angst et al., 2003b),ser mais atípica que a unipolar (Moreno e 
Almeida, 2005), porém também pode ser melancólica (Mitchell et al.,1992). Idade precoce, alta freqüência de episódios depressivos, história familiar positiva de transtornos do humor, grande parte do tempo em atividade mesmo durante a depressão, além de início ou término abrupto de sintomas de depressão são indícios de uma depressão bipolar ao invés de unipolar (Baldassano, 2005).

Depressão atípica é aquela caracterizada por hipersonia, aumento de apetite e peso, maior sensibilidade à rejeição interpessoal, "paralisia de chumbo" matinal. Na melancólica, há um humor depressivo não reativo à estímulos do ambiente, e qualidade distinta de uma tristeza normal, sentimentos de culpa, insônia terminal, piora matutina, perda de apetite e peso e retardo ou agitação psicomotora importante.

\subsubsection{2) Mania}

O episódio clássico (com humor eufórico) da mania é o de maior confiabilidade entre todos os diagnósticos psiquiátricos (Endicott e Spitzer, 1978). O episódio maníaco é caracterizado por um humor eufórico, porém ultimamente há um aumento de pacientes apresentando-se com humor irritável. Pode haver labilidade afetiva, sensação de o paciente ser arrogante, não se importar com outras pessoas (Moreno e Almeida, 2005). Há aumento inicialmente da atenção com posterior distraibilidade com o agravamento do quadro. O raciocínio torna-se rápido, há maior associação de idéias, pressão de discurso até o paciente perderse em seus pensamentos apresentando fuga de idéias. Ele fala palavrões ou 
torna-se "pavio curto" (Moreno e Almeida, 2005). Suas idéias apresentam conteúdo otimista, positivo, grandioso, podendo ser delirantes. Em casos mais graves, em uma avaliação transversal e não longitudinal, pode ser difícil distinguir a mania de uma esquizofrenia. Há aumento da energia, maior disposição para o trabalho, atividades de lazer e prazerosas, sexo, jogo, compras excessivas, uso de álcool e substâncias ilícitas, o paciente trabalha horas sem se cansar, dorme pouco e acorda disposto no dia seguinte. Há aumento do libido, desinibição social e aumento da impulsividade, podendo se tornar agressivo se contrariado, ele começa muitas atividades e não termina, muda de opinião com muita facilidade. Ao contrário da depressão, a mania com muita freqüência vem acompanhada de sintomas psicóticos. O paciente pode apresentar delírios de grandeza como ser Jesus Cristo, apresentar poderes especiais, ser capaz de resolver todos os problemas do mundo.

O episódio maníaco, de acordo com o DSM-IV, é caracterizado por "um período distinto de humor persistentemente elevado, expansivo ou irritável" (APA,1994), durando pelo menos uma semana, se não for necessária uma hospitalização antes. Além da alteração de humor, são precisos três (ou quatro se o humor for irritável) dos sintomas a seguir: auto-estima inflada ou grandiosidade, necessidade de sono diminuída, loquacidade ou pressão por falar, fuga de idéias ou sensação de pensamentos correndo, diatraibilidade, agitação psicomotora ou aumento da atenção dirigida a objetivos, envolvimento excessivo em atividades prazerosas de alto potencial de conseqüências desastrosas (ex: compras, sexo). Estes sintomas devem causar prejuízo social, ocupacional, ser necessária internação ou apresentar características psicóticas. Não podem ser causados por 
uso, abuso ou abstinência de substâncias químicas ou por uma condição médica geral.

A CID-10 apresenta a hipomania e a mania, sendo a última dividida em com ou sem sintomas psicóticos. Na sua classificação de pesquisa, mania é caracterizada por humor "expansivo, elevado ou irritável" por pelo menos uma semana, além de três dos seguintes sintomas (ou quatro se o humor for irritável): inquietação ou atividade aumentada, loquacidade, pensamento acelerado ou fuga de idéias, perda de inibições sociais normais, diminuição da necessidade de sono, grandiosidade, distraibilidade, comportamento imprudente não reconhecido pelo paciente, energia sexual aumentada (WHO,1993).

\subsubsection{3) Episódio Misto}

O episódio misto é caracterizado por uma mistura de sintomas depressivos e de mania ao mesmo tempo ou alternando-se rapidamente. Também é conhecido como mania disfórica ou mista. O número de sintomas depressivos em episódios de mania para caracterizar um episódio misto é controverso, pois sintomas subsindrômicos de depressão são comuns em episódios de mania (McElroy et al.,1992). Menos importância se deu à depressão mista, agitada ou "ansiosa excitada" (Koukopoulos e Koukopoulos, 1999), episódio depressivo com sintomas maníacos ou hipomaníacos (Akiskal et al., 2000). No DSM-IV o critério para episódio misto é bastante restritivo: há necessidade de se preencher critérios por uma semana para um episódio depressivo maior e um episódio maníaco ao mesmo tempo (APA,1994). O grupo de Cincinnati propôs o diagnóstico de mania 
disfórica ou mista com pacientes preenchendo os critérios de episódio maníaco pelo DSM-IV além de três sintomas do episódio depressivo maior da mesma classificação (McElroy et al.,1992). Posteriormente, Cassidy et al. (2000) recomendaram apenas dois sintomas depressivos para o diagnóstico da mania mista. Os critérios de Koukopoulos e Koukopoulos (1999) para a depressão agitada são a presença de um episódio depressivo maior, além de pelo menos dois sintomas seguintes: agitação psicomotora, agitação psíquica ou acentuada tensão interior e pensamentos acelerados ou excesso de pensamentos.

\subsubsection{4) Hipomania}

Ao contrário da mania, a hipomania, conforme definição do DSM-IV, apresenta pouca confiabilidade diagnóstica (Benazzi, 2003). Seu diagnóstico diferencial com o humor normal é muitas vezes difícil. A sua definição e extensão é a origem de dados epidemiológicos discrepantes na prevalência de TB (Angst et al., 2003a).

A hipomania é caracterizada por um período mais curto de elevação do humor ou irritabilidade, sem que esta cause prejuízos sociais ou ocupacionais intensos como os da mania. Não leva a internação, nem apresenta sintomas psicóticos. A duração da hipomania é controversa. O DSM-IV considera necessário quatro dias para o diagnóstico, porém pesquisadores defendem o retorno aos dois dias necessários (Akiskal et al., 2000) presentes nos critérios do Research Diagnostic Criteria (RDC ;Spitzer et al.,1978). O humor deve ser nitidamente diferente do humor habitual não depressivo (APA, 1994). O DSM-IV 
lista os mesmos sintomas de mania para a hipomania, sendo necessários os mesmos três para humor eufórico ou quatro para irritável da mania, considerando portanto a diferença entre hipomania e mania como quantitativa e não qualitativa. A alteração do humor ou funcionamento deve ser observada por outros. Este último critério não aparece na sugestão de critérios de pesquisa da CID-10 (WHO, 1993).

\section{2) ESPECTRO BIPOLAR}

A idéia de uma visão dimensional do espectro do humor não é nova. Kraepelin, como citado anteriormente, acreditava em uma única doença afetiva, a insanidade maníaco-depressiva que englobava desde formas graves de mania e melancolia até "sem clara delimitação o domínio da predisposição pessoal" (Kraepelin, 1921). O espectro bipolar forma um continuum entre sintomas leves de depressão (d) e de hipomania $(m)$, ciclotimia (md), mania (M), depressão (D), mania com leve depressão (Md), TB tipo I (MD) e tipo II (Dm; Goodwin e Jamison, 1990). O espectro bipolar pode também ser descrito de forma categorial, adicionando novos "números" (diagnósticos) aos TB tipos I e II. Não há hoje consenso sobre a definição de espectro bipolar, com diversos autores sugerindo contribuições ao longo dos anos. Em 1981, Klerman chamou de bipolar tipo III os pacientes com virada maníaca induzida por tratamento somático para a depressão (Klerman, 1981). Em 1992, Young e Klerman caracterizaram o espectro bipolar como os subtipos I e II já aceitos, bipolar III, formado por sintomas leves de depressão e hipomania, IV, secundário a doenças clínicas ou substâncias, V, 
história familiar de bipolar em paciente com depressão sem história de mania ou hipomania e VI, mania sem episódios de depressão (Young e Klerman,1992, apud Demetrio, 2005).

Akiskal e Mallya (1987) propuseram que pacientes depressivos com depressões de difícil tratamento e temperamento de base hipertímico ou ciclotímico faziam parte de um espectro bipolar soft ou suave. Posteriormente, Akiskal e Pinto (1999) descreveram o espectro bipolar como subtipos I, II, III e IV. Os subtipos I e II equivalem aos bipolares I e II presentes no DSM-IV (APA, 1994). Entre ambos, há o $11 / 2$, referente a um quadro entre a mania e hipomania associado à depressão, em que a distinção de ambas as síndromes seria difícil. O ॥1/2 é formado por depressões ciclotímicas, cujo diagnóstico diferencial mais importante seria com transtorno de personalidade borderline. O bipolar tipo III é o de hipomania induzida por antidepressivos. O III1/2 é o da bipolaridade apresentada com o abuso de estimulantes. O IV é o da depressão hipertímica (Akiskal e Pinto, 1999). Em uma revisão, Akiskal et al. (2000) descreveram as entidades clínicas que apresentavam evidências suficientes para a inclusão no espectro bipolar: hipomanias breves, durando menos que os quatro dias sugeridos no DSM-IV; manias mistas, definidas de forma mais ampla que o DSM-IV, com dois ou mais sintomas depressivos; depressões com hipomanias induzidas por antidepressivos; e, finalmente, depressões ocorrendo em pessoas com temperamento ciclotímico .

Ghaemi et al. (2002) sugeriram critérios operacionais para o diagnóstico do espectro bipolar, enfatizando a história familiar de TB e hipomania ou mania 
induzidos por antidepressivos, além de características clínicas dos episódios depressivos sugestivas de bipolaridade. Estes são descritos no quadro 1.

Quadro 1. Critérios diagnósticos de Ghaemi e colaboradores para o espectro bipolar
A) Presença de um episódio depressivo maior, de acordo com DSM-IV
B) Ausência de episódios espontâneos de manias ou hipomanias
C) Um dos seguintes itens mais dois dentre os $D$ ou ambos e um D:
1) História familiar de transtorno bipolar em parente do primeiro grau
2) Mania ou hipomania induzida por antidepressivos
D) Se não houver nenhum ítem C, seis dentre as nove a seguir são necessárias:
1) Personalidade hipertímica
2) Mais de três episódios depressivos recorrentes
3) Episódios depressivos durando menos de três meses
4) Sintomas depressivos atípicos
5) Episódios depressivos psicóticos
6) Primeiro episódio depressivo antes dos 25 anos de idade
7) Depressão pós-parto
8) Perda aguda de efeito antidepressivo
9) Falta de resposta a mais de três ensaios antidepressivos

Adaptado de Ghaemi et al., 2002. 
No conceito de Cassano et al. (1999b), espectro refere-se a um campo amplo da fenomenologia de um transtorno mental do eixo I, incluindo: sintomas principais e subliminares do diagnóstico, como descritos nas classificações CID-10 (WHO, 1992) ou DSM-IV (APA, 1994); sintomas atípicos; características associadas, padrões de comportamento ligados aos sintomas principais; e traços de personalidade ou de temperamento. O espectro bipolar envolve muitas vezes sintomas subliminares de depressão e mania. Os da depressão são mais bem estudados que os da mania. Há consenso da importância destes. Os de mania, por outro lado, podem levar a pessoa a maior desempenho no trabalho e impressão subjetiva de melhor qualidade de vida. Podem ser prodrômicos ou aparecem como seqüelas de uma crise plena. Além disso, estes, quando crônicos, podem ser confundidos com transtornos de personalidade. Manifestações do espectro bipolar podem estar presentes durante, entre ou na ausência de um episódio maníaco ou depressivo (Cassano et al., 1999b). Cassano et al. (2004) demonstraram que mesmo em pacientes com depressão unipolar há um considerável número de sintomas maníacos ou hipomaníacos. Os sintomas mais referidos foram estar em um humor persistentemente bom, irritabilidade, sentir-se cheio de energia. Houve ainda, tanto para sujeitos bipolares e unipolares uma correlação quase linear entre sintomas depressivos e maníacos. A importância destes sintomas pode ser verificada pelo aumento que estes conferem a ideação paranóide e ideação suicida: em pacientes unipolares, para cada sintoma maníaco relatado, a chance de ideação suicida aumentou em 4,2 \%. Para este autor, o transtorno afetivo bipolar e as depressões unipolares compõem um único processo mórbido (Cassano et al., 2004; Cassano et al., 2002). 


\subsection{1) Instrumentos para avaliação do espectro bipolar}

Apesar da incerteza quanto aos limites do espectro bipolar, alguns instrumentos auxiliam no seu diagnóstico. Entrevistas estruturadas ou semiestruturadas são utilizadas para o diagnóstico psiquiátrico em pesquisas. Em geral, as estruturadas, como a Composite International Diagnostic Interview (CIDI; Kessler et al.,1994) e a Diagnostic Interview Schedule (DIS; Robins et al., 1981) são utilizadas por leigos treinados em pesquisas epidemiológicas com milhares de sujeitos. As semi-estruturadas, como a Structured Clinical Interview for DSM-IV Axis I Disorder- Patient Edition (SCID-I/P; First et al.,1995), a Schedules for Clinical Assessment in Neuropsychiatry (SCAN; Wing et al., 1990) ou MiniInternational Neuropsychiatric Interview (MINI; Sheehan el al.,1998) são utilizadas por clínicos treinados com experiência na área de saúde mental. Nas primeiras não há julgamento do entrevistador quanto à presença ou ausência de sintomas; nas últimas, a avaliação do entrevistador é essencial para se chegar ao diagnóstico psiquiátrico apropriado.

A maioria das entrevistas estruturadas ou semi-estruturadas fornece 0 diagnóstico pelo DSM-IV ou CID-10. Estes sistemas apresentam problemas no diagnóstico do TB e seu espectro (Akiskal et al., 2000). Alguns questionários foram desenvolvidos para auxiliar na detecção ou rastreamento de sintomas do TB ou espectro bipolar (Phelps e Ghaemi, 2006).

Há poucos instrumentos para este objetivo. O mais estudado é o MDQ (Hirschfeld et al., 2000). Ele é um questionário com treze perguntas, associadas a 
duas questões sobre se os sintomas ocorreram ao mesmo tempo e se estes causaram disfunção. Em uma amostra de 198 pacientes com transtornos do humor, uma pontuação maior ou igual a sete mostrou sensibilidade de 0,73 e especificidade de 0,90 (Hirschfeld et al., 2000). Porém, em outro estudo de 79 pacientes com transtornos do humor, os dados de sensibilidade foram de apenas 0,58 (Miller et al., 2004). O primeiro estudo tinha uma população maior de bipolares de tipo I (70 de 109). No estudo de Miller et al. (2004), a sensibilidade de bipolar tipo I $(0,69)$ foi maior que a de tipo II ou sem outra especificação $(0,30)$. Este instrumento também foi utilizado em uma clínica de medicina de família, apresentando sensibilidade de 0,58 e especificidade de 0,93 (Hirschfeld et al., 2005). O estudo do MDQ na população geral envolveu 711 sujeitos e apresentou uma sensibilidade baixa $(0,28)$ ao contrário da especificidade $(0,97)$ (Calabrese et al., 2003). Concluindo, o desempenho do MDQ como instrumento de rastreamento do espectro bipolar tem sido ruim, não podendo ser recomendado como uso de rotina na prática clínica (Zimmerman et al., 2004).

Outro questionário foi recentemente desenvolvido para o rastreamento do TB: o Bipolar Spectrum Diagnostic Scale (BSDS) (Ghaemi et al., 2005). Este instrumento consiste de duas partes: a primeira, um parágrafo com 19 afirmações descrevendo sintomas de TB, cada uma valendo um ponto; a segunda, uma questão de múltipla escolha perguntando o quanto as afirmações anteriores descreveram bem o sujeito, valendo de 0 a 6 pontos. $O$ escore total da escala varia entre 0 e 25 pontos. Um escore acima de 13 pontos resultou em sensibilidade de 0,75 e especificidade de 0,93, comparando-se pacientes 
unipolares e do espectro bipolar diagnosticados pelo SCID-I/P (Ghaemi et al., 2005).

A Hypomania Checklist (HCL-32) também permite o rastreamento do espectro bipolar. Possui 32 itens e já foi traduzida para várias línguas, incluindo o português de Portugal. Um escore acima de 14 pontos foi o melhor escore para distinguir entre bipolares e unipolares, com uma sensibilidade de 0,8 e especificidade de 0,51 (Angst et al., 2005).

Outros instrumentos foram desenvolvidos para avaliação e diagnóstico do espectro bipolar, porém, devido à sua extensão, não são bons instrumentos para rastreamento. Um deles é a Structured Clinical Interview for Mood Spectrum (SCIMOODS; Anexo A).

\subsection{2) O Projeto Spectrum e a SCI-MOODS}

Diagnósticos categoriais facilitam a confiabilidade do diagnóstico psiquiátrico, mas não abarcam toda a complexa realidade das pessoas que buscam assistência médica ou estão na população geral. Além disso, o sistema categorial atual não permite a avaliação do continuum entre o normal e o patológico.

Há uma constelação de sintomas que acompanham cada diagnóstico clínico do DSM-IV ou CID-10, que muitas vezes não estão listados nestas classificações (Cassano, 2006). Estes sintomas isolados ou grupo de sintomas que são ignorados pelos modelos categoriais vigentes podem causar prejuízos clínicos, sociais e ocupacionais. O modelo do espectro enfatiza estes sintomas, além de outros subsindrômicos, que precedem, seguem ou se manifestam ao mesmo 
tempo que o transtorno principal. Eles podem ter implicações importantes para a evolução da doença, resposta ao tratamento e para comorbidades com outras condições (Frank et al., 2000). O objetivo desde projeto, uma colaboração ítaloamericana, foi desenvolver instrumentos de avaliação das dimensões de características clínicas associadas a transtornos mentais de acordo com o DSM-IV (Cassano, 2006). Inicialmente partiu-se dos sintomas listados pelo diagnóstico principal do DSM-IV. Posteriormente um grupo de especialistas na dimensão avaliada reuniram-se para ampliar os conceitos do transtorno de acordo com a experiência clínica. Foram desenvolvidas versões em italiano e inglês ao mesmo tempo das entrevistas clínicas. Além de entrevistas clínicas, desenvolveram-se versões de auto-aplicação das dimensões estudadas.

Os primeiros espectros estudados foram o do pânico-agorafobia através da entrevista clínica Structured Clinical Interview for Panic-Agoraphobic Spectrum (SCl-PAS; Cassano et al., 1999a; Cassano et al., 1997) e de auto-aplicação PanicAgoraphobic Spectrum, Self-Report (PAS-SR; Shear et al., 2001; Cassano et al. 1999a), o do humor através da SCI-MOODS (Fagiolini et al., 1999) e da Mood Spectrum, Self-Report (MOODS-SR; Dell'Osso et al.,2002a), da ansiedade social pela Structured Clinical Interview for Social Phobia Spectrum (SCI-SHY; Dell'Osso et al.,2000) e Social Phobia Spectrum, Self-Report (SHY-SR; Dell'Osso et al.,2002b), da obsessão-compulsão pela Structured Clinical Interview for Obsessive-Compulsive Spectrum (SCl-OBS; Dell'Osso et al.,2000) e ObsessiveCompulsive Spectrum, Self-Report (OBS-SR; Dell'Osso et al.,2002b) e da anorexia-bulimia pelo Structured Clinical Interview for Anorexic - Bulimic Spectrum (SCl-ABS) e Anorexic - Bulimic Spectrum, Self-Report (ABS-SR; Mauri 
et al., 2000). Todas estas entrevistas clínicas apresentaram boa consistência interna e confiabilidade teste-reteste (Rucci e Maser, 2000). Posteriormente, foram desenvolvidas entrevistas clínicas e de auto-avaliação do espectro das substâncias químicas, a Structured Clinical Interview for the Spectrum of Substance Use (SCI-SUBS) e Spectrum of Substance Use, Self-Report (SUBSSR; Sbrana et al., 2003), das psicoses, a Structured Clinical Interview for the Psychotic Spectrum (SCI-PSY) e Psychotic Spectrum, , Self-Report (PSY-SR; Sbrana et al., 2005), da ansiedade de separação, Structured Clinical Interview for Separation Anxiety Symptoms (SCI-SAS) e Separation Anxiety Symptoms, SelfReport (SAS-SR; Cyranowski et al.,2002). A tabela 1 ilustra os principais resultados dos estudos de validação do projeto Spectrum (Cassano, 2006).

A importância deste conceito de espectro pode ser vista no do pânicoagorafobia, o mais estudado até o momento. Por exemplo, Frank et al. (2002) utilizaram o PAS-SR para avaliar o impacto que os sintomas deste espectro teriam sobre o curso e tratamento de pacientes com TB. Pacientes com maior pontuação no PAS-SR apresentaram maior ideação suicida durante o tratamento agudo, maior número de episódios depressivos prévios, mais sintomas depressivos atuais e levaram 27 semanas a mais para remitir do episódio atual (Frank et al.,2002). Anteriormente, um escore do PAS-SR maior que 35 determinou uma pior resposta à psicoterapia interpessoal para a depressão recorrente, além de maior tempo para responder à associação de um antidepressivo à psicoterapia (Frank et al., 2000). 
Tabela 1 - Principais resultados de estudos de validação do Projeto Spectrum

\begin{tabular}{|c|c|c|c|c|c|}
\hline & $N$ & CONF (ICC) & $\mathrm{Cl}$ & $\begin{array}{l}\text { VD: } \\
\text { CONTROLES }\end{array}$ & $\begin{array}{lc}\text { VD: } & \text { OUTROS } \\
\text { TRANSTORNOS }\end{array}$ \\
\hline SCI-MOODS & 491 & $0.93-0.94$ & $0.79-0.92$ & Todos & $\begin{array}{r}\text { Bipolar vs. unipolar: } \\
\text { todos subdomínios }\end{array}$ \\
\hline SCI-PAS & 422 & $0.65-0.89$ & $0.47-0.94$ & Todos & $\begin{array}{r}\text { Pacientes com hx } \\
\text { pânico vs.pacientes } \\
\text { sem hx pânico: todos } \\
\text { domínios }\end{array}$ \\
\hline SCl-OBS & 254 & $0.94-0.98$ & $0.61-0.90$ & Todos & $\begin{array}{r}\text { TOC vs. DM: todos; } \\
\text { TOC vs. FS: todos } \\
\text { domínios exceto } \\
\text { "dúvida" e } \\
\text { "hipercontrole" }\end{array}$ \\
\hline SCI-SHY & 254 & $0.97-0.99$ & $0.87-0.94$ & Todos & $\begin{array}{r}\text { FS vs. TOC: todos } \\
\text { domínios; FS vs. DM: } \\
\text { todos domínios }\end{array}$ \\
\hline SCI-ABS & 372 & 0.84-0.99 & $0.41-0.93$ & Todos & - \\
\hline SCI-SUBS & 100 & - & $0.64-0.93$ & - & - \\
\hline SCI-PSY & 459 & - & $0.39-0.77$ & - & - \\
\hline SCI-SAS & 111 & - & 0.85 & - & - \\
\hline
\end{tabular}

FONTE: Adaptado de Cassano, 2006

NOTA: $\mathrm{Cl}=$ consistência interna; $\mathrm{CONF}$ = confiabilidade teste reteste e entre examinadores; $\mathrm{DM}$ : depressão maior; FS: fobia social; ICC = correlação intra-classe; $\mathrm{N}$ = número; SCI-ABS = Structured Clinical Interview for Anorexic - Bulimic Spectrum ; SCI-MOODS = Structured Clinical Interview for Mood Spectrum ; SCI-OBS = Structured Clinical Interview for Obsessive-Compulsive Spectrum; SCI-PAS = Structured Clinical Interview for Panic-Agoraphobic Spectrum; SCI-PSY = Structured Clinical Interview for the Psychotic Spectrum; SCI-SAS = Structured Clinical Interview for Separation Anxiety Symptoms ; SCI-SHY = Structured Clinical Interview for Social Phobia Spectrum; SCI-SUBS = Structured Clinical Interview for the Spectrum of Substance Use; TOC: transtorno obsessivo- compulsivo; VD = validade discriminante

A SCI-MOODS avalia o humor de forma dimensional, permitindo um diagnóstico mais preciso de transtornos afetivos. A sua versão original foi construída ao mesmo tempo em italiano e inglês, facilitando a adaptação da entrevista a diferentes culturas. Ela serve para detectar manifestações atípicas ou subliminares do espectro bipolar, no momento da entrevista ou durante toda a vida, incluindo sintomas não listados nos sistemas diagnósticos. Pode ser utilizada para identificar pacientes com risco de desenvolver TB. Possui formas voltadas 
para o último mês ou semana, que auxiliariam na avaliação da resposta a tratamentos ou evolução da doença. Poderia, por exemplo, acompanhar a exposição de bipolares deprimidos a antidepressivos, detectando precocemente a virada maníaca. Além disso, ela auxilia na psicoeducação dos bipolares, fortalecendo a relação médico-paciente (Fagiolini et al., 1999). A MOODS-SR é uma entrevista de auto-avaliação baseada na versão da vida da SCI-MOODS. Em um estudo com 21 pacientes com transtorno do humor e 20 controles, ela apresentou confiabilidade entre 0,88 e 0,97 (Dell'Osso et al., 2002a).

O estudo de validação da primeira versão da SCI-MOODS, de 140 itens, envolveu 491 sujeitos de oito centros psiquiátricos italianos diagnosticados de acordo com a MINI (Sheehan et al., 1998). Os grupos foram divididos em 141 estudantes universitários, 116 pacientes com perturbações gastrintestinais, 112 bipolares e 122 com depressão recorrente. A entrevista apresentou boa validade discriminante, separando os pacientes bipolares e unipolares de controles com perturbações gastrintestinais e universitários. Além disso, ela distinguiu entre bipolares e unipolares. A confiabilidade foi determinada pela consistência interna de domínios e subdomínios, variando entre 0,79 a 0,92. A correlação entre subdomínios maníacos e depressivos entre si foi maior que a de maníacos e depressivos, demonstrando que a entrevista media o que se propunha medir. As pontuações de corte da SCI-MOODS não foram determinadas. Um outro estudo com 30 sujeitos, sendo 10 controles com perturbações ortopédicas, 10 bipolares e 10 unipolares foi feito para determinar a confiabilidade teste-reteste 6 a 8 dias após a primeira entrevista e entre examinadores. A primeira confiabilidade foi entre 0,93-0,94. A segunda se aproximou de um (Fagiolini et al., 1999). 


\section{3) VALIDADE E CONFIABILIDADE}

A validação de um instrumento é um processo contínuo, sem fim, que exige diversos estudos científicos, com populações variadas. Validade define-se como o grau no qual um indicador empírico de um conceito realmente o representa (Goldstein e Simpson, 2002). Uma escala é válida se é capaz de medir o objeto que se propõe a medir (Menezes e Nascimento, 2000). A validação de um instrumento depende do seu fim (Menezes e Nascimento, 2000). A validade envolve um componente conceitual, que é subjetivo e um operacional. Este pode ser dividido em de conteúdo, critério e construção (Menezes e Nascimento, 2000).

A validade de conteúdo refere-se a abrangência da escala, isto é, se ela cobre todos os aspectos relevantes do seu domínio conceitual ou comportamental (Bryant, 2000). Por exemplo, para validar uma escala de depressão maior, o humor depressivo, anedonia, insônia ou hipersônia, inapetência ou aumento de apetite, sintomas cognitivos, entre outros ítens deveriam estar presentes. É importante também que ela não apresente itens que podem ser atribuídos a outros objetos (Menezes e Nascimento, 2000), embora nem sempre isto seja possível. Não costuma ser avaliada por testes estatísticos (Goldstein e Simpson, 2002; Menezes e Nascimento, 2000).Costuma se basear no consenso de especialistas, isto é, sua avaliação é subjetiva (Menezes e Nascimento, 2000).

A validade de critério de um instrumento refere-se ao quanto este mede um indicador externo de um determinado conceito, que ocorreu no passado, presente 
ou futuro (Bryant, 2000; Goldstein e Simpson, 2002). Em um estudo médico, por exemplo, o critério costuma ser o "padrão-ouro" para o diagnóstico de uma doença. A validade pode ser calculada através da correlação momento-produto de Pearson. O coeficiente de correlação é o de validade (Bryant, 2000). A validade de critério pode ser dividida em: preditiva, concorrente ou retrospectiva.

$\mathrm{Na}$ validade preditiva ou prospectiva, o instrumento é aplicado antes da obtenção do critério. Isto implica uma avaliação longitudinal da população estudada. Em psiquiatria, por exemplo, uma das formas de validar um diagnóstico é através do seu curso e prognóstico. Além do uso do coeficiente de correlação de Pearson, a validação preditiva pode ser calculada por técnicas estatísticas multivariáveis (Bryant, 2000). Se a medida do instrumento influencia posteriormente a do critério, ela torna-se enfraquecida (Bryant, 2000).

Na concorrente, o critério é obtido ao mesmo tempo que o instrumento. É um tipo de validade muito utilizado na medicina, através de testes diagnósticos. Por exemplo, se houvesse um teste laboratorial para o diagnóstico de depressão, um instrumento poderia ser aplicado ao mesmo tempo que ele (Goldstein e Simpson, 2002).

Na retrospectiva, ele foi obtido antes da escala. Por exemplo, pode ser uma alteração no desenvolvimento na infância para a validação de um diagnóstico psiquiátrico na idade adulta (Goldstein e Simpson, 2002). Quando o critério depender da lembrança dos sujeitos avaliados, como na história de abuso sexual na infância para validar um diagnóstico de personalidade borderline, o estudo sofrerá de limitações metodológicas. O conhecimento sobre o presente pode distorcer as lembranças do passado (Bryant, 2000). 
A validade de construto é essencial para todos os conceitos abstratos (Cronbach e Meehl,1955). Ela se refere à acurácia de um instrumento ou à capacidade deste de medir o conceito que se propõe medir (Bryant, 2000). A validade de conteúdo e de critério são parte do processo para a avaliação da validade de construto (Goldstein e Simpson, 2002). Esta é definida em um plano teórico como o grau em que a medida de interesse se relaciona com outros conceitos relacionados teoricamente que também são mensurados. Um estudo não permite validar totalmente a medida de um conceito. São necessários vários estudos com diferentes amostras e locais para a validação de um construto (Goldstein e Simpson, 2002). O contexto teórico da validação é denominado rede nomológica (Cronbach e Meehl,1955). Esta rede requer a relação entre construtos teóricos entre si, destes com indicadores empíricos e dos indicadores empíricos entre si (Goldstein e Simpson, 2002). O construto é comparado com outros construtos permitindo fazer previsões usando os indicadores empíricos (Cronbach e Meehl,1955). Há dois tipos básicos de validade de construto: a convergente e a discriminante. A validade convergente entre diferentes medidas de um construto é o grau de concordância ou correlação entre estas medidas. A validade discriminante refere-se ao grau no qual múltiplas medidas de diferentes conceitos divergem. Em geral é avaliada em conjunto à validade convergente (Bryant,2000).

A confiabilidade de um instrumento ou diagnóstico refere-se a capacidade deste ser reproduzido (Menezes e Nascimento, 2000; Shrout, 2002). Três erros costumam afetar a confiabilidade de um diagnóstico: o viés de informação, de situação ou de critério. O primeiro refere-se a problemas no fornecimento de informações pelos sujeitos no momento que estes são avaliados (por exemplo, por 
má-fé, desconhecimento do que é perguntado, cansaço). O segundo ocorre com construtos instáveis, sujeitos a grande flutuação ou modificação com o tempo ou situação. O terceiro refere-se ao uso de critérios particulares do diagnóstico ou, por exemplo, conceitos básicos de psicopatologia que diferem entre examinadores (Menezes e Nascimento, 2000). Quando um instrumento é composto por muitos ítens que medem o mesmo construto, é possível determinar a confiabilidade através de apenas uma avaliação. A esta forma de confiabilidade dá-se o nome de consistência interna, que mede a relação entre diversos itens de um instrumento que medem o mesmo construto (Shrout, 2002; Strube, 2000). Outra forma de confiabilidade, a teste-reteste é calculada por avaliações separadas por um determinado período de tempo. O tempo não pode ser curto demais a ponto dos sujeitos lembrarem-se das respostas dadas ao instrumento ou longo demais a ponto de haver modificações no construto avaliado (Menezes e Nascimento, 2000). A terceira forma de confiabilidade, muito utilizada no diagnóstico psiquiátrico é a entre examinadores. No caso, dois ou mais examinadores avaliam o sujeito ao mesmo tempo sob as mesmas condições (ex: mesmas formas das perguntas serem formuladas). Ela pode ser por entrevistas ao vivo, gravadas ou através da avaliação de registros escritos dos sujeitos (Menezes e Nascimento, 2000). 


\section{4) OBJETIVOS}

O objetivo desta pesquisa é traduzir a versão em inglês da Structured Clinical Interview for Mood Spectrum (SCI-MOODS) para o português do Brasil, determinando a sua validade e confiabilidade em uma população de pacientes bipolares e unipolares, controles esquizofrênicos e normais sem patologia psiquiátrica. Além disso, o outro objetivo é o de estabelecer pontuações de corte da SCI-MOODS-VP para distinguir bipolares de unipolares e pacientes com transtornos do humor e controles.

\section{5) HIPÓTESES}

A tradução para o português do SCI-MOODS apresenta boa confiabilidade e validade discriminante. Ela permite diferenciar entre sujeitos com TB e depressão. Os primeiros deverão ter todos as pontuações maníacas e total maiores que os últimos. Além disso, permite diferenciar entre sujeitos com transtornos afetivos e controles. Os primeiros deverão ter todas as pontuações depressivas, maníacas e totais maiores que os últimos. 


\section{2) CASUÍSTICA E MÉTODOS}

A tradução e adaptação da SCI-MOODS para a língua portuguesa brasileira seguiram as normas de orientação de padronização delineadas pela Organização Mundial de Saúde para World Mental Health Survey (WMHS ; WHO, 2006; Demyttenaere et al., 2004), a partir da versão em inglês norte americano (anexo A). A tradução foi feita pelo investigador principal do estudo, sob orientação de médicos do Grupo de Estudos de Doenças Afetivas (GRUDA) do Instituto de Psiquiatria do Hospital das Clínicas da Faculdade de Medicina da Universidade de São Paulo (IPq HC FMUSP) peritos em transtornos do humor, para evitar possíveis usos inadequados de termos técnicos e/ou expressões idiomáticas. Posteriormente, a versão em português foi retro-traduzida para o inglês por um profissional independente, cuja língua materna era o inglês americano, sem conhecimento prévio sobre psicopatologia ou o instrumento em questão.

A entrevista traduzida foi então testada em um estudo piloto com 10 pacientes do GRUDA com diagnóstico de depressão unipolar e 10 com TB, para avaliar a consistência das questões, ou seja, o que é entendido pelo entrevistado em cada pergunta e se ele responde da maneira que julga entender. A versão final da entrevista (anexo B) passou ainda pela avaliação de uma professora de português, que auxiliou na sintaxe e ortografia da entrevista. A confiabilidade da Entrevista Clínica Esruturada para o Espectro do Humor - Versão em Portguês (SCI-MOODS-VP) foi calculada pela consistência interna e entre examinadores. Esta última foi avaliada através da entrevista ao mesmo tempo por dois psiquiatras 
treinados na aplicação da SCI-MOODS-VP de 10 sujeitos unipolares e 10 bipolares.

No estudo da validade discriminante da SCI-MOODS-VP foram selecionados sujeitos de cada um dos seguintes grupos: 47 pacientes bipolares, $47 \mathrm{com}$ depressão unipolar, 22 controles normais de uma amostra da população geral e 18 controles psiquiátricos (pacientes portadores de esquizofrenia). Os melhores escores que distinguiam entre bipolares e unipolares e entre portadores de transtornos afetivos (bipolares e unipolares) e controles (normais e esquizofrenia) foram determinados por duas curvas receiver operating characteristic (ROC; Swets et al.,2000). Estes escores foram utilizados para calcular a sensibilidade, a especificidade, o valor preditivo positivo, o valor preditivo negativo e o kappa (ou concordância diagnóstica no diagnóstico de bipolares de acordo com um padrãoouro). Além disso, a correlação parcial entre domínios e subdomínios da entrevista controlada por idade e sexo foi determinada para avaliar a sua validade de construto. Uma análise discriminante descritiva passo a passo progressiva (forward stepwise) com a amostra de sujeitos bipolares e unipolares foi utilizada para verificar os subdomínios que apresentavam maior capacidade de distinguir entre bipolares e unipolares.

\section{1) SUJEITOS}

Os sujeitos dos grupos unipolar $(n=47)$, bipolar $(n=47)$ e esquizofrênico $(n=18)$ foram diagnosticados de acordo com os critérios do DSM-IV. 
Apresentavam entre 18 e 60 anos de idade, eram alfabetizados, não podiam ter abuso ou dependência de álcool e outras substâncias (exceto nicotina) nos últimos três meses, nem transtorno mental orgânico ou dificuldade cognitiva significativa, como demência ou retardo mental que impedissem a compreensão da entrevista. Foram considerados capazes pelos seus médicos assistentes de fornecer o Termo de Consentimento Livre e Esclarecido para participar na pesquisa. Os pacientes com transtornos afetivos não podiam apresentar sintomas psicóticos no momento da entrevista. Eles foram selecionados aleatoriamente no ambulatório do GRUDA - IPq HC FMUSP ou do Ambulatório de Saúde Mental da Clínica Heidelberg, de Curitiba (Paraná) (ASM) e encontravam-se em remissão parcial ou total de um episódio afetivo. Os esquizofrênicos foram selecionados aleatoriamente do ASM e do hospital-dia da Clínica Heidelberg, apresentavam poucos sintomas positivos que prejudicassem a sua participação nesta pesquisa, além de não poderem preencher critérios para episódio depressivo maior atual ou no passado.

Os sujeitos do grupo controle populacional $(n=22)$ eram voluntários sadios do ponto de vista físico e mental, do estudo "Bom Humor", que avaliava a ação do antidepressivo clomipramina sobre o humor de voluntários normais. Os sujeitos foram recrutados em São Paulo, apresentavam entre 21 e 50 anos de idade, completaram no mínimo o ensino fundamental e não apresentavam diagnóstico psiquiátrico atual ou pregresso. Os voluntários deste estudo passaram inicialmente por uma triagem por telefone com o Self-Report Questionnaire (SRQ-20) de vinte questões (Harding et al.,1980), apresentando escores menores que 5 para homens e 7 para mulheres, validados como ponto de corte para a população 
brasileira (Mari e Williams, 1986). Posteriormente, foram entrevistados por psiquiatras treinados com a SCID-I/P (First et al.,1995), a Family History Screen (FHS; Weissman et al., 2000) e a Hamilton Depression Rating Scale (HAM-D; Hamilton, 1960). Os sujeitos não podiam apresentar: de acordo com o SCID-I/P, na vida, TB, depressão maior, distimia, transtornos de ansiedade, últimos cinco anos para depressão subsindrômica, transtorno misto de ansiedade e depressão (CID-10), história ou presença de abuso de álcool, outras drogas psicoativas e de tentativa de suicídio; história familiar de primeiro grau e avós de doenças psiquiátricas (psicoses, depressão recorrente, TB), de acordo com o FHS; escore no HAM-D de 21 itens maior que 7; presença de gravidez ou amamentação, ou história de parto nos últimos 6 meses; tratamento com medicamentos psicoativos nos 6 meses anteriores à avaliação; início de psicoterapia em período inferior aos 6 meses anteriores à seleção; índice de massa corporal $\quad(\mathrm{IMC}=$ peso/(altura)2) maior que 30. Finalmente, os sujeitos completaram o Inventário de Temperamento e Caráter (TCl; Cloninger et al., 1993; Fuentes et al., 2000), que avalia a personalidade. Foram excluídos aqueles com fator de auto-direcionamento menor ou igual a 20, isto é, com provável transtorno de personalidade.

Todos os indivíduos (pacientes e controles normais) participantes nesta pesquisa assinaram o Termo de Consentimento Livre e Esclarecido para participar na pesquisa. O protocolo foi aprovado pelos Comitês de Ética do Hospital das Clínicas da Faculdade de Medicina da USP e da Clínica Heidelberg.

\section{2) INSTRUMENTOS}




\subsection{1) SCI-MOODS}

A última versão da SCI-MOODS (anexos A e B), de maio de 2002, é composta por 161 questões, presentes em quatro domínios com o número de itens entre parênteses: "humor" (57), "energia" (23), "cognição" (51) e "ritmicidade" (30). Os primeiros três domínios foram divididos em subdomínios depressivos e maníacos. A maioria das questões refere-se a períodos de três a cinco dias de duração, inclusive durante a infância, abordando sintomas que causaram prejuízos clinicamente significativos.

No domínio "humor" são abordadas oscilações no ânimo, sentimentos, interesses na esfera familiar, de amizades, relacionamentos românticos, trabalho, lazer e esportes. A "energia" refere-se a flutuações no nível de energia. A "cognição" lida com sintomas de esquecimento, dificuldade de raciocínio, que costumam ser associadas a mudanças de humor. "Ritmicidade" aborda um aspecto até então relegado dos transtornos afetivos: a sua periodicidade, relação de sintomas com estações de ano, mudanças climáticas, alternância de humor, hábito alimentar, sono e atividade sexual durante o mesmo dia, por exemplo. As respostas sim às perguntas são pontuadas com um ponto. A resposta não ou não sabe não são pontuadas. As questões múltiplas, como a 46, 51, 52, 93, entre outras, são pontuadas apenas com um ponto. Existem algumas perguntas na entrevista sobre o prejuízo ou disfunção que aqueles sintomas de determinado domínio causaram no sujeito, que não são pontuadas.. São as perguntas 28,57 , $67,80,108,131,161$. A maioria das questões refere-se a períodos de 3 a 5 dias de duração, que ocorreram inclusive quando a pessoa era criança. 
Vários escores são possíveis com o uso da SCI-MOODS: o total ou a soma de todos os itens pontuáveis, que varia de 0 a 154; o depressivo, que é a soma do humor, energia e cognição depressivos, variando entre 0 e 63; o maníaco, isto é, a soma dos subdomínios maníacos, entre 0 e 62; e o escore dos domínios humor (0 a 56), energia (0 a 21), cognição (0 a 49) e ritmicidade (0 a 29) (Cassano, 2006).

\subsection{2) SCID-I/P}

A Entrevista Clínica Estruturada para o DSM-IV Transtornos do Eixo I, Versão de Pacientes (SCID-I/P) foi utilizada como padrão-ouro no diagnóstico dos sujeitos bipolares, unipolares, esquizofrenia e controles sem patologia psiquiátrica (First et al., 1995). A versão utilizada foi a 2.0. Nos controles sem patologia psiquiátrica toda a entrevista foi feita. Nos três primeiros grupos não foram perguntadas questões referentes aos transtornos de ansiedade, somatoformes, alimentares e opcionais, por não serem objetivo principal deste trabalho. Além disso, estas categorias da entrevista não influenciavam nos critérios de inclusão e exclusão do estudo.

\section{3) ANÁLISE ESTATÍSTICA}

A consistência interna da SCI-MOODS-VP, seus domínios e subdomínios, foi calculada pelo alfa de Cronbach. A confiabilidade entre examinadores foi avaliada pela correlação intra-classe (ICC). A comparação entre mais de duas variáveis 
contínuas foi feita por análise de variância (ANOVA) e entre duas pelo teste $t$ de Student (Vieira, 1991). O equivalente não-paramétrico da ANOVA, o teste de Kruskal Wallis foi utilizado para confirmar os resultados da ANOVA (Vieira, 1991). Para saber onde estava esta diferença entre grupos dada pela ANOVA, optou-se pela técnica de post hoc de Dunnett, que é feita quando as variâncias das amostras não são semelhantes. A significância estatística de $5 \%$ foi corrigida pelo teste de Bonferroni. Variáveis categoriais foram abordadas por qui-quadrado (Vieira, 1991). As curvas ROC foram utilizadas para decidir o melhor escore da SCI-MOODS-VP pela relação entre sensibilidade e especificidade no diagnóstico diferencial de: bipolares e unipolares; afetivos e controles (Swets et al. ,2000). A correlação parcial de Pearson foi calculada entre os domínios e subdomínios da SCI-MOODS-VP. A análise discriminante passo a passo progressiva (forward stepwise) foi feita para determinar os subdomínios que melhor diferenciavam os sujeitos bipolares de unipolares. O método utilizado foi o do Wilks lambda. Optouse por uma probabilidade de inclusão conservadora na função discriminante canônica de um $p$ menor que 0,01 . Como critério de exclusão o $p$ selecionado foi de 0,1 (Duarte e Silva e Stam, 1995). Os cálculos estatísticos foram feitos pelo software SPSS versão 12.0 (SPSS, 2003). 


\section{3) RESULTADOS}

\section{1) ESTUDO PILOTO}

O objetivo do projeto piloto foi avaliar as dificuldades na compreensão e aceitação das questões da SCI-MOODS-VP dos sujeitos. Em geral a aceitação do instrumento foi boa. Dentre os participantes do projeto piloto não houve recusas em participar do estudo. As características demográficas e pontuações dos domínios e subdomínios da SCl-MOODS-VP dos 20 primeiros sujeitos do estudo,unipolares e bipolares, que compuseram a amostra do projeto piloto estão na tabela 2. Não houve diferenças significativas em relação a sexo, idade, escolaridade, estado civil, local onde os sujeitos foram selecionados ou estar trabalhando entre bipolares e unipolares. Dentre as pontuações da entrevista, foram significativamente diferentes os seguintes domínios: humor, energia, cognição ( $p<0,05$, teste $t$ bicaudado). Além disso, todos os sub domínios maníacos e cognição depressiva também apresentaram diferença significativa, além dos escores total, maníaco e depressivo $(p<0,05$, teste $t)$.

A população estudada, por exemplo, não entendeu o significado da palavra "assertivo(a)" na questão 76 do sub domínio energia maníaca (em) "você foi mais assertivo(a) ?" (“...you were very assertive ?"). A explicação do conceito de assertividade pelo examinador tornou então a entrevista mais demorada e cansativa. No dicionário de língua portuguesa Aurélio o termo "afirmativo" aparece como sinônimo de "assertivo" (Aurélio, 2004), o que também não facilitaria a compreensão da questão por uma população de baixa escolaridade. Então, 
decidiu-se reformular a questão como "..você fazia afirmações sem se importar com o que os outros iam pensar ?" (ver anexo B).

Tabela 2 -Características demográficas e pontuações da SCI-MOODS-VP dos primeiro vinte sujeitos do estudo piloto

\begin{tabular}{lr|r}
\hline & BIPOLARES & UNIPOLARES \\
\hline Número & 11 & 9 \\
Idade (m \pm DP) & $44 \pm 7,01$ & $45,78 \pm 8,04$ \\
Sexo feminino & 9 & 5 \\
São Paulo & 7 & 5 \\
Escolaridade $<8$ anos & 6 & 5 \\
Casado(a) & 3 & 3 \\
Trabalhando & 1 & 4 \\
Humor & 34,64 & $26^{1}$ \\
Humor depressivo & 18,45 & 17,33 \\
Humor maníaco & 16,18 & $8,67^{1}$ \\
Energia & 17 & $10,33^{1}$ \\
Energia depressiva & 6,27 & 4,67 \\
Energia maníaca & 10,73 & $5,67^{1}$ \\
Cognição & 31,55 & $23,30^{1}$ \\
Cognição depressiva & 20,09 & $14,78^{1}$ \\
Cognição maníaca & 11,45 & $7,33^{1}$ \\
Ritmicidade & 15,91 & 13,89 \\
Escore depressivo & 44,82 & $36,78^{1}$ \\
Escore maníaco & 38,36 & $21,67^{1}$ \\
Escore Total & 99,09 & $72,33^{1}$ \\
\hline \hline
\end{tabular}




\section{2) ESTUDO PRINCIPAL}

\subsection{1) Sujeitos}

Para o trabalho de validação foram selecionados 47 sujeitos bipolares, 47 unipolares, 18 esquizofrênicos e 22 normais. Não houve diferenças significativas em relação ao sexo, idade, local de seleção, escolaridade, trabalho e estado civil entre bipolares e unipolares. Todos os sujeitos esquizofrênicos foram selecionados em Curitiba e os normais em São Paulo. A maioria dos bipolares foi recrutada em São Paulo (31) e dos unipolares (26) em Curitiba. A tabela 3 mostra as características demográficas dos quatro grupos.

Os sujeitos normais eram mais jovens que os bipolares e depressivos (ANOVA, $p=0,002$ ), não havendo diferença significativa entre bipolares, unipolares e esquizofrenicos (post hoc Dunnett' C). Apenas um esquizofrênico era casado, ao contrário dos doze normais (qui-quadrado, 2 lados, $p=0,001$ ). Além disso, os sujeitos sem diagnóstico psiquiátrico apresentavam maior escolaridade que os esquizofrênicos (qui-quadrado, 2 lados, $p=0,003$ ). Apenas dois esquizofrênicos estavam trabalhando, ao contrário dos outros grupos (qui-quadrado, dois lados, $p=0,000)$. 
Tabela 3 - Características demográficas dos sujeitos

\begin{tabular}{|c|c|c|c|c|}
\hline & BIPOLARES & UNIPOLARES & ESQUIZOFRENIA & NORMAIS \\
\hline Número & 47 & 47 & 18 & 22 \\
\hline Idade (m \pm DP) & $39,8 \pm 10$ & $42,2 \pm 10,7$ & $34,7 \pm 11,1$ & $33,4 \pm 6,4^{1}$ \\
\hline \multicolumn{5}{|l|}{ Sexo } \\
\hline Feminino & 34 & 29 & 7 & 16 \\
\hline Masculino & 13 & 18 & 11 & 6 \\
\hline \multicolumn{5}{|l|}{ Local } \\
\hline São Paulo & 31 & 21 & 0 & 22 \\
\hline Curitiba & 16 & 26 & 18 & 0 \\
\hline \multicolumn{5}{|l|}{ Estado Civil } \\
\hline Casados & 16 & 25 & $1^{2}$ & 12 \\
\hline Solteiros & 20 & 15 & 15 & 10 \\
\hline Separados & 11 & 5 & 2 & 0 \\
\hline Viúvos & 0 & 2 & 0 & 0 \\
\hline \multicolumn{5}{|l|}{ Ocupação } \\
\hline Trabalhando & 15 & 22 & $1^{2}$ & 19 \\
\hline $\begin{array}{l}\text { Estudando } \\
\text { ou do lar }\end{array}$ & 6 & 6 & 1 & 2 \\
\hline $\begin{array}{l}\text { Desempregado } \\
\text { ou Aposentado }\end{array}$ & 26 & 19 & 16 & 1 \\
\hline \multicolumn{5}{|l|}{ Escolaridade } \\
\hline Fundamental & 19 & 21 & 6 & 0 \\
\hline Médio & 18 & 13 & 8 & 16 \\
\hline Superior & 7 & 13 & $4^{2}$ & 6 \\
\hline Pós-graduação & 3 & 0 & 0 & 0 \\
\hline
\end{tabular}

\subsection{2) Resultados da SCID-I/P}

A maior parte dos depressivos apresentava depressão recorrente e dos bipolares eram do tipo 1, de acordo com a SCID. Os normais, de acordo com os critérios de inclusão, não apresentavam diagnósticos e os esquizofrênicos eram principalmente do subtipo desorganizado. Os outros esquizofrênicos dividiram-se entre o subtipo paranóide, com cinco e um sujeito com o residual. Houve seis sujeitos com história de dependência de álcool, porém estavam abstinentes nos últimos meses, de acordo com os critérios de inclusão. Destes, quatro eram 
bipolares e dois unipolares. Um bipolar também apresentou na vida dependência de cannabis e cocaína. O outro sujeito com histórico no passado de dependência de cannabis era uma mulher com TB do tipo 2. Não foram avaliadas as sessões da SCID referentes aos transtornos de ansiedade, somatoformes, dissociativos e alimentares. Os diagnósticos pela SCID e comorbidades estão na tabela 4 .

Tabela 4 - Resultados da SCID-I/P

\begin{tabular}{l|r}
\hline DIAGNÓSTICO & NÚMERO \\
\hline Transtorno Bipolar tipo 1 & 38 \\
Transtorno Bipolar tipo 2 & 9 \\
Depressão Maior, recorrente & 35 \\
Episódio Depressivo Maior & 12 \\
Esquizofrenia Desorganizada & 12 \\
Esquizofrenia Paranóide & 5 \\
Esquizofrenia Residual & 1 \\
Ausência de diagnóstico & 22 \\
Dependência Álcool & 6 \\
Dependência Cannabis & 2 \\
Dependência Cocaína & 1 \\
\hline
\end{tabular}

\subsection{3) Confiabilidade}

A consistência interna dos domínios e subdomínios da SCI-MOODS-VP variou entre 0,862 e 0,942 (tabela 5). A maior consistência interna ocorreu no domínio cognição, especialmente na cognição depressiva $(0,938)$. Todos os subdomínios depressivos apresentaram melhor consistência interna que os maníacos. 
Tabela 5 - Consistência interna (Cl) da SCI-MOODS-VP

\begin{tabular}{lll}
\hline DOMÍNIO & Cl & ÍTENS \\
\hline Humor & 0,939 & 57 \\
Humor depressivo & 0,933 & 28 \\
Humor maníaco & 0,881 & 29 \\
Energia & 0,922 & 23 \\
Energia depressiva & 0,901 & 10 \\
Energia maníaca & 0,864 & 13 \\
Cognição & 0,942 & 51 \\
Cognição depressiva & 0,938 & 28 \\
Cognição maníaca & 0,862 & 23 \\
Ritmicidade & 0,869 & 30 \\
\hline
\end{tabular}

Além da consistência interna, a confiabilidade também foi avaliada entre examinadores. Um grupo de 10 sujeitos unipolares e 10 bipolares foram selecionados na amostra total e entrevistados por dois psiquiatras ao mesmo tempo. A tabela 6 apresenta as características demográficas e pontuações da SCI-MOODS-VP de bipolares e unipolares do estudo de confiabilidade entre examinadores. Não houve diferença significativa entre bipolares e unipolares em relação a sexo, idade média, escolaridade, sujeitos atualmente trabalhando, casados. Os primeiros apresentavam pontuações significativamente maiores que os últimos nos domínios humor, energia e cognição, além dos subdomínios maníacos. 
Tabela 6 - Características dos sujeitos do estudo de confiabilidade entre examinadores

\begin{tabular}{|c|c|c|}
\hline & BIPOLARES & UNIPOLARES \\
\hline Número & 10 & 10 \\
\hline 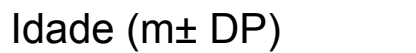 & $40,6 \pm 11$ & $38,5 \pm 12,9$ \\
\hline Sexo feminino & 5 & 6 \\
\hline São Paulo & 6 & 4 \\
\hline Escolaridade $<8$ anos & 4 & 8 \\
\hline Casado(a) & 3 & 5 \\
\hline Trabalhando & 4 & 4 \\
\hline Humor & 37,7 & $26^{*}$ \\
\hline Humor depressivo & 18,9 & 17,8 \\
\hline Humor maníaco & 18,8 & $8,2^{*}$ \\
\hline Energia & 17,1 & $11,2^{*}$ \\
\hline depressiva & 7,4 & 5,8 \\
\hline Energia maníaca & 9,7 & $5,4^{*}$ \\
\hline Cognição & 34,7 & $24,1^{*}$ \\
\hline Cognição depressiva & 19,9 & 17 \\
\hline Cognição maníaca & 14,8 & $7,1^{*}$ \\
\hline Ritmic & 16,4 & 14,9 \\
\hline Escore depressivo & 46,2 & 40,6 \\
\hline Escore maníaco & 43,3 & $20,7^{*}$ \\
\hline Escore Total & 105,9 & $76,2^{*}$ \\
\hline
\end{tabular}

NOTA: ${ }^{\star} p<0,05$

A tabela 7 compara a amostra de bipolares e unipolares $(n=94)$ do estudo original com a utilizada no estudo de confiabilidade entre examinadores $(n=20)$. Não houve diferença significativa nas pontuações da SCI-MOODS-VP e em características demográficas nas populações. O coeficiente de correlação intraclasse foi de 0.956 (Cl $95 \%$ 0,934-0,973 p=0.000). 
Tabela 7 - Comparação entre a amostra original de bipolares e unipolares $(n=94)$ e da do estudo de confiabilidade entre examinadores $(n=20)$

\begin{tabular}{|c|c|c|c|}
\hline & ORIGINAL & CONFIABILIDADE & $\mathrm{p}$ \\
\hline Número & 94 & 20 & \\
\hline São Paulo & 53 & 10 & 0,602 \\
\hline Sexo fem & 63 & 11 & 0,306 \\
\hline Idade (mะ DP) & $40,98 \pm 10,38$ & $39,55 \pm 11,70$ & 0,586 \\
\hline $\begin{array}{ll}\text { Escolaridade } & <8 \\
\text { anos } & \end{array}$ & 29 & 3 & 0,533 \\
\hline Trabalhando & 37 & 7 & 0,685 \\
\hline Casado(a) & 41 & 8 & 0,767 \\
\hline Humor & 31,76 & 31,85 & 0,960 \\
\hline Humor depressivo & 18,57 & 18,35 & 0,816 \\
\hline Humor maníaco & 13,18 & 13,50 & 0,830 \\
\hline Energia & 13,91 & 14,15 & 0,844 \\
\hline $\begin{array}{l}\text { Energia } \\
\text { depressiva }\end{array}$ & 6,17 & 6,17 & 0,522 \\
\hline Energia maníaca & 7,74 & 7,55 & 0,799 \\
\hline Cognição & 28,02 & 29,40 & 0,479 \\
\hline $\begin{array}{l}\text { Cognição } \\
\text { depressiva }\end{array}$ & 18,35 & 18,45 & 0,927 \\
\hline $\begin{array}{l}\text { Cognição } \\
\text { maníaca }\end{array}$ & 9,66 & 10,95 & 0,290 \\
\hline Ritmicidade & 15,28 & 15,65 & 0,712 \\
\hline $\begin{array}{l}\text { Escore } \\
\text { depressivo }\end{array}$ & 43,10 & 43,40 & 0,895 \\
\hline Escore maníaco & 30,59 & 32,00 & 0,651 \\
\hline Escore Total & 88,96 & 91,05 & 0,683 \\
\hline
\end{tabular}

\subsection{4) Correlação parcial}

As correlações parciais entre domínios e subdomínios da SCI-MOODS-VP, controlada por idade e sexo, aparecem na tabela 8. Todas as correlações da tabela foram significativas para um $p$ menor que 0,005 . Estas variaram entre 0,472 (humor maníaco e energia depressiva) e 0,937 (cognição depressiva e cognição). Os subdomínios depressivos e maníacos entre si tiveram correlação maior que os depressivos e maníacos. 
Tabela 8 - Correlação parcial entre domínios e subdomínios da SCI-MOODS-VP, controlada por idade e sexo ${ }^{1}$

\begin{tabular}{llllllllll|l|l|l}
\hline & $H$ & $E$ & $C$ & $R$ & $h d$ & $h m$ & ed & em & $c d$ & $\mathrm{~cm}$ \\
\hline $\mathrm{H}$ & 1 & & & & & & & & & \\
$\mathrm{E}$ & 0,84 & 1 & & & & & & & & \\
$\mathrm{C}$ & 0.86 & 0,86 & 1 & & & & & & & \\
$\mathrm{R}$ & 0.78 & 0.73 & 0.79 & 1 & & & & & & \\
$\mathrm{hd}$ & 0.90 & 0.77 & 0.79 & 0.77 & 1 & & & & & \\
$\mathrm{hm}$ & 0.86 & 0.71 & 0.71 & 0.58 & 0.55 & 1 & & & & \\
$\mathrm{ed}$ & 0.71 & 0.89 & 0.75 & 0.68 & 0.76 & 0.47 & 1 & & & \\
$\mathrm{em}$ & 0.81 & 0.92 & 0.80 & 0.65 & 0.64 & 0.79 & 0.64 & 1 & & \\
$\mathrm{~cd}$ & 0.82 & 0.83 & 0.94 & 0.78 & 0.84 & 0.58 & 0.81 & 0.71 & 1 & \\
$\mathrm{~cm}$ & 0.70 & 0.70 & 0.86 & 0.62 & 0.53 & 0.72 & 0.49 & 0.76 & 0.622 & 1 \\
\hline
\end{tabular}

NOTA: ${ }^{1}$ todas as correlações foram significativas para $p<0,05$

$C=$ cognição; $c d=$ cognição depressiva; $\mathrm{cm}=$ cognição maníaca;

$E=$ energia; ed=energia depressiva ;em=energia maníaca; $H=$ humor;

$h d=$ humor depressivo; $h m=h u m o r$ maníaco; $R=$ ritmicidade .

3.2.5) Validade discriminante

A validade discriminante foi determinada pela capacidade da SCI-MOODS VP em diferenciar bipolares de outros grupos, principalmente unipolares. Os escores médios de cada domínio e subdomínio, além de escores de mania, depressão e total da SCI-MOODS - VP estão na tabela 9. O escore total médio dos bipolares foi em torno de 100, para um máximo de 154. O dos unipolares e esquizofrenia foi cerca de $25 \%$ menor. O maníaco médio foi de 39 para os bipolares e 22 para os unipolares. 
Tabela 9 - Escore médio ( \pm desvio padrão) dos domínios e subdomínios da SCIMOODS-VP em bipolares, unipolares, esquizofrenia, normais e amostra total

\begin{tabular}{lrrrrrr}
\hline & BIPOLARES & UNIPOLARES & ESQUIZOFRENIA & NORMAIS & TOTAL \\
\hline $\mathrm{H}$ & $36,28 \pm 5,10$ & $27,23 \pm 6,75$ & $23,39 \pm 7,9$ & $6,64 \pm 7,37$ & $26,51 \pm 11,91$ \\
$\mathrm{hd}$ & $19,15 \pm 3,63$ & $18,00 \pm 3,98$ & $13,22 \pm 5,87$ & $1,96 \pm 4,30$ & $15,13 \pm 7,43$ \\
$\mathrm{hm}$ & $17,13 \pm 3,28$ & $9,23 \pm 5,19$ & $10,17 \pm 3,55$ & $4,68 \pm 3,97$ & $11,38 \pm 6,17$ \\
$\mathrm{E}$ & $16,75 \pm 2,97$ & $11,09 \pm 4,47$ & $11,17 \pm 3,00$ & $1,41 \pm 1,71$ & $11,49 \pm 6,18$ \\
ed & $6,94 \pm 2,14$ & $5,40 \pm 2,92$ & $5,44 \pm 1,72$ & $0,18 \pm 0,66$ & $5,09 \pm 3,20$ \\
em & $9,81 \pm 1,93$ & $5,68 \pm 2,66$ & $5,72 \pm 1,84$ & $1,23 \pm 1,38$ & $6,40 \pm 3,64$ \\
$\mathrm{C}$ & $32,09 \pm 6,56$ & $23,96 \pm 6,61$ & $28,17 \pm 7,39$ & $3,59 \pm 4,13$ & $24,03 \pm 11,58$ \\
$\mathrm{~cd}$ & $19,85 \pm 3,71$ & $16,85 \pm 4,70$ & $16,72 \pm 5,02$ & $0,73 \pm 1,88$ & $15,24 \pm 7,73$ \\
$\mathrm{~cm}$ & $12,23 \pm 4,25$ & $7,09 \pm 3,91$ & $11,44 \pm 3,84$ & $2,86 \pm 2,88$ & $8,78 \pm 5,17$ \\
$\mathrm{R}$ & $16,38 \pm 4,00$ & $14,17 \pm 3,85$ & $12,33 \pm 4,47$ & $3,55 \pm 3,84$ & $12,96 \pm 5,91$ \\
$\mathrm{D}$ & $45,94 \pm 7,75$ & $40,26 \pm 9,83$ & $35,39 \pm 10,83$ & $2,86 \pm 6,68$ & $35,46 \pm 17,29$ \\
$\mathrm{M}$ & $39,17 \pm 8,00$ & $22,00 \pm 9,81$ & $27,33 \pm 7,56$ & $8,77 \pm 6,82$ & $26,57 \pm 13,64$ \\
$\mathrm{~T}$ & $101,49 \pm 14,7$ & $76,43 \pm 17,05$ & $75,06 \pm 19,39$ & $15,18 \pm 15,03$ & $74,98 \pm 33,16$ \\
\hline
\end{tabular}

NOTA: $\mathrm{HD}=$ humor depressivo; $\mathrm{HM}=$ humor maníaco; $\mathrm{ED}=$ energia depressiva ;EM=energia maníaca; $\mathrm{CD}=$ cognição depressiva; $\mathrm{CM}=$ cognição maníaca; $\mathrm{H}=$ humor; $\mathrm{E}=$ energia; $\mathrm{C}=$ cognição; $\mathrm{R}=$ ritmicidade; $\mathrm{D}=$ escore depressivo; $\mathrm{M}=$ escore maníaco; $\mathrm{T}=$ escore total.

O teste de ANOVA está na tabela 10. Houve diferença significativa em todos os escores médios da SCl-MOODS-VP $(p=0,000)$. Em relação ao escore de mania, os bipolares apresentaram pontuação significativamente maior que unipolares, esquizofrenia e normais. Os grupos de pacientes, inclusive unipolares, também apresentaram escores maníacos maiores que os normais. $\mathrm{O}$ mesmo ocorreu para o escore total, humor e energia maníacos. Na cognição maníaca, os bipolares e os esquizofrenia tiveram valores significativamente maiores que unipolares e normais, e os unipolares que os normais. Quanto ao escore depressivo, humor, energia e cognição depressivos, além da ritmicidade, todos os grupos de pacientes tiveram escores maiores que os controles normais, porém não houve diferença entre eles. Estas diferenças, de acordo com o post hoc Dunnett $C$ para $p<0,004$ (correção de Bonferrroni de 0,05 dividido por 13 testes), estão na tabela 11. 
O teste de Kruskal Wallis, alternativa não-paramétrica a ANOVA, também demonstrou diferença significativa $(p=0,000)$ entre os grupos quanto ao escore total, depressivo, maníaco, dos domínios e subdomínios da SCI-MOODS-VP (tabela 12).

Tabela 10 -ANOVA de escores depressivo, maníaco, total, de domínios e subdomínios da SCI-MOODS-VP

\begin{tabular}{l|l|l}
\hline & $\mathrm{F}$ & $\mathrm{p}$ \\
\hline Humor & 105,41 & 0,000 \\
Humor depressivo & 94,45 & 0,000 \\
Humor maníaco & 52,91 & 0,000 \\
Energia & 99,80 & 0,000 \\
Energia depressiva & 45,64 & 0,000 \\
Energia maníaca & 85,02 & 0,000 \\
Cognição & 103,09 & 0,000 \\
Cognição depressiva & 116,70 & 0,000 \\
Cognição maníaca & 35,29 & 0,000 \\
Ritmicidade & 54,06 & 0,000 \\
Escore Depressivo & 126,69 & 0,000 \\
Escore Maníaco & 71,69 & 0,000 \\
Escore Total & 140,59 & 0,000 \\
\hline
\end{tabular}


Tabela 11 - Diferenças entre escores de domínios e subdomínios da SClMOODS-VP de sujeitos no Post Hoc Dunnett C de ANOVA

\begin{tabular}{|c|c|c|c|c|c|c|}
\hline & \multirow{2}{*}{ (I) TIPO } & \multirow{2}{*}{ (J) TIPO } & \multirow{2}{*}{ DM (I-J) } & \multirow{2}{*}{ EP } & \multicolumn{2}{|c|}{ IC $99,6 \%$} \\
\hline & & & & & $\mathrm{LI}$ & LS \\
\hline \multirow[t]{12}{*}{ Escore Maníaco } & bipolar & unipolar & $17,17^{*}$ & 1,85 & 10,50 & 23,85 \\
\hline & & esquizofrenia & $11,84^{*}$ & 2,13 & 3,46 & 20,22 \\
\hline & & normal & $30,40 *$ & 1,87 & 23,30 & 37,49 \\
\hline & unipolar & bipolar & $-17,17^{*}$ & 1,85 & $-23,85$ & $-10,50$ \\
\hline & & esquizofrenia & $-5,33$ & 2,29 & $-14,23$ & 3,56 \\
\hline & & normal & $13,23^{*}$ & 2,04 & 5,53 & 20,93 \\
\hline & esquizofrenia & bipolar & $-11,84^{*}$ & 2,13 & $-20,22$ & $-3,46$ \\
\hline & & unipolar & 5,33 & 2,29 & $-3,56$ & 14,23 \\
\hline & & normal & $18,56^{*}$ & 2,30 & 9,33 & 27,79 \\
\hline & normal & bipolar & $-30,40^{*}$ & 1,87 & $-37,49$ & $-23,30$ \\
\hline & & unipolar & $-13,23^{*}$ & 2,04 & $-20,93$ & $-5,53$ \\
\hline & bipolar & $\begin{array}{l}\text { esquizofrenia } \\
\text { unipolar }\end{array}$ & $\begin{array}{r}-18,56^{*} \\
5,68\end{array}$ & $\begin{array}{l}2,30 \\
1,83\end{array}$ & $\begin{array}{r}-27,79 \\
-0,92\end{array}$ & $\begin{array}{l}-9,33 \\
12,28\end{array}$ \\
\hline \multirow{8}{*}{$\begin{array}{l}\text { Escore } \\
\text { Depressivo }\end{array}$} & & esquizofrenia & 10,55 & 2,79 & $-0,61$ & 21,70 \\
\hline & & normal & $43,07^{*}$ & 1,82 & 36,16 & 49,99 \\
\hline & unipolar & bipolar & $-5,68$ & 1,83 & $-12,28$ & 0,92 \\
\hline & & esquizofrenia & 4,87 & 2,93 & $-6,73$ & 16,46 \\
\hline & & normal & $37,39 *$ & 2,02 & 29,78 & 45,01 \\
\hline & esquizofrenia & bipolar & $-10,55$ & 2,79 & $-21,70$ & 0,61 \\
\hline & & unipolar & $-4,87$ & 2,93 & $-16,46$ & 6,73 \\
\hline & normal & $\begin{array}{l}\text { normal } \\
\text { bipolar } \\
\text { unipolar }\end{array}$ & $\begin{array}{r}32,53^{*} \\
-43,07^{*} \\
-37,39^{*}\end{array}$ & $\begin{array}{l}2,92 \\
1,82 \\
2,02\end{array}$ & $\begin{array}{r}20,73 \\
-49,99 \\
-45,01\end{array}$ & $\begin{array}{r}44,32 \\
-36,16 \\
-29,78\end{array}$ \\
\hline \multirow[t]{12}{*}{ Escore Total } & bipolar & $\begin{array}{l}\text { esquizofrenia } \\
\text { unipolar }\end{array}$ & $\begin{array}{l}-32,53^{*} \\
25,06^{*}\end{array}$ & $\begin{array}{l}2,92 \\
3,28\end{array}$ & $\begin{array}{r}-44,32 \\
13,19\end{array}$ & $\begin{array}{r}-20,73 \\
36,94\end{array}$ \\
\hline & & esquizofrenia & $26,43^{*}$ & 5,05 & 6,29 & 46,58 \\
\hline & & normal & $86,31^{*}$ & 3,86 & 71,54 & 101,07 \\
\hline & unipolar & bipolar & $-25,06^{*}$ & 3,28 & $-36,94$ & $-13,19$ \\
\hline & & esquizofrenia & 1,37 & 5,20 & $-19,27$ & 22,01 \\
\hline & & normal & $61,24^{*}$ & 4,06 & 45,80 & 76,69 \\
\hline & esquizofrenia & bipolar & $-26,43^{*}$ & 5,05 & $-46,58$ & $-6,29$ \\
\hline & & unipolar & $-1,37$ & 5,20 & $-22,01$ & 19,27 \\
\hline & & normal & $59,87^{*}$ & 5,58 & 37,42 & 82,33 \\
\hline & normal & bipolar & $-86,31^{*}$ & 3,86 & $-101,07$ & $-71,54$ \\
\hline & & unipolar & $-61,24^{*}$ & 4,06 & $-76,69$ & $-45,80$ \\
\hline & & esquizofrenia & $-59,87^{*}$ & 5,58 & $-82,33$ & $-37,42$ \\
\hline
\end{tabular}


Tabela 11 - Diferenças entre escores de domínios e subdomínios da SCI-MOODSVP de sujeitos no Post Hoc Dunnett C de ANOVA

\begin{tabular}{|c|c|c|c|c|c|c|}
\hline & & & \multicolumn{4}{|c|}{ continuação } \\
\hline & \multirow[t]{2}{*}{ (I) TIPO } & \multirow[t]{2}{*}{ (J) TIPO } & \multirow[t]{2}{*}{ DM (I-J) } & \multirow[t]{2}{*}{ EP } & \multicolumn{2}{|c|}{ IC $99,6 \%$} \\
\hline & & & & & $\mathrm{LI}$ & LS \\
\hline \multirow{12}{*}{$\begin{array}{l}\text { Humor } \\
\text { depressivo }\end{array}$} & \multirow[t]{3}{*}{ bipolar } & unipolar & 1,15 & 0,79 & $-1,69$ & 3,99 \\
\hline & & esquizofrenia & 5,93 & 1,48 & $-0,02$ & 11,87 \\
\hline & & normal & $17,19^{*}$ & 1,06 & 13,12 & 21,27 \\
\hline & \multirow[t]{3}{*}{ unipolar } & bipolar & $-1,15$ & 0,79 & $-3,99$ & 1,69 \\
\hline & & esquizofrenia & 4,78 & 1,50 & $-1,23$ & 10,78 \\
\hline & & normal & $16,05^{*}$ & 1,09 & 11,88 & 20,21 \\
\hline & \multirow[t]{3}{*}{ esquizofrenia } & bipolar & $-5,93$ & 1,48 & $-11,87$ & 0,02 \\
\hline & & unipolar & $-4,78$ & 1,50 & $-10,78$ & 1,23 \\
\hline & & normal & $11,27^{*}$ & 1,66 & 4,59 & 17,95 \\
\hline & \multirow[t]{3}{*}{ normal } & bipolar & $-17,19^{*}$ & 1,06 & $-21,27$ & $-13,12$ \\
\hline & & unipolar & $-16,05^{*}$ & 1,09 & $-20,21$ & $-11,88$ \\
\hline & & $\begin{array}{l}\text { esquizofrenia } \\
\text { unipolar }\end{array}$ & $\begin{array}{r}-11,27^{*} \\
7,89^{*}\end{array}$ & $\begin{array}{l}1,66 \\
0,90\end{array}$ & $\begin{array}{r}-17,95 \\
4,66\end{array}$ & $\begin{array}{l}-4,59 \\
11,13\end{array}$ \\
\hline \multirow{11}{*}{$\begin{array}{l}\text { Humor } \\
\text { maníaco }\end{array}$} & \multirow{2}{*}{ bipolar } & esquizofrenia & $6,96^{*}$ & 0,96 & 3,14 & 10,78 \\
\hline & & normal & $12,45^{*}$ & 0,97 & 8,70 & 16,19 \\
\hline & \multirow[t]{3}{*}{ unipolar } & bipolar & $-7,89^{*}$ & 0,90 & $-11,13$ & $-4,66$ \\
\hline & & esquizofrenia & $-0,93$ & 1,13 & $-5,30$ & 3,43 \\
\hline & & normal & $4,55^{\star}$ & 1,14 & 0,25 & 8,85 \\
\hline & \multirow[t]{3}{*}{ esquizofrenia } & bipolar & $-6,96^{*}$ & 0,96 & $-10,78$ & $-3,14$ \\
\hline & & unipolar & 0,93 & 1,13 & $-3,43$ & 5,30 \\
\hline & & normal & $5,49^{*}$ & 1,19 & 0,73 & 10,24 \\
\hline & \multirow[t]{3}{*}{ normal } & bipolar & $-12,45^{*}$ & 0,97 & $-16,19$ & $-8,70$ \\
\hline & & unipolar & $-4,55^{*}$ & 1,14 & $-8,85$ & $-0,25$ \\
\hline & & $\begin{array}{l}\text { esquizofrenia } \\
\text { unipolar }\end{array}$ & $\begin{array}{r}-5,49^{*} \\
1,53\end{array}$ & $\begin{array}{l}1,19 \\
0,53\end{array}$ & $\begin{array}{r}-10,24 \\
-0,38\end{array}$ & $\begin{array}{r}-0,73 \\
3,44\end{array}$ \\
\hline \multirow{11}{*}{$\begin{array}{l}\text { Energia } \\
\text { depressiva }\end{array}$} & \multirow{2}{*}{ bipolar } & esquizofrenia & 1,49 & 0,51 & $-0,51$ & 3,49 \\
\hline & & normal & $6,75^{*}$ & 0,34 & 5,50 & 8,01 \\
\hline & \multirow[t]{3}{*}{ unipolar } & bipolar & $-1,53$ & 0,53 & $-3,44$ & 0,38 \\
\hline & & esquizofrenia & $-0,04$ & 0,59 & $-2,29$ & 2,21 \\
\hline & & normal & $5,22^{*}$ & 0,45 & 3,59 & 6,86 \\
\hline & \multirow[t]{3}{*}{ esquizofrenia } & bipolar & $-1,49$ & 0,51 & $-3,49$ & 0,51 \\
\hline & & unipolar & 0,04 & 0,59 & $-2,21$ & 2,29 \\
\hline & & normal & $5,26^{*}$ & 0,43 & 3,52 & 7,01 \\
\hline & \multirow[t]{2}{*}{ normal } & bipolar & $-6,75^{*}$ & 0,34 & $-8,01$ & $-5,50$ \\
\hline & & unipolar & $-5,22^{*}$ & 0,45 & $-6,86$ & $-3,59$ \\
\hline & \multirow{3}{*}{ bipolar } & $\begin{array}{l}\text { esquizofrenia } \\
\text { unipolar }\end{array}$ & $\begin{array}{r}-5,26^{*} \\
4,13^{*}\end{array}$ & $\begin{array}{l}0,43 \\
0,48\end{array}$ & $\begin{array}{r}-7,01 \\
2,39\end{array}$ & $\begin{array}{r}-3,52 \\
5,86\end{array}$ \\
\hline \multirow{4}{*}{$\begin{array}{l}\text { Energia } \\
\text { maníaca }\end{array}$} & & esquizofrenia & $4,09^{*}$ & 0,52 & 2,05 & 6,12 \\
\hline & & normal & $8,58^{*}$ & 0,41 & 7,05 & 10,12 \\
\hline & \multirow[t]{2}{*}{ unipolar } & bipolar & $-4,13^{*}$ & 0,48 & $-5,86$ & $-2,39$ \\
\hline & & esquizofrenia & $-0,04$ & 0,58 & $-2,29$ & 2,21 \\
\hline
\end{tabular}


Tabela 11 - Diferenças entre escores de domínios e subdomínios da SCI-MOODSVP de sujeitos no Post Hoc Dunnett C de ANOVA

continuação

\begin{tabular}{|c|c|c|c|c|c|c|}
\hline & \multirow[t]{2}{*}{ (I) TIPO } & \multirow[t]{2}{*}{ (J) TIPO } & \multirow[t]{2}{*}{ DM (I-J) } & \multirow[t]{2}{*}{ EP } & \multicolumn{2}{|c|}{ IC 99,6\% } \\
\hline & & & & & $\mathrm{LI}$ & LS \\
\hline \multirow{17}{*}{$\begin{array}{l}\text { Cognição } \\
\text { depressiva }\end{array}$} & \multirow{4}{*}{ esquizofrenia } & normal & $4,45^{\star}$ & 0,49 & 2,64 & 6,27 \\
\hline & & bipolar & $-4,09^{*}$ & 0,52 & $-6,12$ & $-2,05$ \\
\hline & & unipolar & 0,04 & 0,58 & $-2,21$ & 2,29 \\
\hline & & normal & $4,50^{*}$ & 0,52 & 2,39 & 6,60 \\
\hline & \multirow[t]{2}{*}{ normal } & bipolar & $-8,58^{*}$ & 0,41 & $-10,12$ & $-7,05$ \\
\hline & & unipolar & $-4,45^{\star}$ & 0,49 & $-6,27$ & $-2,64$ \\
\hline & \multirow{3}{*}{ bipolar } & esquizofrenia & $-4,50^{*}$ & 0,52 & $-6,60$ & $-2,39$ \\
\hline & & unipolar & 3,00 & 0,87 & $-0,16$ & 6,16 \\
\hline & & esquizofrenia & 3,13 & 1,30 & $-2,06$ & 8,32 \\
\hline & \multirow{3}{*}{ unipolar } & normal & $19,12^{*}$ & 0,67 & 16,61 & 21,63 \\
\hline & & bipolar & $-3,00$ & 0,87 & $-6,16$ & 0,16 \\
\hline & & esquizofrenia & 0,13 & 1,37 & $-5,28$ & 5,54 \\
\hline & \multirow{3}{*}{ esquizofrenia } & normal & $16,12^{*}$ & 0,79 & 13,19 & 19,06 \\
\hline & & bipolar & $-3,13$ & 1,30 & $-8,32$ & 2,06 \\
\hline & & unipolar & $-0,13$ & 1,37 & $-5,54$ & 5,28 \\
\hline & \multirow{3}{*}{ normal } & normal & $15,99^{*}$ & 1,25 & 10,93 & 21,06 \\
\hline & & bipolar & $-19,12^{*}$ & 0,67 & $-21,63$ & $-16,61$ \\
\hline \multirow{7}{*}{$\begin{array}{l}\text { Cognição } \\
\text { maníaca }\end{array}$} & & unipolar & $-16,12^{*}$ & 0,79 & $-19,06$ & $-13,19$ \\
\hline & \multirow[t]{2}{*}{ bipolar } & $\begin{array}{l}\text { esquizofrenia } \\
\text { unipolar }\end{array}$ & $\begin{array}{r}-15,99^{*} \\
5,15^{*}\end{array}$ & $\begin{array}{l}1,25 \\
0,84\end{array}$ & $\begin{array}{r}-21,06 \\
2,11\end{array}$ & $\begin{array}{r}-10,93 \\
8,19\end{array}$ \\
\hline & & esquizofrenia & 0,79 & 1,10 & $-3,52$ & 5,10 \\
\hline & \multirow{3}{*}{ unipolar } & normal & $9,37^{*}$ & 0,87 & 6,08 & 12,66 \\
\hline & & bipolar & $-5,15^{*}$ & 0,84 & $-8,19$ & $-2,11$ \\
\hline & & esquizofrenia & $-4,36^{*}$ & 1,07 & $-8,57$ & $-0,15$ \\
\hline & \multirow{3}{*}{ esquizofrenia } & normal & $4,22^{*}$ & 0,84 & 1,05 & 7,39 \\
\hline \multirow{13}{*}{ Humor } & & bipolar & $-0,79$ & 1,10 & $-5,10$ & 3,52 \\
\hline & & unipolar & $4,36^{*}$ & 1,07 & 0,15 & 8,57 \\
\hline & \multirow[t]{2}{*}{ normal } & $\begin{array}{l}\text { normal } \\
\text { bipolar }\end{array}$ & $\begin{array}{r}8,58^{*} \\
-9,37^{*}\end{array}$ & $\begin{array}{l}1,09 \\
0,87\end{array}$ & $\begin{array}{r}4,18 \\
-12,66\end{array}$ & $\begin{array}{l}12,98 \\
-6,08\end{array}$ \\
\hline & & unipolar & $-4,22^{*}$ & 0,84 & $-7,39$ & $-1,05$ \\
\hline & \multirow[t]{2}{*}{ bipolar } & $\begin{array}{l}\text { esquizofrenia } \\
\text { unipolar }\end{array}$ & $\begin{array}{r}-8,58^{*} \\
9,04^{*}\end{array}$ & $\begin{array}{l}1,09 \\
1,24\end{array}$ & $\begin{array}{r}-12,98 \\
4,58\end{array}$ & $\begin{array}{l}-4,18 \\
13,51\end{array}$ \\
\hline & & esquizofrenia & $12,89^{*}$ & 2,01 & 4,85 & 20,93 \\
\hline & \multirow{3}{*}{ unipolar } & normal & $29,64^{*}$ & 1,74 & 22,91 & 36,37 \\
\hline & & bipolar & $-9,04^{*}$ & 1,24 & $-13,51$ & $-4,58$ \\
\hline & & esquizofrenia & 3,85 & 2,11 & $-4,52$ & 12,21 \\
\hline & \multirow{4}{*}{ esquizofrenia } & normal & $20,60^{*}$ & 1,86 & 13,48 & 27,72 \\
\hline & & bipolar & $-12,89^{*}$ & 2,01 & $-20,93$ & $-4,85$ \\
\hline & & unipolar & $-3,85$ & 2,11 & $-12,21$ & 4,52 \\
\hline & & normal & $16,75^{*}$ & 2,44 & 6,98 & 26,52 \\
\hline
\end{tabular}


Tabela 11 - Diferenças entre escores de domínios e subdomínios da SClMOODS-VP de sujeitos no Post Hoc Dunnett C de ANOVA

\begin{tabular}{|c|c|c|c|c|c|c|}
\hline & & & & & & Usão \\
\hline & (I) TIPO & (J) TIPO & DM (I-J) & EP & IC 9 & \\
\hline & & & & & $\mathrm{LI}$ & LS \\
\hline Humor & normal & bipolar & $-29,64^{*}$ & 1,74 & $-36,37$ & $-22,91$ \\
\hline & & unipolar & $-20,60^{*}$ & 1,86 & $-27,72$ & $-13,48$ \\
\hline & & esquizofrenia & $-16,75^{*}$ & 2,44 & $-26,52$ & $-6,98$ \\
\hline Energia & bipolar & unipolar & $5,66^{*}$ & 0,78 & 2,83 & 8,49 \\
\hline & & esquizofrenia & $5,58^{*}$ & 0,83 & 2,31 & 8,85 \\
\hline & & normal & $15,34^{*}$ & 0,57 & 13,22 & 17,46 \\
\hline & unipolar & bipolar & $-5,66^{*}$ & 0,78 & $-8,49$ & $-2,83$ \\
\hline & & esquizofrenia & $-0,08$ & 0,96 & $-3,79$ & 3,63 \\
\hline & & normal & $9,68^{*}$ & 0,75 & 6,92 & 12,43 \\
\hline & esquizofrenia & bipolar & $-5,58^{*}$ & 0,83 & $-8,85$ & $-2,31$ \\
\hline & & unipolar & 0,08 & 0,96 & $-3,63$ & 3,79 \\
\hline & & normal & $9,76^{*}$ & 0,79 & 6,55 & 12,97 \\
\hline & normal & bipolar & $-15,34^{*}$ & 0,57 & $-17,46$ & $-13,22$ \\
\hline & & unipolar & $-9,68^{*}$ & 0,75 & $-12,43$ & $-6,92$ \\
\hline & normal & esquizofrenia & $-9,76^{*}$ & 0,79 & $-12,97$ & $-6,55$ \\
\hline Cognição & bipolar & unipolar & $8,13^{*}$ & 1,36 & 3,22 & 13,04 \\
\hline & & esquizofrenia & 3,92 & 1,99 & $-3,96$ & 11,80 \\
\hline & & normal & $28,49^{*}$ & 1,30 & 23,61 & 33,38 \\
\hline & unipolar & bipolar & $-8,13^{*}$ & 1,36 & $-13,04$ & $-3,22$ \\
\hline & & esquizofrenia & $-4,21$ & 1,99 & $-12,10$ & 3,68 \\
\hline & & normal & $20,37^{*}$ & 1,31 & 15,47 & 25,27 \\
\hline & esquizofrenia & bipolar & $-3,92$ & 1,99 & $-11,80$ & 3,96 \\
\hline & & unipolar & 4,21 & 1,99 & $-3,68$ & 12,10 \\
\hline & & normal & $24,58^{*}$ & 1,95 & 16,69 & 32,46 \\
\hline & normal & bipolar & $-28,49^{*}$ & 1,30 & $-33,38$ & $-23,61$ \\
\hline & & unipolar & $-20,37^{\star}$ & 1,31 & $-25,27$ & $-15,47$ \\
\hline Ritmicidade & bipolar & $\begin{array}{l}\text { esquizofrenia } \\
\text { unipolar }\end{array}$ & $\begin{array}{r}-24,58^{*} \\
2,21\end{array}$ & $\begin{array}{l}1,95 \\
0,81\end{array}$ & $\begin{array}{r}-32,46 \\
-0,71\end{array}$ & $\begin{array}{r}-16,69 \\
5,14\end{array}$ \\
\hline & & esquizofrenia & 4,05 & 1,21 & $-0,73$ & 8,83 \\
\hline & & normal & $12,84^{*}$ & 1,01 & 9,00 & 16,68 \\
\hline & unipolar & bipolar & $-2,21$ & 0,81 & $-5,14$ & 0,71 \\
\hline & & esquizofrenia & 1,84 & 1,19 & $-2,91$ & 6,58 \\
\hline & & normal & $10,63^{*}$ & 0,99 & 6,83 & 14,42 \\
\hline & esquizofrenia & bipolar & $-4,05$ & 1,21 & $-8,83$ & 0,73 \\
\hline & & unipolar & $-1,84$ & 1,19 & $-6,58$ & 2,91 \\
\hline & & normal & $8,79^{*}$ & 1,34 & 3,43 & 14,15 \\
\hline & normal & bipolar & $-12,84^{*}$ & 1,01 & $-16,68$ & $-9,00$ \\
\hline & & unipolar & $-10,63^{*}$ & 0,99 & $-14,42$ & $-6,83$ \\
\hline & & esquizofrenia & $-8,79^{*}$ & 1,34 & $-14,15$ & $-3,43$ \\
\hline
\end{tabular}

NOTA:* $p<0,004$

$E P=$ erro padrão; $L I=$ limite inferior; $L S=$ limite superior; $I C=$ intervalo de confiança; 
Tabela 12 - Teste de Kruskal-Wallis -Rank de escores maníaco, depressivo, total, subdomínios domínios da SCI-MOODS-VP

continua

\begin{tabular}{|c|c|c|c|c|}
\hline & TIPO & RANK & QUI2 & $p$ \\
\hline \multirow[t]{4}{*}{ Escore Maníaco } & bipolar & 104,16 & 83,24 & 0,000 \\
\hline & unipolar & 53,59 & & \\
\hline & esquizofrenia & 68,17 & & \\
\hline & normal & 18,36 & & \\
\hline \multirow[t]{4}{*}{ Escore Depressivo } & bipolar & 91,94 & 65,28 & 0,000 \\
\hline & unipolar & 72,62 & & \\
\hline & esquizofrenia & 57,92 & & \\
\hline & normal & 12,21 & & \\
\hline \multirow[t]{4}{*}{ Escore Total } & bipolar & 103,02 & 84,92 & 0,000 \\
\hline & unipolar & 60,44 & & \\
\hline & esquizofrenia & 59,75 & & \\
\hline & normal & 13,05 & & \\
\hline \multirow[t]{4}{*}{ Humor depressivo } & bipolar & 87,98 & 60,33 & 0,000 \\
\hline & unipolar & 77,68 & & \\
\hline & esquizofrenia & 52,11 & & \\
\hline & normal & 14,59 & & \\
\hline \multirow[t]{4}{*}{ Humor maníaco } & bipolar & 103,59 & 72,41 & 0,000 \\
\hline & unipolar & 53,80 & & \\
\hline & esquizofrenia & 59,67 & & \\
\hline & $\begin{array}{l}\text { normal } \\
\text { bipolar }\end{array}$ & $\begin{array}{l}26,09 \\
90,00\end{array}$ & 57,68 & 0,000 \\
\hline
\end{tabular}


Tabela 12 - Teste de Kruskal-Wallis -Rank de escores maníaco, depressivo, total, subdomínios domínios da SCI-MOODS-VP

\begin{tabular}{|c|c|c|c|c|}
\hline & & & \multicolumn{2}{|c|}{ conclusão } \\
\hline \multirow{4}{*}{ Energia depressiva } & TIPO & RANK & QUI2 & $\mathrm{p}$ \\
\hline & unipolar & 70,29 & 57,68 & 0,000 \\
\hline & esquizofrenia & 65,92 & & \\
\hline & normal & 14,77 & & \\
\hline \multirow[t]{4}{*}{ Energia maníaca } & bipolar & 104,42 & 86,75 & 0,000 \\
\hline & unipolar & 58,50 & & \\
\hline & esquizofrenia & 58,58 & & \\
\hline & normal & 15,16 & & \\
\hline \multirow[t]{4}{*}{ Cognição depressiva } & bipolar & 91,11 & 63,43 & 0,000 \\
\hline & unipolar & 69,78 & & \\
\hline & esquizofrenia & 68,22 & & \\
\hline & normal & 11,61 & & \\
\hline \multirow[t]{4}{*}{ Cognição maníaca } & bipolar & 92,96 & 60,85 & 0,000 \\
\hline & unipolar & 54,57 & & \\
\hline & esquizofrenia & 89,61 & & \\
\hline & normal & 22,64 & & \\
\hline \multirow[t]{4}{*}{ Humor } & bipolar & 102,34 & 81,29 & 0,000 \\
\hline & unipolar & 63,46 & & \\
\hline & esquizofrenia & 50,61 & & \\
\hline & normal & 15,52 & & \\
\hline \multirow[t]{4}{*}{ Energia } & bipolar & 102,84 & 85,60 & 0,000 \\
\hline & unipolar & 61,36 & & \\
\hline & esquizofrenia & 58,50 & & \\
\hline & normal & 12,48 & & \\
\hline \multirow[t]{4}{*}{ Cognição } & bipolar & 96,22 & 73,37 & 0,000 \\
\hline & unipolar & 60,68 & & \\
\hline & esquizofrenia & 77,97 & & \\
\hline & normal & 12,14 & & \\
\hline \multirow[t]{4}{*}{ Ritmicidade } & bipolar & 90,02 & 56,01 & 0,000 \\
\hline & unipolar & 72,14 & & \\
\hline & esquizofrenia & 59,36 & & \\
\hline & normal & 16,14 & & \\
\hline
\end{tabular}

\subsection{6) Análise Discriminante}

A análise discriminante progressiva passo a passo (forward stepwise) foi feita nos 47 sujeitos unipolares e 47 bipolares. A igualdade das matrizes de covariância 
foi avaliada por meio do teste $\mathrm{M}$ de Box. $\mathrm{O}$ teste foi significativo com um $\mathrm{p}$ menor que 0,05 (tabela 13).

Tabela 13 - Teste M de Box

\begin{tabular}{llc}
\hline TESTE M DE BOX & & 13,392 \\
\hline $\mathrm{F}$ & Aprox. & 4,359 \\
& $\mathrm{~g} 11$ & 3 \\
$\mathrm{gl} 2$ & $1.523,520$ \\
$\mathrm{p}$ & 0,04
\end{tabular}

NOTA: $g \mathrm{l}=$ graus de liberdade

Os determinantes log (log determinants) não apresentaram grande variação entre si (tabela 14).

Tabela 14 - Determinantes log do teste M de Box

\begin{tabular}{|c|c|c|}
\hline TIPO & RANK & DETERMINANTE LOG \\
\hline bipolar & 2 & 3,483 \\
\hline unipolar & 2 & 4,997 \\
\hline Agrupados dentro dos grupos & 2 & 4,386 \\
\hline
\end{tabular}

Os subdomínios humor maníaco $(\mathrm{hm})$ e energia maníaca (em), com lambda de Wilks de 0,542 e 0,470 , respectivamente, foram os subdomínios que melhor 
distinguiram os bipolares de unipolares sendo mantidos na função discriminante canônica (tabela 15).

Tabela 15 - Análise discriminante passo a passo (forward stepwise) progressiva dos subdomínios da SCI-MOODS-VP em bipolares $(n=47)$ e unipolares $(n=47)$

\begin{tabular}{|c|c|c|c|c|c|c|c|c|c|}
\hline \multirow{3}{*}{ PASSO } & \multirow[t]{3}{*}{ INCLUÍDOS } & \multicolumn{8}{|c|}{ LAMBDA DE WILKS } \\
\hline & & \multirow[t]{2}{*}{ valores } & \multirow[t]{2}{*}{ gl1 } & \multirow[t]{2}{*}{ gl2 } & \multirow[t]{2}{*}{ gl3 } & \multicolumn{4}{|c|}{$\mathrm{F}$} \\
\hline & & & & & & valores & gl1 & gl2 & $\mathrm{p}$ \\
\hline 1 & $\mathrm{hm}$ & 0,542 & 1 & 1 & 92 & 77,704 & 1 & 92 & 0,000 \\
\hline 2 & $\mathrm{em}$ & 0,470 & 2 & 1 & 92 & 51,398 & 2 & 91 & 0,000 \\
\hline
\end{tabular}

NOTA: gl = grau de liberdade.

A função discriminante canônica apresentou um eigenvalue de 1,13, explicando $100 \%$ da variância $(p=0,000$, tabela 16$)$.

Tabela 16 - Função discriminante canônica

\begin{tabular}{l|l|ll|l|l|l|l|l|l}
\hline $\mathrm{F}$ & EIG & $\%$ & DA & $\%$ & CORR & WILKS & QUI2 & gl & $p$ \\
& & $\mathrm{~V}$ & CUM & CAN & & & & \\
\hline 1 & 1,130 & 100,0 & 100,0 & 0,728 & 0,470 & 68,792 & 2 & 0,000 \\
\hline
\end{tabular}

NOTA: \% da V: \% da variância; \% Cum: \% cumulativa;Corr Can: correlação canônica; Eig: eigenvalue; gl: graus de liberdade; 
Os coeficientes não corrigidos e corrigidos da função discriminante canônica são mostrados na tabela 17. O humor maníaco apresentou coeficiente de 0,604 e a energia maníaca de 0,566 .

Tabela 17- Coeficientes da função discriminante canônica

\begin{tabular}{llllll}
\hline FUNÇÃO & \multicolumn{2}{l}{ NÃO CORRIGIDOS } & \multicolumn{2}{l}{ CORRIGIDOS } \\
\hline & $\mathrm{hm}$ & $\mathrm{em}$ & Constante & $\mathrm{hm}$ & $\mathrm{em}$ \\
1 & 0,139 & 0,243 & $-3,719$ & 0,604 & 0,566
\end{tabular}

NOTA: em= energia maníaca; $\mathrm{hm}=$ humor maníaco

\subsection{7) Curvas ROC}

Uma curva ROC foi feita para avaliar as propriedades da SCI-MOODS - VP como teste diagnóstico para diferenciar os bipolares (47) de unipolares (47). Ela está no gráfico 1 e tabela 18 e suas coordenadas na tabela 19. Foram utilizados os escores maníacos, totais e depressivos na confecção da curva. A melhor área sobre a curva (AUC) da curva ROC foi 0,909 , do escore maníaco. A pontuação total e depressiva apresentaram AUC respectivamente de 0,877 e de 0,674. 
Gráfico 1. Curva ROC (sensibilidade $\times 1$-especificidade) de escore total, maníaco e depressivo entre bipolares $(n=47)$ e unipolares $(n=47)$.

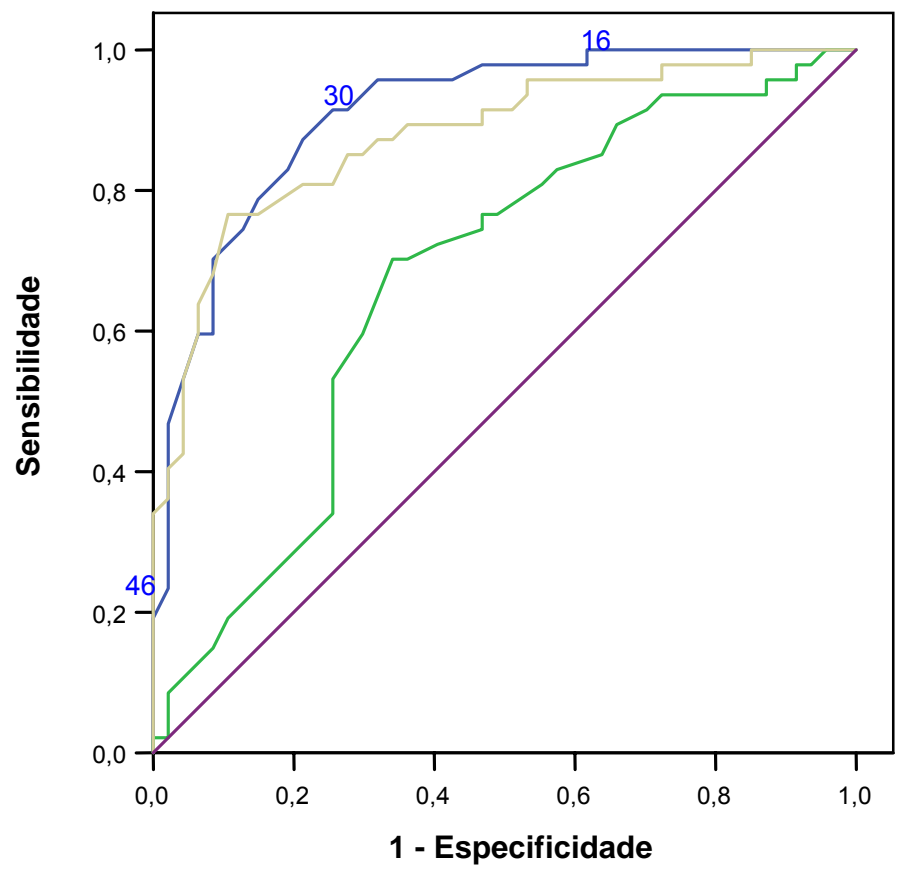

Escore Maníaco

Escore Depressivo Escore Total

L Linha de referência 
Tabela 18 - AUC dos escores maníaco, depressivo e total da curva ROC entre bipolares $(n=47)$ e unipolares $(n=47)$.

\begin{tabular}{|c|c|c|c|c|c|}
\hline \multirow[t]{2}{*}{ VARIÁVEIS } & \multirow[t]{2}{*}{ AUC } & \multirow[t]{2}{*}{ EP } & \multirow[t]{2}{*}{$P$} & \multicolumn{2}{|c|}{ IC $95 \%$} \\
\hline & & & & $\mathrm{LI}$ & LS \\
\hline Escore maníaco & 0,909 & 0,030 & 0,000 & 0,850 & 0,967 \\
\hline Escore depressivo & 0,674 & 0,056 & 0,004 & 0,563 & 0,784 \\
\hline Escore total & 0,877 & 0,036 & 0,000 & 0,807 & 0,947 \\
\hline
\end{tabular}

Decidiu-se então pelo uso do escore maníaco para diferenciar bipolares e unipolares. Em relação ao equilíbrio de sensibilidade e especificidade, o escore maníaco maior ou igual a 30 foi escolhido como ponto de corte. Ele apresentou sensibilidade de $91 \%$ e especificidade de $74 \%$, além de excelente valor preditivo negativo. A concordância diagnóstica da SCID com o escore maníaco maior que 30 da SCI-MOODS-VP, medida pelo Kappa, foi de 61,6 \% (tabela 20). 
Tabela 19 - Coordenadas da curva ROC do escore maníaco entre bipolares ( $n=$ 47) e unipolares $(n=47)$

\begin{tabular}{|c|c|c|}
\hline POSITIVO SE MAIOR OU IGUAL A: & SENSIBILIDADE & 1 - ESPECIFICIDADE \\
\hline $\begin{array}{r}6,00 \\
\end{array}$ & 1,000 & 1,000 \\
\hline 8,50 & 1,000 & 0,957 \\
\hline 10,00 & 1,000 & 0,872 \\
\hline 11,50 & 1,000 & 0,830 \\
\hline 12,50 & 1,000 & 0,809 \\
\hline 13,50 & 1,000 & 0,787 \\
\hline 14,50 & 1,000 & 0,723 \\
\hline 15,50 & 1,000 & 0,681 \\
\hline 16,50 & 1,000 & 0,617 \\
\hline 17,50 & 0,979 & 0,617 \\
\hline 18,50 & 0,979 & 0,574 \\
\hline 19,50 & 0,979 & 0,553 \\
\hline 20,50 & 0,979 & 0,532 \\
\hline 21,50 & 0,979 & 0,468 \\
\hline 22,50 & 0,957 & 0,426 \\
\hline 24,50 & 0,957 & 0,404 \\
\hline 26,50 & 0,957 & 0,362 \\
\hline 27,50 & 0,957 & 0,319 \\
\hline 28,50 & 0,915 & 0,277 \\
\hline 29,50 & 0,915 & 0,255 \\
\hline 30,50 & 0,872 & 0,213 \\
\hline 31,50 & 0,830 & 0,191 \\
\hline 32,50 & 0,809 & 0,170 \\
\hline 33,50 & 0,787 & 0,149 \\
\hline 34,50 & 0,745 & 0,128 \\
\hline 35,50 & 0,702 & 0,085 \\
\hline 37,50 & 0,596 & 0,064 \\
\hline 38,50 & 0,532 & 0,043 \\
\hline 39,50 & 0,468 & 0,021 \\
\hline 40,50 & 0,426 & 0,021 \\
\hline 41,50 & 0,404 & 0,021 \\
\hline 42,50 & 0,362 & 0,021 \\
\hline 43,50 & 0,298 & 0,021 \\
\hline 44,50 & 0,277 & 0,021 \\
\hline 45,50 & 0,234 & 0,021 \\
\hline 46,50 & 0,191 & 0,000 \\
\hline 48,00 & 0,128 & 0,000 \\
\hline 49,50 & 0,085 & 0,000 \\
\hline 51,50 & 0,064 & 0,000 \\
\hline 53,50 & 0,043 & 0,000 \\
\hline 55,00 & 0,000 & 0,000 \\
\hline
\end{tabular}


Tabela 20 - Propriedades do escore maníaco da SCI-MOODS-VP maior ou igual

\begin{tabular}{ll} 
a $30(\mathrm{em} \%)$ & \\
\hline Sensibilidade & 91,49 \\
Especificidade & 74,47 \\
Valor Preditivo Positivo & 78,18 \\
Valor Preditivo Negativo & 89,74 \\
Kappa & 65,96
\end{tabular}

Uma segunda curva ROC foi desenhada comparando-se os escores depressivo, maníaco e total de 94 sujeitos com transtornos afetivos (bipolares e unipolares) e 40 controles (normais e esquizofrenia, gráfico 2). Ao contrário da primeira curva ROC, a melhor AUC foi 0,869 , a do escore depressivo. A do maníaco foi de 0,784 e a do total, 0,856 (tabela 21). As coordenadas do escore depressivo da curva ROC, a sensibilidade e um menos a especificidade estão na tabela 23. 
Gráfico 2. Curva ROC (sensibilidade $\times$ 1-especificidade) de escores total, maníaco e depressivo entre pacientes portadores de transtornos afetivos $(n=94)$ e controles $(n=40)$.

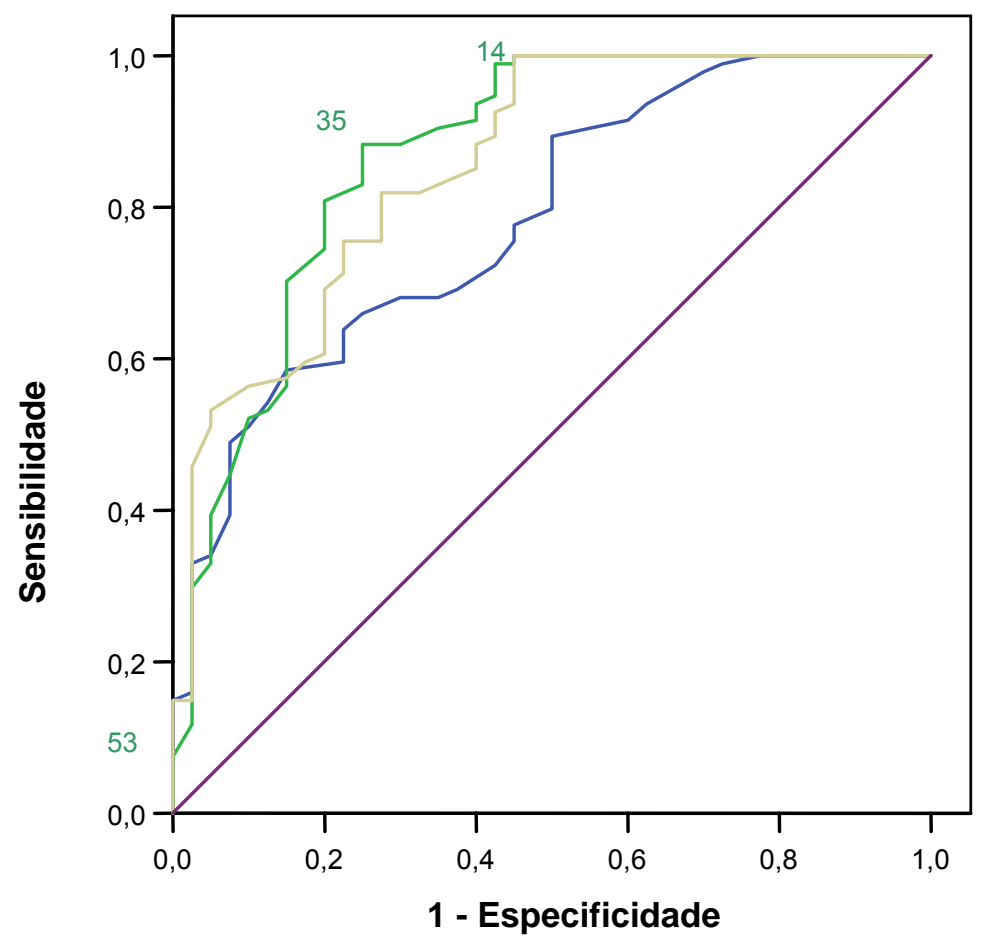

Escore Maníaco

Escore Depressivo Escore Total

Linha de referência 
Tabela 21 - AUC da curva ROC, escore maníaco, depressivo e total entre sujeitos com transtornos afetivos $(n=94)$ e controles $(n=40)$.

\begin{tabular}{|c|c|c|c|c|c|}
\hline \multirow[t]{2}{*}{ VARIÁVEIS } & \multirow[t]{2}{*}{ AUC } & \multirow[t]{2}{*}{ EP } & \multirow[t]{2}{*}{$\mathrm{P}$} & \multicolumn{2}{|c|}{ IC $95 \%$} \\
\hline & & & & $\mathrm{LI}$ & LS \\
\hline Escore maníaco & 0,784 & 0,042 & 0,000 & 0,702 & 0,866 \\
\hline Escore depressivo & 0,869 & 0,037 & 0,000 & 0,797 & 0,942 \\
\hline Escore total & 0,856 & 0,036 & 0,000 & 0,785 & 0,926 \\
\hline
\end{tabular}

NOTA: $E P=$ erro padrão; $L I=$ limite inferior; $L S=$ limite superior; $I C=$ intervalo de confiança. 
Tabela 22 - Coordenadas da curva ROC do escore depressivo entre sujeitos com transtornos afetivos $(n=94)$ e controles $(n=40)$.

\begin{tabular}{|c|c|c|}
\hline POSITIVO SE MAIOR OU IGUAL A: & SENSIBILIDADE & 1 - ESPECIFICIDADE \\
\hline $\begin{array}{r}1,00 \\
\end{array}$ & 1,000 & 1,000 \\
\hline 0,50 & 1,000 & 0,700 \\
\hline 1,50 & 1,000 & 0,600 \\
\hline 2,50 & 1,000 & 0,575 \\
\hline 4,50 & 1,000 & 0,550 \\
\hline 7,00 & 1,000 & 0,525 \\
\hline 9,00 & 1,000 & 0,500 \\
\hline 11,00 & 1,000 & 0,475 \\
\hline 14,00 & 1,000 & 0,450 \\
\hline 17,00 & 0,989 & 0,450 \\
\hline 18,50 & 0,989 & 0,425 \\
\hline 20,00 & 0,979 & 0,425 \\
\hline 23,00 & 0,957 & 0,425 \\
\hline 26,00 & 0,947 & 0,425 \\
\hline 27,50 & 0,936 & 0,400 \\
\hline 28,50 & 0,915 & 0,400 \\
\hline 29,50 & 0,904 & 0,350 \\
\hline 30,50 & 0,883 & 0,300 \\
\hline 31,50 & 0,883 & 0,250 \\
\hline 32,50 & 0,872 & 0,250 \\
\hline 33,50 & 0,840 & 0,250 \\
\hline 34,50 & 0,830 & 0,250 \\
\hline 35,50 & 0,809 & 0,200 \\
\hline 36,50 & 0,777 & 0,200 \\
\hline 37,50 & 0,745 & 0,200 \\
\hline 38,50 & 0,702 & 0,150 \\
\hline 39,50 & 0,681 & 0,150 \\
\hline 40,50 & 0,628 & 0,150 \\
\hline 41,50 & 0,617 & 0,150 \\
\hline 42,50 & 0,606 & 0,150 \\
\hline 43,50 & 0,564 & 0,150 \\
\hline 44,50 & 0,532 & 0,125 \\
\hline 45,50 & 0,521 & 0,100 \\
\hline 46,50 & 0,447 & 0,075 \\
\hline 47,50 & 0,394 & 0,050 \\
\hline 48,50 & 0,330 & 0,050 \\
\hline 50,50 & 0,255 & 0,025 \\
\hline 51,50 & 0,149 & 0,025 \\
\hline 52,50 & 0,117 & 0,025 \\
\hline 53,50 & 0,074 & 0,000 \\
\hline 55,00 & 0,053 & 0,000 \\
\hline 56,50 & 0,021 & 0,000 \\
\hline 57,50 & 0,011 & 0,000 \\
\hline 59,00 & 0,000 & 0,000 \\
\hline
\end{tabular}


Decidiu-se por um ponto de corte do escore depressivo de 35. Este apresentou sensibilidade de cerca de $83 \%$ e especificidade de $75 \%$, com melhor valor preditivo positivo que negativo. A concordância diagnóstica da SCID e escore depressivo da SCI-MOODS-VP maior que 35 foi de $55 \%$ (tabela 23).

Tabela 23 - Propriedades do escore depressivo da SCI-MOODS-VP maior ou igual a $35(\mathrm{em} \%)$

\begin{tabular}{ll}
\hline Sensibilidade & 82,98 \\
Especificidade & 75 \\
Valor Preditivo Positivo & 88,64 \\
Valor Preditivo Negativo & 65,22 \\
Kappa & 55,58 \\
\hline
\end{tabular}




\section{4) DISCUSSÃO:}

Este é o primeiro estudo a validar uma entrevista para auxiliar o diagnóstico do espectro bipolar em português no Brasil. No Brasil, apenas entrevistas semiestruturadas para o diagnóstico de transtornos mentais, incluindo o TB, como a MINI (Sheehan et al., 1998), a SCID (First et al., 1995), a SCAN (Wing et al., 1990) e estruturadas, como a CIDI (Robins et al., 1988), foram traduzidas. A SCID, versão para pacientes e transtornos do eixo I de acordo com o DSM-IIIR, demonstrou boa confiabilidade entre-examinadores e consistência interna em 39 sujeitos. (Del-Bem et al., 1996). A CIDI foi desenvolvida para uso em estudos epidemiológicos populacionais, sendo aplicada por entrevistadores leigos treinados. A versão 2.1 da CIDI em português teve a sua confiabilidade entreexaminadores determinada em 186 sujeitos entrevistados por 13 entrevistadores leigos e 3 não-leigos. A confiabilidade do diagnóstico de TB na vida foi de 0,77 , menor que transtornos ligados ao álcool, por exemplo (Quintana et al., 2004).

Dentre as escalas para avaliar a intensidade do TB, há poucas escalas validadas em português do Brasil. A escala de avaliação de mania de Young (YMRS) foi validada em 55 pacientes entre 18 e 60 anos de idade em episódio de mania atual de acordo com o DSM-IIIR. Ela apresentou boa confiabilidade testereteste (duas medidas em intervalo entre 7 a 10 dias) com correlação intra-classe de 0,97 para a pontuação total e concordância entre itens individuais superior à 0,8. A consistência interna foi de 0,67 . A validade concorrente foi medida em relação à Escala Breve de Avaliação Psiquiátrica (BPRS), apresentando 
coeficiente de correlação de Pearson de 0,78 (Vilela et al., 2005). O Guia para Avaliação do Estado Maníaco (GAEM) foi desenvolvido para auxiliar o preenchimento de três escalas de mania: a Mania Rating Scale (MRS), a BechRafaelsen Mania Scale (BRMS) e a Clinician Administered Rating Scale (CARSM). Estudo preliminar em quinze pacientes em episódio maníaco demonstrou boa aceitabilidade do GAEM, que será utilizado no processo de validação destas três escalas (Shansis et al., 2003). Geralmente, escalas desenvolvidas para depressão unipolar são utilizadas em pacientes com depressão bipolar. Infelizmente, sintomas comuns em depressões bipolares não são contemplados por essas escalas. A hipersônia, por exemplo, não é avaliada na versão original da Escala para Depressão de Hamilton, ao contrário da insônia, contemplada com três itens (Berk et al., 2004).

A validação concorrente foi empregada para validar a Escala de Depressão de Montgomery-Asberg (MADRS) em depressivos unipolares. Ela foi traduzida para o português e validada frente a Escala para Depressão de Hamilton (HAMD), a Escala de Humor Visual-Analógica e uma avaliação clínica realizada por psiquiatras independentes (Dractu et al., 1987). A correlação entre a MADRS e a HAM-D foi alta, enquanto que a destas duas com a Visual Analógica foi moderada. Esta última escala é de auto-avaliação, o que pode explicar esta correlação menor com duas escalas de avaliação por um entrevistador (Calil e Pires, 2000). O Inventário de Depressão de Beck (BDI) foi validado em uma população de 270 estudantes universitários, 117 pacientes com transtorno do pânico e 30 depressivos unipolares. Os últimos apresentaram maior escore médio que os outros dois grupos, com o segundo apresentando maior pontuação média que os 
primeiros, isto é, a escala apresentou boa validade discriminante. Sua consistência interna foi de 0,81 em estudantes e 0,88 em depressivos. Ela apresentou correlação significativa com o Inventário de Ansiedade Traço-Estado (STAI) em todas as amostras, ou seja, apresentou boa validade de critério concorrente (Gorenstein e Andrade, 1996).

O TB costuma ser pouco diagnosticado. Por exemplo, Ghaemi et al. (1999) revisaram os prontuários de bipolares tipo I $(n=44)$ e transtorno esquizoafetivo, subtipo bipolar $(n=4)$ internados em um hospital acadêmico americano durante um ano. Anteriormente $40 \%$ (19 de 48) destes tinha recebido um diagnóstico errado, sendo a maioria de depressão unipolar (Ghaemi et al., 1999). Até 43, 4 \% de pacientes depressivos atendidos em consultórios privados podem ser bipolares, em uma proporção de 1:1 (Benazzi, 1999; Benazzi, 1997). Em uma pesquisa realizada entre 300 psiquiatras americanos e 200 ingleses, que tratam pelo menos 15 pacientes com TB por mês, as barreiras para o manejo efetivo do TB foram avaliadas. A necessidade de instrumentos para auxiliar no diagnóstico precoce do TB foi uma das principais barreiras enfrentadas pelos bipolares antes da entrada no tratamento (Chengappa e Williams, 2005).

A SCI-MOODS-VP avalia os sintomas do humor de forma dimensional. A relação dos diversos tipos de transtornos afetivos entre si ainda é desconhecida. Judd et al. (2003) estudaram o curso clínico prospectivo de bipolares para testar a relação entre o tipo I e II do TB do humor, se esta poderia melhor ser compreendida como de natureza categorial ou dimensional. A amostra foi composta de 135 bipolares tipo I e 71 do tipo II, diagnosticados pelo RDC (Spitzer et al.,1978) que entraram em um estudo entre 1978 e 1981 e posteriormente 
foram seguidos por 20 anos. Os bipolares I e II tiveram idades de início e características demográficas semelhantes. Houve uma variedade de intensidade de episódios menores e maiores de depressão e de mania ou hipomania a longo prazo, com os bipolares tipo II apresentando curso mais crônico e mais depressões. Os autores concluem que assim como para os transtornos unipolares, o TB é provavelmente dimensional, não havendo descontinuidade entre os bipolares I e II apesar de diferenças em gravidade, cronicidade e comorbidades (Judd et al., 2003). Provavelmente o espectro bipolar também apresenta-se de forma contínua com os TB tipo I e II .

Além dos sintomas clínicos, a SCl-MOODS-VP mede sintomas afetivos subsindrômicos. Sintomas depressivos leves, subsindrômicos, têm sido estudados há algum tempo em psiquiatria. Eles são freqüentes na população geral e em coortes de pacientes depressivos, como sintomas residuais ou prodrômicos, causando grande disfunção psicossocial (Judd et al., 2002b). Os sintomas hipomaníacos subclínicos, por outro lado, são ainda pouco estudados. Segundo o DSM-IV (APA,1994) a duração mínima do episódio de hipomania é de 4 dias. Angst avaliou a validade da hipomania breve, durando 1 a 3 dias, no estudo de coorte de Zurich (Angst, 1998). Desde 1978 este estudo acompanha 4547 jovens (homens de 19 e mulheres de 20 anos) com alto risco de transtornos mentais e controles do cantão de Zurich. A mania ou hipomania de acordo com o DSM-IV apresentou uma prevalência de 5,5 \% da população e a hipomania breve, de 2,8 \%. Não houve diferença em relação à duração da hipomania (breve vs. de acordo com o DSM) em relação à história familiar de transtornos de humor, história de tentativas de suicídio e tratamento para depressão. Os sujeitos com hipomania 
apresentavam maior risco de transtornos ansiosos e abuso de substâncias, demonstrando que sintomas hipomaníacos não são "benignos", não importando se são breves ou não. Por exemplo, o transtorno do pânico foi 10 vezes mais freqüente em hipomaníacos que controles. A fobia social foi 3 vezes mais freqüente em hipomanias breves que em controles. A dependência de nicotina e o abuso ou dependência de álcool foram mais freqüentes em hipomaníacos que em depressivos ou controles. A freqüência de divórcios foi 3 a 6 vezes maior em hipomaníacos que em controles (Angst, 1998) .

Regeer et al. (2006) estudaram a importância de sintomas hipomaníacos e depressivos no início de transtornos afetivos clínicos em um estudo epidemiológico populacional. Estes sintomas foram avaliados pela CIDI em 7076 sujeitos inicialmente e após 1 e 2 anos. Na primeira avaliação, os sintomas depressivos subsindrômicos afetavam na vida 17,2 \% dos sujeitos e os hipomaníacos $1,2 \%$. Os valores preditivos de sintomas afetivos para um transtorno do humor variaram entre $14,3 \%$ e $50 \%$. Os sintomas hipomaníacos subsindrômicos tiveram um valor preditivo muito maior que os depressivos, não apenas para TB, mas também para depressão maior. Os autores concluem que seus dados apoiam a hipótese de uma doença única, contínua, englobando depressão e TB. Além disso, os sintomas hipomaníacos tornariam os sujeitos mais vulneráveis a posteriores transtornos afetivos, através de uma desregulação do humor.

Há ainda poucos estudos utilizando a SCI-MOODS e a sua versão de autoaplicação MOODS-SR. Porém elas vêm crescentemente ganhando importância. Elas são os primeiras entrevistas para avaliar o transtorno e espectro bipolar que 
contém um domínio destinado à manifestações cíclicas no apetite, atividade sexual, sono (ritmicidade), que incluem questões de mudanças de humor no período pre-menstrual ou após viagens através de fusos horários, além de sintomas vegetativos. A importância deste domínio pode ser vista no estudo de Balestrieri e. Neste estudo, a MOODS-SR foi utilizada para avaliar ideação e tentativas de suicídio em uma população clínica de 77 pacientes com esquizofrenia, 60 com transtorno borderline de personalidade, 61 bipolares, 88 unipolares, 57 com transtorno de pânico e 102 sujeitos controles universitários. Enquanto as tentativas de suicídio foram mais freqüentes em borderlines, a ideação suicida foi mais freqüente em depressivos (50\%) e bipolares $(42,4 \%)$. Independentemente do diagnóstico, houve correlação entre ideação ou tentativas de suicídio e ritmicidade, além de sintomas hipomaníacos ou maníacos e depressivos (Balestrieri et al., 2006).

\section{1) SUJEITOS}

Apenas bipolares e unipolares foram escolhidos para o estudo piloto. 0 objetivo deste estudo foi avaliar a compreensão das questões da SCI-MOODS-VP, isto é, não foi o de determinar a validade discriminante entre os sujeitos. Porém, apesar do tamanho pequeno da amostra, houve diferença em todos os sub domínios maníacos entre os sujeitos. Esta diferença manteve-se no estudo 
principal ao contrário da diferença entre os domínios humor, energia e cognição e sub domínios cognição depressiva, que não se mantiveram .

Não houve diferença estatística no sexo, idade média, escolaridade e estado ocupacional entre bipolares e unipolares, tanto no estudo piloto quanto no principal. Cerca de $72 \%$ dos bipolares e $61 \%$ dos unipolares deste estudo eram do sexo feminino (tabela 4). Em relação a diferenças epidemiológicas entre unipolares e bipolares relatadas na literatura, uma das mais replicadas é o maior número de mulheres com depressão unipolar. No TB tipo I não há esta diferença entre os sexos e no tipo II também há um predomínio feminino (Berk e Dodd, 2005). Nos primeiros mil pacientes bipolares (71 \% do tipo I) tratados pelo estudo Systematic Treatment Enhancement Program for Bipolar Disorder (STEP-BD), um estudo multicêntrico de efetividade de tratamento no TB, 58 \% dos sujeitos eram mulheres (Kogan et al., 2004).As diferenças entre a proporção entre os sexos relatadas na literatura e neste estudo poderia ser explicadas pelo maior número de mulheres dentre a população em tratamento para transtornos afetivos nos ambulatórios da Clínica Heidelberg e GRUDA ou por um viés de seleção para as mulheres aceitarem participar do estudo com maior freqüência que os homens.

Algumas diferenças entre os sujeitos participantes no estudo original da SCIMOODS e deste estudo merecem ser enfatizadas. Além de sujeitos com depressão recorrente, nós trabalhamos com pacientes no primeiro episódio de depressão. Ao invés de sujeitos com problemas gastrintestinais, nós decidimos utilizar esquizofrenia no nosso estudo de validação. A decisão deve-se à dificuldade do diagnóstico diferencial entre TB e esquizofrenia. Os esquizofrênicos apresentaram maior chance de serem solteiros e desempregados que os 
bipolares, relembrando a idéia kraepeliniana de pior prognóstico da dementia praecox. Várias pesquisas demonstraram uma maior prevalência de esquizofrenia em posições sócio-econômicas inferiores (Muntaner et al., 2004). Acredita-se que esta posição socioeconômica inferior dos esquizofrenia seja devido à disfunção ocupacional e social que a doença causa (teoria da seleção social), embora alguns autores argumentem que ocorre uma causalidade social, isto é, a reação do meio social à doença é o que leva a disfunção (Saraceno et al., 2005). Há poucos estudos sobre desvantagem socioeconômica e TB. Apesar de alguns estudos demonstrarem taxas e desemprego de até $60 \%$ em bipolares (Sajatovic, 2005), não há evidências de ligação entre desvantagem sócio-econômica e TB (Muntaner et al., 2004).

Nossos sujeitos sem diagnóstico psiquiátrico eram mais jovens que os outros grupos, talvez devido aos rígidos critérios de inclusão no projeto Bom Humor.

\section{2) RESULTADOS DA SCID-I/P}

A SCID-I/P foi utilizada como padrão-ouro do diagnóstico psiquiátrico no nosso estudo. Até o momento a procura de um padrão-ouro biológico para o diagnóstico psiquiátrico tem se mostrado infrutífera. A SCID-I/P é uma entrevista muito utilizada como padrão-ouro para o diagnóstico em psiquiatria. Ela 
demonstrou grande confiabilidade e validade em diversas populações (Baldassano, 2005), podendo ser utilizada para validação de entrevistas clínicas não-estruturadas (Steiner et al.,1995). Por exemplo, Shear et al. (2000) investigaram a concordância diagnóstica entre o diagnóstico clínico por meio de revisão de prontuários e o por meio da SCID-I/P em 164 pacientes ambulatoriais não psicóticos, achando uma baixa concordância. Skyre et al. (1991), trabalhando com uma amostra de 54 pessoas e utilizando a SCID-I/P na versão para o DSMIIIR (Spitzer et al., 1990), demonstraram uma confiabilidade entre examinadores para o diagnóstico de TB de 0,79 e depressão maior de 0,93. Williams et al. (1992) selecionaram 592 sujeitos entre pacientes internados, ambulatoriais e não pacientes, também utilizando a versão para o DSM-IIIR da SCID-I/P (Spitzer et al., 1990) e calcularam a confiabilidade teste-reteste (1 a 3 semanas de intervalo), que foi de 0,84 para TB e 0,64 para depressão maior.

A maioria dos bipolares era do tipo I. Porém, a prevalência do TB tipo II é maior que a do I na comunidade (Berk e Dodd, 2005). A SCID-I/P valoriza o conceito de bipolar tipo I em detrimento do tipo II e espectro bipolar. Afasta-se primeiro os quadros de mania para só então se diagnosticar a hipomania. Os critérios do episódio hipomaníaco do DSM-IV apresentam problemas, levando à baixa confiabilidade do TB tipo 2 (Benazzi, 2003). Recentemente, Simpson et al. (2002) questionaram a baixa confiabilidade no diagnóstico da hipomania, demonstrando um kappa de 0,72 no seu estudo. Porém, o diagnóstico foi feito de acordo com os critérios do RDC (Spitzer et al., 1978). No estudo brasileiro de confiabilidade da SCID-I/P, a concordância diagnóstica entre os examinadores não foi estatísticamente significativa para transtornos bipolares não-especificados (Del- 
Bem et al., 1996). Estes "não especificados" englobariam a maior parte dos quadros de espectro bipolar. Benazzi e Akiskal (2003) sugeriram recentemente uma modificação no módulo de transtornos do humor do SCID para o diagnóstico do espectro bipolar, valorizando não apenas a alteração de humor, mas mudanças no nível de energia e atividades.

\section{3) CONFIABILIDADE}

A SCI-MOODS-VP apresentou uma excelente confiabilidade, sendo a confiabilidade dos subdomínios depressivos maior que a dos maníacos. A consistência interna é a forma de confiabilidade medida pela relação dos ítens que medem um construto entre si. Ela mede o quanto consistentemente indivíduos responderam às questões do instrumento. A consistência interna de uma entrevista é considerada boa acima de 0,7 (Bech et al., 1993). No nosso estudo, ela variou entre 0,86 a 0,94 e no de Fagiolini, entre 0,79 a 0,92. Ela foi calculada pelo alfa de Cronbach no nosso estudo e no de Fagiolini pelo método de Kuder Richardson, um tipo especial de alfa de Cronbach para variáveis dicotômicas, o que por si só não justificaria a diferença de resultados.A consistência interna depende do número de itens do instrumento. Quanto maior o número, maior a consistência interna. Isto poderia justificar o valor mais alto no nosso estudo, que se baseou na versão de 161 itens da SCI-MOODS. O estudo de Fagiolini e colaboradores foi feita com a versão de 140 itens da entrevista (Fagiolini et al., 1999). Outra possível explicação é a dos itens da entrevista apresentarem alta 
correlação entre si.Uma consistência interna alta não significa necessariamente que o instrumento avaliado possui uma só dimensão, mas pode ser um indício de unidimensionalidade.

Quanto à confiabilidade entre examinadores, a amostra de bipolares e unipolares foi representativa em relação à amostra global de pacientes afetivos.Não houve diferença em relação a confiabilidade entre examinadores em relação a este estudo e o estudo original da SCI-MOODS. O maior número de itens da SCI-MOODS-VP poderia levar a uma diminuição na confiabilidade entre examinadores. Porém, a confiabilidade entre examinadores foi de 0,956 e no de Fagiolini "próxima da unidade".

\section{4) TIPOS DE VALIDADE E A SCI-MOODS-VP}

Uma das formas de avaliar a estrutura de uma entrevista, se há consistência na sua elaboração é através da correlação parcial entre as suas partes. Todos os domínios e subdomínios da SCI-MOODS-VP apresentaram correlação positiva e significativa entre si $(p<0,05)$. Ela é um indício da validade de construto desta entrevista. A validade de construto apenas poderá ser determinada após vários estudos, com populações diferentes e diversos instrumentos que medem o mesmo construto.

A validação é um processo sem fim (Bryant, 2000). Em geral começa com a validade de conteúdo, passando para a de critério e posteriormente para a de 
construto. A de conteúdo da SCI-MOODS foi desenvolvida de forma subjetiva, através de reuniões entre pesquisadores italianos e americanos. Participaram psiquiatras, psicólogos e estatísticos da Universidade de Pisa, Itália, de Pittsburgh e de Columbia, dos Estados Unidos. Sintomas maníacos e depressivos foram escolhidos dentre aqueles presentes nas classificações oficiais, como a CID-10 e o DSM-IV, além de outros listados em artigos científicos sobre a fenomenologia do TB e da depressão. Além disso, a experiência clínica dos profissionais envolvidos também foi utilizada. Além destes se destacarem em pesquisas, eles são referências em seus países no atendimento de pacientes com transtornos afetivos. A validade de conteúdo também foi facilitada no caso da SCI-MOODS pelo fato desta ter sido desenvolvida ao mesmo tempo em inglês americano e em italiano. Aspectos culturais, presentes em culturas latinas, como a italiana e anglo-saxã, como a americana foram levados em conta.

A validade de critério de um instrumento é feito muitas vezes comparando-o a um outro instrumento. Em geral, por exemplo, uma escala é comparada à outra escala que teoricamente mede o mesmo critério. A técnica estatística tradicionalmente utilizada é correlação momento-produto de Pearson. O coeficiente de correlação é o de validade (Bryant, 2000). Não há escala semelhante à SCI-MOODS, que aborde a amplitude de sintomas do espectro bipolar. As escalas para avaliar a intensidade de sintomas de mania, como a de Young, apresentam maiores pontuações quanto mais grave o episódio maníaco. A SCI-MOODS apresenta maior pontuação quanto maior for a probabilidade do espectro bipolar. Ela não avalia de modo geral a intensidade de sintomas, mas sim o número de sintomas. É possível um quadro do espectro bipolar ter inclusive 
maior pontuação que um bipolar tipo I, pela maior variedade de sintomas, que se confundem com traços de personalidade, como estar mais sensível a natureza, ter maior inspiração artística. Um paciente com bipolar tipo II poderia também apresentar maior pontuação que um bipolar tipo I, que apresente menor variedade de sintomas. Além disso, os sintomas abordados na SCI-MOODS referem-se ao período de toda a vida e as escalas de avaliação de mania ou depressão abordam os sintomas atuais. No estudo de validação original da SCI-MOODS, a validade concorrente não foi determinada (Fagiolini et al., 1999). Por estes motivos,além da carência de instrumentos validados em português para o TB, decidimos não utilizar escalas que avaliam intensidade de mania ou depressão para a validação concorrente da SCI-MOODS. Recentemente, no estudo de validação para uma amostra espanhola da MOODS-SR, entrevista de auto-avaliação baseada na SCIMOODS, decidiu-se por uma abordagem diferente. Quarenta e nove pacientes ambulatoriais com ansiedade generalizada ou transtornos do humor foram comparados com 22 controles normais.Além de boa consistência interna e confiabilidade teste-reteste, houve correlações positivas entre os sub domínios depressivos da entrevista e o Inventário de Depressão de Beck (BDI) e entre os hipomaníacos ou maníacos e a Clinician-Administered Rating Scale for Mania (CARS-M). Isto é, nesta população a MOODS-SR apresentou boa validade concorrente. Os pacientes apresentaram pontuações médias maiores que os controles em todos os domínios. Os bipolares tiveram escores maníacos maiores que os unipolares, principalmente na energia e cognição maníaca. Houve pouca diferença entre sujeitos com ansiedade generalizada e transtornos de humor, apesar dos primeiros não apresentarem diferença em relação aos controles 
normais em vários sub domínios (Berrocal et al., 2006). Algumas limitações devem ser mencionadas em relação a este estudo: a primeira, foi o tamanho pequeno da amostra de bipolares e unipolares; a segunda, o uso de uma população mista com transtorno de ansiedade generalizada. Além disso, CARS-M não é de autoavaliação ao contrário da MOODS e da BDI.

O principal tipo de validação buscado neste estudo foi a validação discriminante. Ela baseia-se nas diferenças entre construtos, no caso, entre o construto maníaco-depressivo e outros, como a esquizofrenia. Porém, um estudo não permite validar totalmente a medida de uma doença. Variações nos resultados podem ocorrer dependendo das populações estudadas, definição do construto, instrumentos utilizados para a sua medida .

Neste estudo, os bipolares apresentavam mais sintomas maníacos que qualquer outro grupo, demonstrando a boa validade discriminante da SCIMOODS-VP. O mesmo foi encontrado no estudo original de validação (Fagiolini et al., 1999). A diferença na pontuação cognitiva maníaca não foi significativa entre bipolares e esquizofrenia. Este subdomínio da SCI-MOODS-VP contém vários sintomas psicóticos. Os esquizofrenia também não apresentaram significativamente menos sintomas depressivos que os unipolares. Talvez os sintomas negativos da esquizofrenia tenham sido confundidos com estes sintomas. Além disso, sintomas depressivos durante a vida são comuns em esquizofrenia e a depressão pode ser difícil de ser diagnosticada na esquizofrenia (Kim et al., 2006).

Os depressivos unipolares apresentaram mais sintomas maníacos que os sujeitos normais. Isto apóia a visão da depressão maior e TB como parte de um 
mesmo espectro. A grande correlação entre subdomínios da SCI-MOODS-VP também suporta a visão do humor como uma única dimensão. Cassano et al. (2004) compararam sintomas hipomaníacos em 117 sujeitos com depressão recorrente ( $73 \%$ de mulheres, idade média de 43,7 anos) e 106 com TB tipo I (51 $\%$ mulheres, idade média de 48,7 anos) através da versão de 140 questões da SCI-MOODS. O número médio de sintomas de humor relatados foi de 64,8 em depressivos e 83,7 em bipolares. A correlação entre sintomas depressivos e hipomaníacos em depressivos recorrentes $(r=0,40, p<0,001)$ foi similar à correlação em bipolares $(r=0,45, p<0,001)$. A distribuição de sintomas depressivos de acordo com o teste de Kolmogorov-Smirnov foi normal em depressivos e bipolares. Já a distribuição de sintomas hipomaníacos, apesar de normal em bipolares, apresentou um desvio à direita em unipolares (teste de KolmogorovSmirnov $=1,4, p<0,03)$. A ideação paranóide, alucinações auditivas e tentativas de suicídio foram mais freqüentes em bipolares que unipolares. Estes sintomas foram utilizados como indicadores de gravidade da depressão em bipolares e unipolares. A relação entre sintomas hipomaníacos ou maníacos e estes indicadores de gravidade depressiva foi estudada por regressão logística em bipolares e unipolares. Nos unipolares, o maior número de sintomas hipomaníacos ou maníacos aumentou a probabilidade de sintomas psicóticos ou de suicidalidade. Por exemplo, para cada sintoma hipomaníaco ou maníaco referido, houve um aumento de 4,2 \% na chance de se apresentar ideação suicida (Odds Ratio= 1,042, $p<0,03)$. Um início precoce do primeiro episódio depressivo apresentou correlação com maior número de sintomas hipomaníacos $(r=-0,32, p<0,01)$. O risco atual de suicídio de acordo com o MINI também aumentou com a presença 
de maior número de sintomas hipomaníacos (Cassano et al., 2004). Este estudo corrobora uma visão unitária do espectro do humor. Além disso, enfatiza a importância de sintomas hipomaníacos. Judd e Akiskal (2003) analisaram os dados do estudo Epidemiological Catchment Area (ECA) e demonstraram que mesmo sintomas maníacos subsindrômicos estariam ligados a maior uso de serviços de saúde mental e pagamento de auxílio-doença.

\section{5) ANÁLISE DISCRIMINANTE}

A análise discriminante progressiva passo a passo (forward stepwise) foi feita nos sujeitos unipolares e bipolares. Ela se baseia na normalidade multivariável ou igualdade das matrizes de covariância (Duarte Silva e Stam, 1995). Esta foi avaliada por meio do teste M de Box . O teste foi significativo com um p menor que 0,05 , isto é, as matrizes de covariância não seriam iguais, violando um dos princípios da análise discriminante (tabela 14). Porém, quanto maior a amostra, maior a chance de pequenos desvios na normalidade multivariável serem significativos. Além disso, a análise discriminante é uma técnica robusta, suportando pequenos desvios da normalidade multivariável (Wuensch, 2006). Quando o teste de Box é significativo, costuma-se observar os determinantes log (log determinants) para verificar se algum valor destoa dos demais (tabela 15). Se há similaridade nestes valores, a análise pode continuar (Wuensch, 2006). A análise discriminante utiliza-se do lambda de Wilks para 
avaliar as variáveis independentes que são mantidas na função discriminante canônica. O lambda de Wilks é uma medida que varia de zero a um e testa a diferença média entre os vetores das variáveis independentes contínuas (ex: subdomínios) dos grupos (variáveis dependentes, isto é, categoriais ou seja, o diagnóstico) e a presença de efeitos de interação em modelos de análise de variância multivariável (MANOVA) (Duarte Silva e Stam, 1995). Quanto menor o seu valor, maior é a diferença média, e mais expressiva é a separação de grupos. Os subdomínios humor maníaco (hm) e energia maníaca (em), com lambda de Wilks de 0,542 e 0,470, respectivamente, foram os subdomínios que melhor distinguiram os bipolares de unipolares sendo mantidos na função discriminante canônica (tabela 16). Esta apresentou um eigenvalue de 1,13, explicando 100 \% da variância $(p=0,000$, tabela 17$)$. Um eigenvalue é um coeficiente calculado através da matriz de covariância que é utilizada na análise do componente principal, além de na análise discriminante O eigenvalue é o total da variância que é explicada por um eigenvector, ou seja, uma função linear ou componente principal (Bryant e Yarnold, 1995). Quanto maior o eigenvalue de uma função discriminante, mais variância da variável dependente é explicada por esta função. Outro valor importante na tabela 17 é a correlação canônica $(0,728)$, que ajuda a escolher a melhor função discriminante canônica quando há mais de dois grupos para serem discriminados. Os coeficientes não corrigidos e corrigidos da função discriminante canônica são mostrados na tabela 18. Quanto maior o coeficiente corrigido, maior a importância da variável independente em prever a variável dependente. Nossa análise discriminante apresentou os subdomínios humor maníaco e energia maníacos como os que melhor distinguiram bipolares de 
unipolares. O estudo de Fagiolini apresentou um resultado diferente em sua análise discriminante. Naquele estudo, os subdomínios que melhor diferenciaram bipolares e unipolares foram a energia maníaca, a cognição maníacas e o humor depressivo (Fagiolini et al., 1999). A análise discriminante de Fagiolini e colaboradores foi feita pelo método de maximizar a distância Mahalanobis entre grupos, enquanto a nossa baseou-se primariamente no lambda de Wilks, que é a técnica mais utilizada. Nós repetimos nossa análise desta vez baseando-se na distância Mahalanobis sem diferença em relação ao resultado prévio. A discrepância dos resultados pode ser devida a amostras diferentes e uso de entrevistas com o número de itens diferentes.

No estudo de Fagiolini, nove centros italianos participaram, no nosso apenas dois. A sua amostra foi maior, permitindo além de uma análise discriminante, uma análise fatorial dos itens dos domínios que melhor distinguiram unipolares e bipolares (Fagiolini et al., 1999). Esta permite a redução do número de itens da escala, reduzindo o tempo de sua aplicação e permitindo a sua utilização como instrumento para o rastreamento do TB.

\section{6) CURVAS ROC}

As pontuações da SCI-MOODS para auxiliar no diagnóstico de diferentes populações não haviam sido estabelecidas. A pontuação que melhor diferenciou sujeitos bipolares de unipolares foi a maníaca. Este escore acima de 30 ajuda a diagnosticar um bipolar de acordo com o SCID com $78 \%$ certeza (valor preditivo positivo). Um sujeito com escore maníaco abaixo de 30 não seria bipolar com 90 
$\%$ certeza (valor preditivo negativo). Os valores preditivos positivo e negativo variam conforme a prevalência da doença na população. Neste estudo, a prevalência de bipolares foi de $50 \%$ (47 de 94). Na comunidade, com uma prevalência menor, o valor preditivo positivo da escala tende a diminuir e o negativo aumentar. Apesar da diferença na duração de sintomas entre SClMOODS-VP e SCID, por exemplo, a duração de 3 a 5 dias no primeiro e de pelo menos 4 dias para hipomania ou 7 para mania no último, mais de $60 \%$ dos sujeitos foram diagnosticados por ambas as entrevistas, considerando uma pontuação maníaca acima de 30. Recentemente, Angst e Cassano (2005), trabalhando com a amostra de validação original da SCI-MOODS, usaram um limiar de 22 no escore maníaco para distinguir bipolares de unipolares. Na nossa amostra, um escore maníaco de 22 teria sensibilidade de $97,87 \%$, porém uma especificidade de apenas 53,19 \% e um Kappa de 51,06 \%. Esta sensibilidade seria ótima para um instrumento de rastreamento. Porém, a SCl-MOODS tem muitas questões e demora muito tempo para este uso.

A melhor pontuação que diferenciou sujeitos com transtornos afetivos de controles foi a depressiva. Sintomas depressivos são a expressão mais comum de transtornos afetivos. Não houve diferença das pontuações depressivas entre bipolares e unipolares.

\section{7) A IMPORTÂNCIA DA SCI-MOODS-VP}

Validar uma entrevista que aborda o humor de forma dimensional é muito importante no nosso meio. Ela permitirá auxiliar no diagnóstico de transtornos de 
humor, especialmente do TB. Em geral, o TB é pouco diagnosticado e quando é diagnosticado, não é adequadamente tratado. Apesar de poder afetar até $8 \%$ da população (Moreno e Andrade, 2005), o TB aparentemente é uma doença desconhecida pelos gestores de saúde pública. Informações do sistema de dados do governo federal, o DATASUS, parecem apontar a esta conclusão (DATASUS, 2006). A tabela 24 mostra a relação das internações por esquizofrenia e transtornos de humor, divididos por sexo, entre novembro de 2005 e outubro 2006 no estado de São Paulo. As internações por transtornos do humor englobam todas as internações por TB e depressões unipolares. Há um número muito maior de internações por esquizofrenia do que por transtornos de humor, principalmente do sexo masculino. Há maior número de mulheres internadas por transtornos do humor. É necessário lembrar que a mediana da prevalência na vida da esquizofrenia na comunidade é de 0,72\%, sem diferença entre os sexos (Saha et al., 2005). As formas graves de transtorno bipolar afetam em torno de 1 a $2 \%$ da população (Kessler et al., 1994; Grant et al., 2005). Provavelmente, há um excesso de diagnósticos de esquizofrenia principalmente em homens internados com sintomas psicóticos e o TB não está sendo adequadamente diagnosticado. 
Tabela 24 -Internações públicas por esquizofrenia e transtorno bipolar no estado de São Paulo entre novembro de 2005 e Outubro de 2006.

\begin{tabular}{l|l|r|r|r|r|rr}
\hline & \multicolumn{3}{c}{ ESQUIZOFRENIA } & \multicolumn{4}{c}{ TRANSTORNOS DO HUMOR } \\
\hline Ano & Mês & Masculino & Feminino & Total & Masculino & Feminino & Total \\
\hline 2006 & Outubro & 1381 & 909 & 2290 & 311 & 771 & 1082 \\
& Setembro & 1280 & 963 & 2243 & 335 & 782 & 1117 \\
& Agosto & 1379 & 907 & 2286 & 365 & 763 & 1128 \\
& Julho & 1229 & 937 & 2166 & 320 & 709 & 1029 \\
& Junho & 1257 & 889 & 2146 & 339 & 682 & 1021 \\
& Maio & 1272 & 951 & 2223 & 313 & 786 & 1099 \\
& Abril & 1208 & 844 & 2052 & 302 & 646 & 948 \\
& Março & 1333 & 1049 & 2382 & 329 & 676 & 1005 \\
& Fevereiro & 1378 & 1076 & 2454 & 354 & 690 & 1044 \\
& Janeiro & 3994 & 2715 & 6710 & 507 & 932 & 1439 \\
& Dezembro & 1312 & 982 & 2294 & 366 & 701 & 1067 \\
& Novembro & 3950 & 2654 & 6605 & 495 & 925 & 1420
\end{tabular}

FONTE: DATASUS, 2006

Outros fatores demonstram a pouca importância dada ao TB pelos gestores de saúde. Medicações úteis em seu manejo, como os antipsicóticos atípicos, são liberadas pelo Ministério da Saúde apenas para casos de esquizofrenia resistentes ao tratamento. A principal medicação para tratar o TB, o carbonato de lítio, disponível há décadas no Brasil, tem seu uso reduzido pela dificuldade de se realizar litemias no serviço público, além do desconhecimento dos clínicos gerais no seu uso. 
O uso da SCI-MOODS-VP pode permitir um aumento no diagnóstico do TB e o reconhecimento de formas mais leves do espectro bipolar, comuns em ambulatórios de medicina de família. Por exemplo, Manning et al. (1997) estudaram 108 pacientes ansiosos ou depressivos consecutivos em um ambulatório de medicina de família por meio de uma entrevista semi-estruturada. Cerca de $25 \%$ dos pacientes era do espectro bipolar. Dentre os depressivos, um terço fazia parte do espectro bipolar. O diagnóstico errado como depressão unipolar destes sujeitos pode ter graves conseqüências, como o uso de antidepressivos tricíclicos, ainda os mais utilizados em serviços públicos no Brasil, levando à piora do quadro (Wehr e Goodwin, 1987).

Um dos problemas para a disseminação do uso da SCI-MOODS-VP entre psiquiatras e, principalmente, clínicos gerais é a duração da entrevista. A maioria das consultas em atendimento primário ou até mesmo ambulatórios públicos de psiquiatria não dura uma hora. A análise discriminante permitiu separar os sub domínios humor maníaco e energia maníaca, que melhor distinguiram bipolares de unipolares. O uso apenas destes itens para uma entrevista de rastreamento poderia ser útil. Outra possibilidade seria a validação e o uso da MOODS-SR, que é preenchida pelo paciente, economizando o tempo do entrevistador. Porém, estudos são necessários para testar estas hipóteses.

Este estudo estabeleceu o escore maníaco de 30 como o que melhor auxiliaria no diagnóstico diferencial entre bipolares e unipolares com uma boa relação entre sensibilidade e especificidade. Esta pontuação precisa ser testada em diferentes populações, por exemplo, de atendimento primário, comunitárias e em pacientes do espectro bipolar. A SCI-MOODS-VP também pode auxiliar no 
estudo da relação entre diferentes TB, como o tipo I e II, no teste de diferentes definições do espectro, por exemplo, enfatizando a história familiar de TB (Depue e Monroe, 1978) ou temperamento pré-mórbido, como o hipertímico ou ciclotímico (Akiskal et al., 2005). Além disso, pode auxiliar no estudo da relação entre o espectro bipolar e transtornos caracterizados por elevada impulsividade, como o de personalidade borderline, as dependências químicas, os transtornos do controle de impulso, como o explosivo intermitente e o jogo patológico e a bulimia nervosa.

\section{8) LIMITAÇÕES}

Nosso estudo apresentou algumas limitações. Nós selecionamos pacientes com esquizofrenia e transtornos afetivos de centros terciários, podendo estes serem mais doentes que os pacientes de outros locais, como atendimento primário ou comunidade. Nós trabalhamos apenas com sujeitos atualmente bem, assim considerados por seus médicos. Porém, não aplicamos escalas de gravidade no momento da entrevista. Nosso grupo controle sem diagnóstico psiquiátrico apresentou critérios de exclusão rígidos, então eles poderiam ser "supernormais". Outros sujeitos sem diagnóstico psiquiátrico poderiam ser utilizados como controles, como estudantes universitários. Porém, este grupo controle "de ocasião" também não seria o ideal, por apresentar escolaridade superior à média da população. Além disso, estes sujeitos, caso não passassem por uma avaliação rigorosa como à que foi feita, provavelmente não seriam "normais" no sentido estrito do termo. Isto é, teriam algum diagnóstico psiquiátrico como uma 
depressão leve ou episódios hipomaníacos breves no passado. Os resultados dos valores preditivos positivo e negativos das curvas ROC tem de ser interpretados com cautela. Populações com prevalências diferentes de TB, maior proporção de bipolares tipo II ou de espectro bipolar poderiam determinar diferentes pontuações de corte. Outra limitação do estudo foi a reunião de esquizofrenia e controles normais em um único grupo controle para a segunda curva ROC (figura 2)., tornando o grupo heterogêneo. 


\section{5) CONCLUSÃO :}

O diagnóstico do transtorno bipolar (TB) é extremamente importante. Há várias razões para esta importância. O diagnóstico diferencial entre depressões unipolares e TB é um dos mais difíceis na psiquiatria. A maioria dos bipolares acaba recebendo um diagnóstico de esquizofrenia ou depressão antes de corretamente diagnosticado. O uso de antidepressivos em TB pode piorar o curso clínico da doença. $\mathrm{O}$ atraso no tratamento adequado do TB também pode piorar o seu curso, expondo os pacientes a alto risco de suicídio, prejuízo social e ocupacional. Freqüentemente se encontra associada a outras clínicas e psiquiátricas, o que aumenta a sua morbidade e mortalidade. $\mathrm{O}$ espectro bipolar compartilha muitas das características anteriores do TB, também não sendo diagnosticado. Há poucas entrevistas em português tanto para o diagnóstico quanto para a avaliação do espectro bipolar. Dada a importância clínica e epidemiológica do conceito doespectro bipolar, a SCI-MOODS-VP veio preencher esta lacuna.

A SCI-MOODS-VP apresentou boa confiabilidade entre examinadores e consistência interna. Ela apresentou boa validade discriminante, sendo capaz de diferenciar bipolares, unipolares, esquizofrenia e sujeitos sem diagnóstico psiquiátrico. Apresentou maior dificuldade de distinguir depressivos unipolares de esquizofrenia. Estudos com maiores amostras de sujeitos com esquizofrenia são necessários, para entender a relação entre os sintomas negativos e depressivos da SCI-MOODS-VP. 
A pontuação maníaca de 30 apresentou excelente sensibilidade e boa especificidade para distinguir bipolares de unipolares. A pontuação depressiva de 35 foi a melhor para distinguir bipolares de controles. 


\title{
6) ANEXOS
}

6.1) ANEXO A. VERSÃO EM INGLÊS AMERICANO DA SCI-MOODS

\section{SCI-MOODS (Structured Clinical Interview for Mood Spectrum), Version 3.0}

\author{
May 31, 2002 \\ Cassano GB, Shear MK, Michelini S, Coli E, Frank E, \\ Maser JD, Mauri M, Dell'Osso L
}

Acknowledgements: The development of this instrument was supported by a grant from PfizerRoering and NIMH grant MH30915.

Thank you for coming in to talk with me today. The interview we are going to do is focused on symptoms that you may or may not have experienced in your life. We want to identify whether you have had these symptoms at any time, even if it was a long time ago. We are interested in whether you had the symptoms at all, especially if having them bothered you or disturbed you. There are four sections of the interview and it should take us about an hour to complete it. Do you have any questions before we start?

\section{DOMAIN I. MOOD}

I am going to ask you questions which refer to situations that you may have experienced in the past or that you may be experiencing currently.

The first set of questions refer to your mood.

In the course of your life, including when you were a child, have you ever had periods of at least 3-5 days in which...

\begin{tabular}{|l|l|l|l|c|}
\hline 1. & $\begin{array}{l}\text {..you felt frustrated and defeated although you couldn't think of any } \\
\text { reason for this? }\end{array}$ & $\begin{array}{l}\text { Do Not } \\
\text { Know }\end{array}$ & Yes & No \\
\hline 2. & ․you felt very nostalgic? & $\begin{array}{l}\text { Do Not } \\
\text { Know }\end{array}$ & Yes & No \\
\hline
\end{tabular}




\begin{tabular}{|c|c|c|c|c|}
\hline 3. & $\begin{array}{l}\text {...you felt lonely? } \\
\text { Note: Without any real loss of friends or loved ones. }\end{array}$ & $\begin{array}{l}\text { Do Not } \\
\text { Know }\end{array}$ & Yes & No \\
\hline 4. & ...you were serious, introverted or gloomy? & $\begin{array}{l}\text { Do Not } \\
\text { Know }\end{array}$ & Yes & No \\
\hline 5. & ...you felt very bored? & $\begin{array}{l}\text { Do Not } \\
\text { Know }\end{array}$ & Yes & No \\
\hline 6. & ...you were deeply annoyed with everything? & $\begin{array}{l}\text { Do Not } \\
\text { Know }\end{array}$ & Yes & No \\
\hline 7. & ...the littlest thing could make you sad? & $\begin{array}{l}\text { Do Not } \\
\text { Know }\end{array}$ & Yes & No \\
\hline 8. & ...you completely lost your capacity to laugh, have fun, enjoy your life? & $\begin{array}{l}\text { Do Not } \\
\text { Know }\end{array}$ & Yes & No \\
\hline 9. & $\begin{array}{l}\text {...you found it unusually hard to take rejections, particularly those } \\
\text { involving friendships or romantic relationships? }\end{array}$ & $\begin{array}{l}\text { Do Not } \\
\text { Know }\end{array}$ & Yes & No \\
\hline 10. & ...you felt persistently sad or empty, blue, or down in the dumps? & $\begin{array}{l}\text { Do Not } \\
\text { Know }\end{array}$ & Yes & No \\
\hline 11. & ...you found yourself crying very easily? & $\begin{array}{l}\text { Do Not } \\
\text { Know }\end{array}$ & Yes & No \\
\hline 12. & ...you were constantly complaining? & $\begin{array}{l}\text { Do Not } \\
\text { Know }\end{array}$ & Yes & No \\
\hline 13. & ...you felt purposeless, as if everything had lost its significance? & $\begin{array}{l}\text { Do Not } \\
\text { Know }\end{array}$ & Yes & No \\
\hline 14. & ...you lost interest in how you looked? & $\begin{array}{l}\text { Do Not } \\
\text { Know }\end{array}$ & Yes & No \\
\hline 15. & ...nothing you put on looked or felt right? & $\begin{array}{l}\text { Do Not } \\
\text { Know }\end{array}$ & Yes & No \\
\hline 16. & $\begin{array}{l}\text {...your mood became depressed when you had some sort of medical } \\
\text { problem such as the flu or a cold? }\end{array}$ & $\begin{array}{l}\text { Do Not } \\
\text { Know }\end{array}$ & Yes & No \\
\hline 17. & $\begin{array}{l}\text {...your mood became depressed when you took medications (that are } \\
\text { not prescribed to change one's mood), such as antibiotics, } \\
\text { contraceptives, or steroids? } \\
\text { (.) subject has never taken such medications }\end{array}$ & $\begin{array}{l}\text { Do Not } \\
\text { Know }\end{array}$ & Yes & No \\
\hline
\end{tabular}




\begin{tabular}{|c|c|c|c|c|}
\hline 18. & $\begin{array}{l}\text {...your mood became depressed as a result of using a lot of alcohol, } \\
\text { sleeping pills, anti-anxiety drugs, marijuana or similar substances? } \\
\text { (.) subject has never taken such substances }\end{array}$ & $\begin{array}{l}\text { Do Not } \\
\text { Know }\end{array}$ & Yes & No \\
\hline 19. & $\begin{array}{l}\text {...your mood became depressed within a month of stopping any of these } \\
\text { substances? } \\
\text { ( ) subject has never taken such substances }\end{array}$ & $\begin{array}{l}\text { Do Not } \\
\text { Know }\end{array}$ & Yes & No \\
\hline 20. & $\begin{array}{l}\text {...your mood became depressed as a result of using alcohol, sleeping } \\
\text { pills, anti-anxiety drugs, nicotine, caffeine, stimulants or similar } \\
\text { substances even though you took them in order to feel better? } \\
\text { ( ) subject has never taken such substances }\end{array}$ & $\begin{array}{l}\text { Do Not } \\
\text { Know }\end{array}$ & Yes & No \\
\hline 21. & $\begin{array}{l}\text {...you lost interest and pleasure in your social life and you preferred } \\
\text { spending most of your time alone, withdrawing from your family and } \\
\text { friends? }\end{array}$ & $\begin{array}{l}\text { Do Not } \\
\text { Know }\end{array}$ & Yes & No \\
\hline 22. & $\begin{array}{l}\text {...you lost interest in making new friends or you found it difficult to make } \\
\text { new friends? }\end{array}$ & $\begin{array}{l}\text { Do Not } \\
\text { Know }\end{array}$ & Yes & No \\
\hline 23. & ...you lost interest in your romantic life? & $\begin{array}{l}\text { Do Not } \\
\text { Know }\end{array}$ & Yes & No \\
\hline 24. & Are you the kind of person who always had a very limited romantic life? & $\begin{array}{l}\text { Do Not } \\
\text { Know }\end{array}$ & Yes & No \\
\hline 25. & ...you lost interest in your hobbies or in playing games or sports? & $\begin{array}{l}\text { Do Not } \\
\text { Know }\end{array}$ & Yes & No \\
\hline 26. & $\begin{array}{l}\text {...you felt indifferent about everything (either positive or negative) that } \\
\text { happened to you or your family? }\end{array}$ & $\begin{array}{l}\text { Do Not } \\
\text { Know }\end{array}$ & Yes & No \\
\hline 27. & $\begin{array}{l}\text {...you lost interest or pleasure in all or almost all the things you usually } \\
\text { enjoyed? }\end{array}$ & $\begin{array}{l}\text { Do Not } \\
\text { Know }\end{array}$ & Yes & No \\
\hline 28. & $\begin{array}{l}\text { If you answered YES to any one of the questions from } 1 \text { to } 27 \text {, were you } \\
\text { seriously impaired, worried or troubled by what was happening to you? } \\
\text { ( ) subject did not answer YES to any of the above questions. }\end{array}$ & $\begin{array}{l}\text { Do Not } \\
\text { Know }\end{array}$ & Yes & No \\
\hline
\end{tabular}

In the course of your life, including when you were a child, have you ever had periods of at least 3-5 days in which...

\begin{tabular}{|l|l|l|l|l|}
\hline 29. & $\ldots$ you felt persistently good or high? & $\begin{array}{l}\text { Do Not } \\
\text { Know }\end{array}$ & Yes & No \\
\hline
\end{tabular}




\begin{tabular}{|c|c|c|c|c|}
\hline 30. & $\begin{array}{l}\text {...you (or others) found that your sense of humor and irony were very } \\
\text { acute? }\end{array}$ & $\begin{array}{l}\text { Do Not } \\
\text { Know }\end{array}$ & Yes & No \\
\hline 31. & ...even the smallest thing could make you very enthusiastic? & $\begin{array}{l}\text { Do Not } \\
\text { Know }\end{array}$ & Yes & No \\
\hline 32. & ...you liked to make puns or plays on words? & $\begin{array}{l}\text { Do Not } \\
\text { Know }\end{array}$ & Yes & No \\
\hline 33. & $\begin{array}{l}\text {...you liked to make a lot of jokes (even ones that might have been } \\
\text { inappropriate or out of place)? }\end{array}$ & $\begin{array}{l}\text { Do Not } \\
\text { Know }\end{array}$ & Yes & No \\
\hline 34. & $\begin{array}{l}\text {...you were intrusive, insulting, or tactless, or others thought that you } \\
\text { were? }\end{array}$ & $\begin{array}{l}\text { Do Not } \\
\text { Know }\end{array}$ & Yes & No \\
\hline 35. & $\begin{array}{l}\text {...you found it very pleasurable and easy to buy things, even things you } \\
\text { didn't need? }\end{array}$ & $\begin{array}{l}\text { Do Not } \\
\text { Know }\end{array}$ & Yes & No \\
\hline 36. & ...you gave lots of presents, even when you really couldn't afford them? & $\begin{array}{l}\text { Do Not } \\
\text { Know }\end{array}$ & Yes & No \\
\hline 37. & $\begin{array}{l}\text {...you were warm, extroverted and sociable and it was very easy to } \\
\text { introduce yourself to others or to make new friends? }\end{array}$ & $\begin{array}{l}\text { Do Not } \\
\text { Know }\end{array}$ & Yes & No \\
\hline 38. & $\begin{array}{l}\text {...you were the kind of person to whom others were attracted because of } \\
\text { your confidence, energy and enthusiasm? }\end{array}$ & $\begin{array}{l}\text { Do Not } \\
\text { Know }\end{array}$ & Yes & No \\
\hline 39. & ...you did a lot of entertaining, either at home or in restaurants? & $\begin{array}{l}\text { Do Not } \\
\text { Know }\end{array}$ & Yes & No \\
\hline 40. & $\begin{array}{l}\text {...you enjoyed being the center of attention or were particularly seductive } \\
\text { or flirtatious, as if yo u were playing a role? }\end{array}$ & $\begin{array}{l}\text { Do Not } \\
\text { Know }\end{array}$ & Yes & No \\
\hline 41. & ...you had a particularly intense romantic life? & $\begin{array}{l}\text { Do Not } \\
\text { Know }\end{array}$ & Yes & No \\
\hline 42. & Are you the kind of person who has always had an intense romantic life? & $\begin{array}{l}\text { Do Not } \\
\text { Know }\end{array}$ & Yes & No \\
\hline
\end{tabular}

In the course of your life, including when you were a child, have you ever had periods of at least 3-5 days in which...

\begin{tabular}{|c|l|l|l|l|}
\hline 43. & $\begin{array}{l}\text {..you wore clothing or a hairstyle that was dramatic, extravagant, very } \\
\text { high fashion or very unusual? }\end{array}$ & $\begin{array}{l}\text { Do Not } \\
\text { Know }\end{array}$ & Yes & No \\
\hline 44. & $\begin{array}{l}\text { fyou were full of plans or got involved in many projects, jumping from } \\
\text { one activity to another? }\end{array}$ & $\begin{array}{l}\text { Do Not } \\
\text { Know }\end{array}$ & Yes & No \\
\hline
\end{tabular}




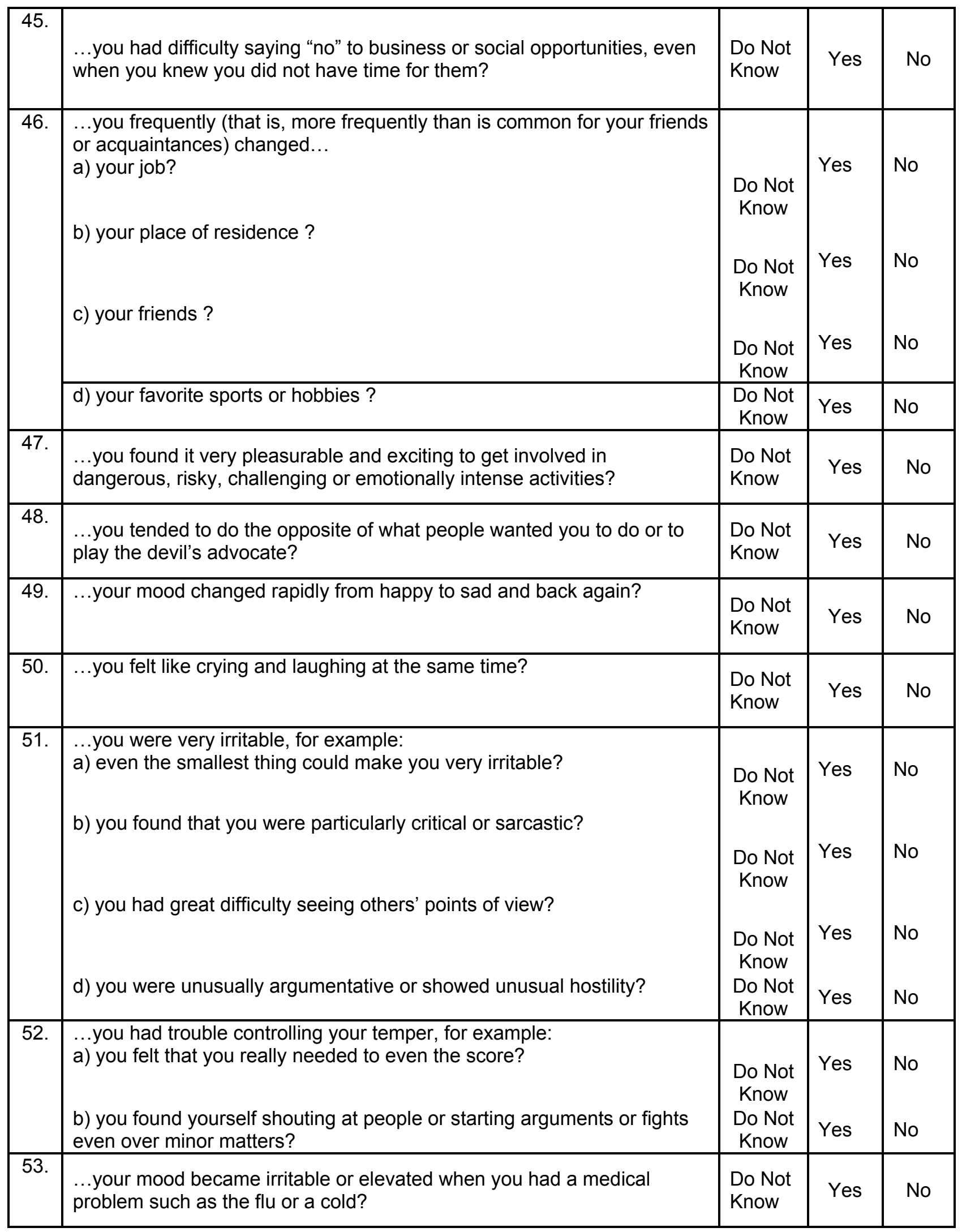




\begin{tabular}{|c|c|c|c|c|}
\hline 54. & $\begin{array}{l}\text {...your mood became irritable or elevated when you took medications } \\
\text { (that are not prescribed to change one's mood), such as antibiotics, } \\
\text { contraceptives, or steroids? } \\
\text { ( ) subject has never taken such medications. }\end{array}$ & $\begin{array}{l}\text { Do Not } \\
\text { Know }\end{array}$ & Yes & No \\
\hline 55. & $\begin{array}{l}\text {...your mood became irritable or elevated when you were abusing (and } \\
\text { clearly in relation to) alcohol, sedatives, hypnotics, anxiolytics, other } \\
\text { substances, or within a month of withdrawal? } \\
\text { ( ) subject has never taken such substances. }\end{array}$ & $\begin{array}{l}\text { Do Not } \\
\text { Know }\end{array}$ & Yes & No \\
\hline 56 & $\begin{array}{l}\text {...your mood became even more irritable or elevated when you } \\
\text { increased your use of alcohol, sedatives, nicotine, caffeine, stimulants } \\
\text { and similar substances and you were already irritable or high? } \\
\text { ( ) subject has never taken such substances. }\end{array}$ & $\begin{array}{l}\text { Do Not } \\
\text { Know }\end{array}$ & Yes & No \\
\hline 57. & $\begin{array}{l}\text { If yo u answered YES to any of the questions from } 29 \text { to } 56 \text {, were you } \\
\text { ever seriously impaired, worried or troubled by what was happening to } \\
\text { you? } \\
\text { ( ) subject did not answer YES to any of the above questions. }\end{array}$ & $\begin{array}{l}\text { Do Not } \\
\text { Know }\end{array}$ & Yes & No \\
\hline
\end{tabular}

The next set of questions refers to your energy and activity level.

In the course of your life, including when you were a child, have you ever had periods of at least 3-5 days in which...

\begin{tabular}{|c|c|c|c|c|}
\hline 58. & ...you had difficulty starting to do anything? & $\begin{array}{l}\text { Do Not } \\
\text { Know }\end{array}$ & Yes & No \\
\hline 59. & $\begin{array}{l}\text {...you felt physically "slowed down," as if every movement was in slow } \\
\text { motion? }\end{array}$ & $\begin{array}{l}\text { Do Not } \\
\text { Know }\end{array}$ & Yes & No \\
\hline 60. & ...your speech or thinking seemed slowed down? & $\begin{array}{l}\text { Do Not } \\
\text { Know }\end{array}$ & Yes & No \\
\hline 61. & ...you experienced time as passing very slowly, hanging heavy? & $\begin{array}{l}\text { Do Not } \\
\text { Know }\end{array}$ & Yes & No \\
\hline 62. & $\begin{array}{l}\text {...you felt passive, sluggish, and failed to take care of your usual } \\
\text { commitments and responsibilities? }\end{array}$ & $\begin{array}{l}\text { Do Not } \\
\text { Know }\end{array}$ & Yes & No \\
\hline 63. & ...you had a lot of trouble getting out of bed in the morning? & $\begin{array}{l}\text { Do Not } \\
\text { Know }\end{array}$ & Yes & No \\
\hline 64. & $\begin{array}{l}\text {...you had difficulty taking care of yourself (for example, you showered } \\
\text { less, wore the same clothes, did not put on make-up or shave)? }\end{array}$ & $\begin{array}{l}\text { Do Not } \\
\text { Know }\end{array}$ & Yes & No \\
\hline
\end{tabular}




\begin{tabular}{|c|l|l|l|l|}
\hline 65. & $\begin{array}{l}\text {...you felt fatigued, weak, or tired as though the smallest task (for } \\
\text { instance, washing your face or filling the sugar bowl) was an effort and } \\
\text { required a great deal of energy? }\end{array}$ & $\begin{array}{l}\text { Do Not } \\
\text { Know }\end{array}$ & Yes & No \\
\hline 66. & $\begin{array}{l}\text { keven though you had no energy, you found it difficult to sit still or to lie } \\
\text { down, or you needed to pace the room or to be constantly in motion? }\end{array}$ & $\begin{array}{l}\text { Do Not } \\
\text { Know }\end{array}$ & Yes & No \\
\hline 67. & $\begin{array}{l}\text { If you answered YES to any of the questions from } 58 \text { to 66, were you } \\
\text { ever seriously impaired, worried or troubled by what was happening to } \\
\text { you? } \\
\text { ( ) subject did not answer YES to any of the above questions. }\end{array}$ & $\begin{array}{l}\text { Do Not } \\
\text { Know }\end{array}$ & Yes & No \\
\hline
\end{tabular}

In the course of your life, including when you were a child, have you ever had periods of at least 3-5 days in which...

\begin{tabular}{|c|c|c|c|c|}
\hline 68. & $\begin{array}{l}\text {...you felt an irresistible urge to communicate by phone calls, letters, e- } \\
\text { mails or faxes? }\end{array}$ & $\begin{array}{l}\text { Do Not } \\
\text { Know }\end{array}$ & Yes & No \\
\hline 69. & $\begin{array}{l}\text {...you felt a strong desire to reconnect with people you hadn't seen or } \\
\text { spoken with for a long time? }\end{array}$ & $\begin{array}{l}\text { Do Not } \\
\text { Know }\end{array}$ & Yes & No \\
\hline 70. & $\begin{array}{l}\text {...you were overly talkative, spoke rapidly and loudly, or were difficult to } \\
\text { interrupt or had little regard for others' wishes to speak? }\end{array}$ & $\begin{array}{l}\text { Do Not } \\
\text { Know }\end{array}$ & Yes & No \\
\hline 71. & $\begin{array}{l}\text {...you were so noisy that others complained (for instance, you kept your } \\
\text { radio or television very loud)? }\end{array}$ & $\begin{array}{l}\text { Do Not } \\
\text { Know }\end{array}$ & Yes & No \\
\hline 72. & $\begin{array}{l}\text {...you felt that your ideas came and went unusually easily, as if your } \\
\text { thoughts were racing? }\end{array}$ & $\begin{array}{l}\text { Do Not } \\
\text { Know }\end{array}$ & Yes & No \\
\hline 73. & $\begin{array}{l}\text {...you had so many thoughts and ideas all at once that you found it } \\
\text { difficult to express them? }\end{array}$ & $\begin{array}{l}\text { Do Not } \\
\text { Know }\end{array}$ & Yes & No \\
\hline 74. & $\begin{array}{l}\text {...you found your interest shifting frequently from one thing to another } \\
\text { and were easily distracted so that, for example, it was hard to finish a } \\
\text { newspaper or magazine article or to watch a television program from } \\
\text { beginning to end? }\end{array}$ & $\begin{array}{l}\text { Do Not } \\
\text { Know }\end{array}$ & Yes & No \\
\hline 75. & ...you spent a lot of time on social, political or religious causes? & $\begin{array}{l}\text { Do Not } \\
\text { Know }\end{array}$ & Yes & No \\
\hline 76. & ...you were very assertive? & $\begin{array}{l}\text { Do Not } \\
\text { Know }\end{array}$ & Yes & No \\
\hline 77. & ...you felt vigorous, much livelier than usua I and full of energy? & $\begin{array}{l}\text { Do Not } \\
\text { Know }\end{array}$ & Yes & No \\
\hline
\end{tabular}




\begin{tabular}{|c|l|l|l|l|}
\hline 78. & $\ldots$ you were very impatient? & $\begin{array}{l}\text { Do Not } \\
\text { Know }\end{array}$ & Yes & No \\
\hline 79. & $\begin{array}{l}\text { fyou were constantly active and had the pleasant sensation of never } \\
\text { getting tired and your energy was so high that it exhausted or irritated } \\
\text { others? }\end{array}$ & $\begin{array}{l}\text { Do Not } \\
\text { Know }\end{array}$ & Yes & No \\
\hline 80. & $\begin{array}{l}\text { If you answered YES to any of the questions 68 to 79, were you } \\
\text { seriously impaired, worried or troubled by what was happening to you? } \\
\text { (.)subject did not answer YES to any of the above questions. }\end{array}$ & $\begin{array}{l}\text { Do Not } \\
\text { Know }\end{array}$ & Yes & No \\
\hline
\end{tabular}

DOMAIN III. COGNITIVE FUNCTIONING

The following questions refer to your thoughts.

In the course of your life, including when you were a child, have you ever had periods of at least 3-5 days in which...

\begin{tabular}{|c|c|c|c|c|}
\hline 81. & $\begin{array}{l}\text {...you were hypercritical or skeptical about all the things that people } \\
\text { ordinarily value in life? }\end{array}$ & $\begin{array}{l}\text { Do Not } \\
\text { Know }\end{array}$ & Yes & No \\
\hline 82. & $\begin{array}{l}\text {...you were preoccupied with yourself and your own problems, thoughts } \\
\text { and feelings? }\end{array}$ & $\begin{array}{l}\text { Do Not } \\
\text { Know }\end{array}$ & Yes & No \\
\hline 83. & $\begin{array}{l}\text {...you felt very vulnerable, or you were constantly afraid of doing } \\
\text { something wrong? }\end{array}$ & $\begin{array}{l}\text { Do Not } \\
\text { Know }\end{array}$ & Yes & No \\
\hline 84. & $\begin{array}{l}\text {...you were disappointed in yourself, you felt useless, as if you were } \\
\text { without any talent and you couldn't do anything right? }\end{array}$ & $\begin{array}{l}\text { Do Not } \\
\text { Know }\end{array}$ & Yes & No \\
\hline 85. & ...you felt as if your body were diseased or somehow transformed? & $\begin{array}{l}\text { Do Not } \\
\text { Know }\end{array}$ & Yes & No \\
\hline 86. & $\begin{array}{l}\text {...you were very preoccupied with money even though you didn't have } \\
\text { any real financial problems? }\end{array}$ & $\begin{array}{l}\text { Do Not } \\
\text { Know }\end{array}$ & Yes & No \\
\hline 87. & ...you felt a strong need to take refuge in religion or prayer? & $\begin{array}{l}\text { Do Not } \\
\text { Know }\end{array}$ & Yes & No \\
\hline 88. & $\begin{array}{l}\text {...you had problems with your memory such as finding the right word or } \\
\text { remembering things that should have been easy to remember? } \\
\text { Note: Not due to medications or a physical illness. }\end{array}$ & $\begin{array}{l}\text { Do Not } \\
\text { Know }\end{array}$ & Yes & No \\
\hline 89. & $\begin{array}{l}\text {...your housework, child care or your performance at school, work, } \\
\text { sports or hobbies deteriorated? } \\
\text { Note: Not due to medications or a physical illness. }\end{array}$ & $\begin{array}{l}\text { Do Not } \\
\text { Know }\end{array}$ & Yes & No \\
\hline
\end{tabular}




\begin{tabular}{|c|c|c|c|c|}
\hline 90. & $\begin{array}{l}\text {...you had difficulty making even minor decisions (such as what clothes } \\
\text { to wear, what household task to do first)? }\end{array}$ & $\begin{array}{l}\text { Do Not } \\
\text { Know }\end{array}$ & Yes & No \\
\hline 91. & $\begin{array}{l}\text {...you had a lot of trouble thinking or concentrating, such as trouble } \\
\text { taking part in a discussion, reading, writing, doing math, following a } \\
\text { television program, newspaper or magazine article? } \\
\text { Note: Not due to medications or a physical illness. }\end{array}$ & $\begin{array}{l}\text { Do Not } \\
\text { Know }\end{array}$ & Yes & No \\
\hline 92. & $\begin{array}{l}\text {...you felt mentally dull or confused? } \\
\text { Note: Not due to medications or a physical illness. }\end{array}$ & $\begin{array}{l}\text { Do Not } \\
\text { Know }\end{array}$ & Yes & No \\
\hline \multirow[t]{2}{*}{93.} & $\begin{array}{l}\text {...you felt guilty or remorseful, for example: } \\
\text { a) you thought you should be blamed even for problems that others were } \\
\text { experiencing? }\end{array}$ & $\begin{array}{l}\text { Do Not } \\
\text { Know }\end{array}$ & Yes & No \\
\hline & $\begin{array}{l}\text { b) you felt you couldn't possibly do enough for your family, employer, co- } \\
\text { workers, etc? } \\
\text { c) you thought a lot about things in the past that you wished you had } \\
\text { done differently? } \\
\text { d) you thought you should be punished for all the wrong things you had } \\
\text { done? }\end{array}$ & $\begin{array}{l}\text { Do Not } \\
\text { Know } \\
\text { Do Not } \\
\text { Know } \\
\text { Do Not } \\
\text { Know }\end{array}$ & $\begin{array}{l}\text { Yes } \\
\text { Yes } \\
\text { Yes }\end{array}$ & No \\
\hline 94. & ...you felt as if others were causing all of your problems? & $\begin{array}{l}\text { Do Not } \\
\text { Know }\end{array}$ & Yes & No \\
\hline 95. & $\begin{array}{l}\text {...you felt surrounded by hostility, as if everybody was against you, for } \\
\text { example: } \\
\text { a) you thought that everybody accused and hated you? } \\
\text { b) you felt as if everybody was looking at you? } \\
\text { c) you thought you were being persecuted or that you were wanted by } \\
\text { the police }\end{array}$ & $\begin{array}{l}\text { Do Not } \\
\text { Know } \\
\text { Do Not } \\
\text { Know } \\
\text { Do Not } \\
\text { Know }\end{array}$ & $\begin{array}{l}\text { Yes } \\
\text { Yes } \\
\text { Yes }\end{array}$ & $\begin{array}{l}\text { No } \\
\text { No }\end{array}$ \\
\hline 96. & ...you felt as if everyone was talking about you? & $\begin{array}{l}\text { Do Not } \\
\text { Know }\end{array}$ & Yes & No \\
\hline 97. & $\begin{array}{l}\text {...you heard voices speaking against you, or voices that were hostile to } \\
\text { you or swore at you? }\end{array}$ & $\begin{array}{l}\text { Do Not } \\
\text { Know }\end{array}$ & Yes & No \\
\hline 98. & $\begin{array}{l}\text { If you heard voices, did you hear those voices clearly? } \\
\text { ( )subject did not hear voices. }\end{array}$ & $\begin{array}{l}\text { Do Not } \\
\text { Know }\end{array}$ & Yes & No \\
\hline
\end{tabular}

In the course of your life, including when you were a child, have you ever had periods of at least 3-5 days in which...

\begin{tabular}{|c|l|l|l|l|}
\hline 99. & $\begin{array}{l}\text {...you thought there was nothing you could do to change the way things } \\
\text { were going or you saw the future as very bleak? }\end{array}$ & $\begin{array}{l}\text { Do Not } \\
\text { Know }\end{array}$ & Yes & No \\
\hline
\end{tabular}




\begin{tabular}{|c|c|c|c|c|}
\hline 100. & $\begin{array}{l}\text {...you felt as if you would like to run away from your current life, for } \\
\text { example, by getting on the highway and driving away or just getting on } \\
\text { a bus or a plane with no destination in mind? }\end{array}$ & $\begin{array}{l}\text { Do Not } \\
\text { Know }\end{array}$ & Yes & No \\
\hline 101. & ...you used sleep as an escape? & $\begin{array}{l}\text { Do Not } \\
\text { Know }\end{array}$ & Yes & No \\
\hline 102. & ...you thought that life was not worth living? & $\begin{array}{l}\text { Do Not } \\
\text { Know }\end{array}$ & Yes & No \\
\hline 103. & $\begin{array}{l}\text {...you hoped that you would not wake up in the morning, or that you } \\
\text { would die in an accident or from something like a heart attack or a } \\
\text { stroke? }\end{array}$ & $\begin{array}{l}\text { Do Not } \\
\text { Know }\end{array}$ & Yes & No \\
\hline 104. & ...you wanted to die or hurt yourself? & $\begin{array}{l}\text { Do Not } \\
\text { Know }\end{array}$ & Yes & No \\
\hline 105. & $\begin{array}{l}\text { If you felt that you wanted to die, did you have a specific plan to hurt or } \\
\text { kill yourself? } \\
\text { (.)subject never wanted to die. }\end{array}$ & $\begin{array}{l}\text { Do Not } \\
\text { Know }\end{array}$ & Yes & No \\
\hline 106. & Did you actually try to kill yourself? & $\begin{array}{l}\text { Do Not } \\
\text { Know }\end{array}$ & Yes & No \\
\hline 107. & $\begin{array}{l}\text { If you tried to kill yourself, did you require medical attention? ( ) subject } \\
\text { never tried to kill him or herself. }\end{array}$ & $\begin{array}{l}\text { Do Not } \\
\text { Know }\end{array}$ & Yes & No \\
\hline 108. & $\begin{array}{l}\text { If yo u answered YES to any of the questions from } 81 \text { to } 107, \text { were you } \\
\text { ever seriously impaired, worried or troubled by what was happening to } \\
\text { you? } \\
\text { ( ) subject did not answer YES to any of the above questions. }\end{array}$ & $\begin{array}{l}\text { Do Not } \\
\text { Know }\end{array}$ & Yes & No \\
\hline
\end{tabular}

The following questions refer to times when your thoughts were more positive.

In the course of your life, including when you were a child, have you ever had periods of at least 3-5 days in which...

\begin{tabular}{|c|l|l|l|l|}
\hline 109. & ...you (or others) thought you were very artistic and creative? & $\begin{array}{l}\text { Do Not } \\
\text { Know }\end{array}$ & Yes & No \\
\hline 110. & $\begin{array}{l}\text { fyou had bursts of inspiration or creativity (for instance, rapidly and } \\
\text { easily wrote prose or poetry or composed music, painted, sculpted, or } \\
\text { did other crafts)? }\end{array}$ & $\begin{array}{l}\text { Do Not } \\
\text { Know }\end{array}$ & Yes & No \\
\hline 111. & $\ldots$ you were particularly sensitive to the forms and harmony in nature? & $\begin{array}{l}\text { Do Not } \\
\text { Know }\end{array}$ & Yes & No \\
\hline 112. & $\ldots$ you were overly curious and interested in everything and everybody? & $\begin{array}{l}\text { Do Not } \\
\text { Know }\end{array}$ & Yes & No \\
\hline
\end{tabular}




\begin{tabular}{|c|c|c|c|c|}
\hline 113. & $\begin{array}{l}\text {...your housework, child care or your performance at school, work, } \\
\text { sports or hobbies improved a lot? }\end{array}$ & $\begin{array}{l}\text { Do Not } \\
\text { Know }\end{array}$ & Yes & No \\
\hline 114. & ...you felt really good about how you looked? & $\begin{array}{l}\text { Do Not } \\
\text { Know }\end{array}$ & Yes & No \\
\hline 115. & ...you felt you were mentally very sharp, brilliant and clever? & $\begin{array}{l}\text { Do Not } \\
\text { Know }\end{array}$ & Yes & No \\
\hline 116. & $\begin{array}{l}\text {...you felt self-assured, charismatic or tended to assume a leadership } \\
\text { role? }\end{array}$ & $\begin{array}{l}\text { Do Not } \\
\text { Know }\end{array}$ & Yes & No \\
\hline 117. & $\begin{array}{l}\text {...you felt you were always right, incapable of making mistakes and } \\
\text { indifferent to criticism? }\end{array}$ & $\begin{array}{l}\text { Do Not } \\
\text { Know }\end{array}$ & Yes & No \\
\hline 118. & $\begin{array}{l}\text {...you thought that you could make decisions for others because you } \\
\text { knew their thoughts, intentions, or wishes? }\end{array}$ & $\begin{array}{l}\text { Do Not } \\
\text { Know }\end{array}$ & Yes & No \\
\hline 119. & $\begin{array}{l}\text {...you felt unappreciated because others did not understand or share } \\
\text { your optimistic or imaginative ideas? }\end{array}$ & $\begin{array}{l}\text { Do Not } \\
\text { Know }\end{array}$ & Yes & No \\
\hline 120. & $\begin{array}{l}\text {...you had unusually high self-esteem, feelings of superiority or } \\
\text { unrealistic ideas that you had amazing abilities, talents, knowledge or } \\
\text { powers? }\end{array}$ & $\begin{array}{l}\text { Do Not } \\
\text { Know }\end{array}$ & Yes & No \\
\hline 121. & $\begin{array}{l}\text {...you felt particularly strong and invulnerable, resistant to illnesses and } \\
\text { accidents? }\end{array}$ & $\begin{array}{l}\text { Do Not } \\
\text { Know }\end{array}$ & Yes & No \\
\hline 122. & ...you were unusually spiritual or mystical? & $\begin{array}{l}\text { Do Not } \\
\text { Know }\end{array}$ & Yes & No \\
\hline 123. & $\begin{array}{l}\text {...you felt you had direct access to the truth, could see the grand } \\
\text { scheme of things, understand the meaning of existence? }\end{array}$ & $\begin{array}{l}\text { Do Not } \\
\text { Know }\end{array}$ & Yes & No \\
\hline 124. & ...you heard voices that inspired or praised you? & $\begin{array}{l}\text { Do Not } \\
\text { Know }\end{array}$ & Yes & No \\
\hline 125. & ...you were (or other people judged you to be) irresponsible? & $\begin{array}{l}\text { Do Not } \\
\text { Know }\end{array}$ & Yes & No \\
\hline 126. & $\begin{array}{l}\text {...you made very important decisions (such as selling or buying a house } \\
\text { or car, or changing jobs) extremely rapidly? }\end{array}$ & $\begin{array}{l}\text { Do Not } \\
\text { Know }\end{array}$ & Yes & No \\
\hline 127. & $\begin{array}{l}\text {...you did things such as: } \\
\text { a) spending too much money? } \\
\text { b) driving recklessly or speeding? }\end{array}$ & $\begin{array}{l}\text { Do Not } \\
\text { Know } \\
\text { Do Not } \\
\text { Know }\end{array}$ & $\begin{array}{l}\text { Yes } \\
\text { Yes }\end{array}$ & $\begin{array}{l}\text { No } \\
\text { No }\end{array}$ \\
\hline
\end{tabular}




\begin{tabular}{|c|c|c|c|c|}
\hline & c) making foolish business decisions? & $\begin{array}{l}\text { Do Not } \\
\text { Know }\end{array}$ & Yes & No \\
\hline 128. & $\begin{array}{l}\text {...you intended to ignore everyday rules and social etiquette or } \\
\text { engaged in illegal activities? }\end{array}$ & $\begin{array}{l}\text { Do Not } \\
\text { Know }\end{array}$ & Yes & No \\
\hline 129. & ...you had mystical experiences or visions? & $\begin{array}{l}\text { Do Not } \\
\text { Know }\end{array}$ & Yes & No \\
\hline 130. & ...you felt like you had ESP? & $\begin{array}{l}\text { Do Not } \\
\text { Know }\end{array}$ & Yes & No \\
\hline 131. & $\begin{array}{l}\text { If you answered YES to any of the questions from } 109 \text { to } 130 \text {, were you } \\
\text { ever seriously impaired, worried or troubled by what was happening to } \\
\text { you? } \\
\text { ( ) subject did not answer YES to any of the above questions. }\end{array}$ & $\begin{array}{l}\text { Do Not } \\
\text { Know }\end{array}$ & Yes & No \\
\hline
\end{tabular}

A lot of people have some variation in mood, energy, interest and efficiency over the course of the year or even over the course of the day.

\begin{tabular}{|c|l|l|l|l|}
\hline 132. & $\begin{array}{l}\text { Is it difficult (that is, more difficult than is common for your friends or } \\
\text { acquaintances) for you to work or be productive in the early morning? }\end{array}$ & $\begin{array}{l}\text { Do Not } \\
\text { Know }\end{array}$ & Yes & No \\
\hline 133. & $\begin{array}{l}\text { Is it difficult (that is, more difficult than is common for your friends or } \\
\text { acquaintances) for you to work or be productive in the evening or night? }\end{array}$ & $\begin{array}{l}\text { Do Not } \\
\text { Know }\end{array}$ & Yes & No \\
\hline 134. & $\begin{array}{l}\text { Do you become irritable or have difficulty functioning if your daily routine } \\
\text { is disrup ted (for instance, if you had to get up, eat or work at a time that } \\
\text { wasn't usual for you)? }\end{array}$ & $\begin{array}{l}\text { Do Not } \\
\text { Know }\end{array}$ & Yes & No \\
\hline 135. & $\begin{array}{l}\text { Do you find that your mood, energy, interest and efficiency improve if } \\
\text { you are in a regular routine? }\end{array}$ & $\begin{array}{l}\text { Do Not } \\
\text { Know }\end{array}$ & Yes & No \\
\hline 136. & $\begin{array}{l}\text { If, for some reason, you get much less sleep than is normal for you, do } \\
\text { you find that you actually have more energy rather than less the next } \\
\text { day? } \\
\text { Note: Do not count travel across time zones in response to this } \\
\text { question. }\end{array}$ & $\begin{array}{l}\text { Do Not } \\
\text { Know } \\
\text { Are you the kind of person whose mood, energy and physical well-being } \\
\text { change: }\end{array}$ & $\begin{array}{l}\text { Yes } \\
\text { b) in a dependable way in response to the weather (for example, when }\end{array}$ & $\begin{array}{l}\text { No } \\
\text { Know } \\
\text { Do Not } \\
\text { Know }\end{array}$ \\
\hline 137. & Yes & Yes \\
\hline
\end{tabular}




\begin{tabular}{|l|l|l|c|c|}
\hline $\begin{array}{l}\text { c) when you travel across more than 4 times zones? } \\
\text { ()subject has never traveled across more than 4 time zones }\end{array}$ & $\begin{array}{l}\text { Do Not } \\
\text { Know } \\
\text { d) over the course of your menstrual cycle? } \\
\text { () subject has never had menstrual cycles }\end{array}$ & $\begin{array}{c}\text { Do Not } \\
\text { Know }\end{array}$ & Yes & No \\
\hline
\end{tabular}

In the course of your life, including when you were a child, have you ever had periods of at least 3-5 days in which...

\begin{tabular}{|c|c|c|c|c|}
\hline 138. & ...you felt sleepy all the time? Note: Not due to work schedules. & $\begin{array}{l}\text { Do Not } \\
\text { Know }\end{array}$ & Yes & No \\
\hline 139. & $\begin{array}{l}\text {...you repeatedly had difficulty falling asleep? Note: Not due to work } \\
\text { schedules. }\end{array}$ & $\begin{array}{l}\text { Do Not } \\
\text { Know }\end{array}$ & Yes & No \\
\hline 140. & $\begin{array}{l}\text {...you repeatedly woke up in the middle of the night and had difficulty } \\
\text { falling asleep again? Note: Not due to work schedules. }\end{array}$ & $\begin{array}{l}\text { Do Not } \\
\text { Know }\end{array}$ & Yes & No \\
\hline 141. & $\begin{array}{l}\text {...you repeatedly woke up much earlier than you wanted to, and were } \\
\text { unable to go back to sleep? Note: Not due to work schedules. }\end{array}$ & $\begin{array}{l}\text { Do Not } \\
\text { Know }\end{array}$ & Yes & No \\
\hline 142. & $\begin{array}{l}\text {...you needed much more sleep than usual either at night or during the } \\
\text { day? Note: Not due to work schedules. }\end{array}$ & $\begin{array}{l}\text { Do Not } \\
\text { Know }\end{array}$ & Yes & No \\
\hline 143. & $\begin{array}{l}\text {...you went for days without sleeping or with much less sleep than usual } \\
\text { but didn't feel tired? }\end{array}$ & $\begin{array}{l}\text { Do Not } \\
\text { Know }\end{array}$ & Yes & No \\
\hline 144. & $\begin{array}{l}\text { Do you have a lot of difficulty sleeping before or after stimulating } \\
\text { physical, social, or professional activities (such as a vacation or a trip, } \\
\text { or starting a new school year or a new work assignment)? }\end{array}$ & $\begin{array}{l}\text { Do Not } \\
\text { Know }\end{array}$ & Yes & No \\
\hline
\end{tabular}

Some people find that their sleep changes a lot either in a particular season of the year, or when the seasons change, or when they travel across time zones, or (if female) over the course of the menstrual cycle.

\begin{tabular}{|c|l|l|l|l|}
\hline 145. & $\begin{array}{l}\text { Does the quality of your sleep or your need for sleep increase in a } \\
\text { particular season of the year or during the change of seasons? }\end{array}$ & $\begin{array}{l}\text { Do Not } \\
\text { Know }\end{array}$ & Yes & No \\
\hline 146. & $\begin{array}{l}\text { Does the quality of your sleep or your need for sleep increase when you } \\
\text { travel across at least } 4 \text { time zones? } \\
\text { (.) subject has never traveled across more than 4 time zones. }\end{array}$ & $\begin{array}{l}\text { Do Not } \\
\text { Know }\end{array}$ & Yes & No \\
\hline 147. & $\begin{array}{l}\text { Does the quality of your sleep or your need for sleep decrease when } \\
\text { you travel across more than at least 4 time zones? } \\
\text { () subject has never traveled across more than 4 time zones. }\end{array}$ & $\begin{array}{l}\text { Do Not } \\
\text { Know }\end{array}$ & Yes & No \\
\hline
\end{tabular}




\begin{tabular}{|c|l|l|l|l|}
\hline 148. & $\begin{array}{l}\text { Does the quality of your sleep or your need for sleep increase over the } \\
\text { course of the menstrual cycle? } \\
\text { () subject has never had menstrual cycles. }\end{array}$ & $\begin{array}{l}\text { Do Not } \\
\text { Know }\end{array}$ & Yes & No \\
\hline 149. & $\begin{array}{l}\text { Does the quality of your sleep or your need for sleep decrease over the } \\
\text { course of the menstrual cycle? } \\
\text { ( ) subject has never had menstrual cycles. }\end{array}$ & $\begin{array}{l}\text { Do Not Know } \\
\text { Knos }\end{array}$ & Yes \\
\hline
\end{tabular}

The following questions refer to changes in your appetite, sexual interest or experiences, or to physical symptoms that you may have experienced. We are only interested in changes that may have occurred at times other than when you were pregnant, nursing, physically ill or taking medications.

In the course of your life, including when you were a child, have you ever had periods of at least 3-5 days in which...

\begin{tabular}{|c|l|l|l|l|}
\hline 150. & $\ldots$ there was no food that appealed to you or tasted good to you? & $\begin{array}{l}\text { Do Not } \\
\text { Know }\end{array}$ & Yes & No \\
\hline 151. & $\ldots$ you constantly craved sweets or carbohydrates? & $\begin{array}{l}\text { Do Not } \\
\text { Know }\end{array}$ & Yes & No \\
\hline 152. & $\ldots$ your appetite or weight increased? & $\begin{array}{l}\text { Do Not } \\
\text { Know }\end{array}$ & Yes & No \\
\hline 153. & $\ldots$ your appetite or weight decreased? & $\begin{array}{l}\text { Do Not } \\
\text { Know }\end{array}$ & Yes & No \\
\hline
\end{tabular}

The following questions are about changes in your sexual interest or experiences.

In the course of your life have you ever had periods of at least 3-5 days in which...

\begin{tabular}{|c|l|l|l|c|}
\hline 154. & $\ldots$ you were less sexually active than is typical for you? & $\begin{array}{l}\text { Do Not } \\
\text { Know }\end{array}$ & Yes & No \\
\hline 155. & $\ldots$ you had difficulty becoming sexually aroused? & $\begin{array}{l}\text { Do Not } \\
\text { Know }\end{array}$ & Yes & No \\
\hline 156. & $\ldots$ you had difficulty achieving orgasm? & $\begin{array}{l}\text { Do Not } \\
\text { Know }\end{array}$ & Yes & No \\
\hline 157. & $\ldots$ you were more interested in sex? & $\begin{array}{l}\text { Do Not } \\
\text { Know }\end{array}$ & Yes & No \\
\hline 158. & $\ldots$ you frequently changed sexual partners? & $\begin{array}{l}\text { Do Not } \\
\text { Know }\end{array}$ & Yes & No \\
\hline
\end{tabular}

In the course of your life, including when you were a child, have you ever had periods of at least 3-5 days in which... 


\begin{tabular}{|c|c|c|c|c|}
\hline \multirow[t]{2}{*}{159.} & $\begin{array}{l}\text {...you repeatedly had distressing physical symptoms, for instance: } \\
\text { a) frequent headaches? } \\
\text { b) your mouth felt dry? } \\
\text { c) you were constipated? }\end{array}$ & $\begin{array}{l}\text { Do } \\
\text { Not } \\
\text { Know } \\
\text { Do } \\
\text { Not } \\
\text { Know } \\
\text { Do } \\
\text { Not } \\
\text { Know }\end{array}$ & $\begin{array}{l}\text { Yes } \\
\text { Yes } \\
\text { Yes }\end{array}$ & $\begin{array}{l}\text { No } \\
\text { No } \\
\text { No }\end{array}$ \\
\hline & d) you had nausea or other stomach or bowel problems? & $\begin{array}{l}\text { Do } \\
\text { Not } \\
\text { Know }\end{array}$ & Yes & No \\
\hline 160. & $\begin{array}{l}\text {...you were more sensitive or less sensitive than usual to heat, cold or } \\
\text { pain? }\end{array}$ & $\begin{array}{l}\text { Do } \\
\text { Not } \\
\text { Know }\end{array}$ & Yes & No \\
\hline 161. & $\begin{array}{l}\text { If you answered YES to any of the questions from } 132 \text { to } 160 \text {, were you } \\
\text { ever seriously impaired, worried or troubled by what was happening to } \\
\text { you? subject did not answer YES to any of the above questions. }\end{array}$ & $\begin{array}{l}\text { Do } \\
\text { Not } \\
\text { Know }\end{array}$ & Yes & No \\
\hline
\end{tabular}


6.2) ANEXO B. VERSÃO FINAL DA SCI-MOODS-VP

\title{
Entrevista Clinica Estruturada para o Espectro do Humor - SCI-MOODS -
}

Versão 3.0

\author{
Cassano GB, Shear MK, Michelini S, Coli E, Frank E, Maser JD, Mauri M, \\ Dell Osso L
}

\author{
Versão brasileira traduzida - Junho 2005 \\ Moreno RA, Moreno DH, Ratzke R
}

Grupo de Estudos de Doenças Afetivas (GRUDA) - Instituto de Psiquiatria- Hospital das Cínicas da Faculdade de Medicina da Universidade de São Paulo

Rua Dr. Ovidio Pires de Campos s/n

05403-010 - São Paulo, Brasil

Telefone: 55-11-30696648

Fax: 55-11-30697894

Identificação:

Sujeito: Registro

Entrevistador: Data:

\section{INTRODUÇÃO: ESPECTRO DO HUMOR}

Obrigado(a) por ter vindo conversar comigo hoje. A entrevista que vamos fazer agora estará voltada para alguns sintomas que você pode ou não ter experimentado na sua vida. Nós queremos identificar se você teve esses sintomas, mesmo se foi há muito tempo, e principalmente se eles incomodaram ou perturbaram você. A entrevista tem quatro etapas e deve durar cerca de uma hora. Você tem alguma pergunta antes de começarmos?

\section{DOMÍNIO I HUMOR}

Eu vou fazer perguntas sobre situações que podem ter ocorrido com você no passado ou atualmente.

O primeiro grupo de perguntas refere-se ao seu humor.

Durante a sua vida, inclusive quando você era criança, você teve períodos de pelo menos 3 a 5 dias nos quais...

\begin{tabular}{|l|l|l|l|l|}
\hline 1 & $\begin{array}{l}\text {...você se sentiu frustrado(a) ou derrotado(a), apesar de não } \\
\text { conseguir pensar em qualquer razão para isso? }\end{array}$ & não sei & sim & não \\
\hline 2 & ..você se sentiu muito nostálgico(a) ou saudoso(a)? & não sei & sim & não \\
\hline
\end{tabular}




\begin{tabular}{|c|c|c|c|c|}
\hline 3 & $\begin{array}{l}\text {...você se sentiu solitário(a)? } \\
\text { Nota: sem perda real de amigos ou pessoas amadas }\end{array}$ & não sei & $\operatorname{sim}$ & não \\
\hline 4 & ...você ficava introvertido(a), sério(a) ou abatido(a)? & não sei & $\operatorname{sim}$ & não \\
\hline 5 & ...você se sentiu entediado(a)? & não sei & $\operatorname{sim}$ & não \\
\hline 6 & ... você se sentiu extremamente incomodado(a) com tudo? & não sei & sim & não \\
\hline 7 & ...as menores coisas deixavam você triste? & não sei & $\operatorname{sim}$ & não \\
\hline 8 & $\begin{array}{l}\text {... você perdeu completamente a vontade de rir, se divertir, } \\
\text { aproveitar a vida? }\end{array}$ & não sei & $\operatorname{sim}$ & não \\
\hline 9 & $\begin{array}{l}\text {...você achou realmente difícil aceitar rejeições, particularmente } \\
\text { as que envolviam amizades ou relacionamentos românticos? }\end{array}$ & não sei & sim & não \\
\hline 10 & $\begin{array}{l}\text {...você se sentiu triste, vazio(a) ou muito infeliz por longos } \\
\text { períodos? }\end{array}$ & não sei & $\operatorname{sim}$ & não \\
\hline
\end{tabular}

Durante a sua vida, inclusive quando você era criança, você teve períodos de pelo menos 3 a 5 dias nos quais...

\begin{tabular}{|c|c|c|c|c|}
\hline 11 & ...você chorava com facilidade? & não sei & $\operatorname{sim}$ & não \\
\hline 12 & ...você se queixava constantemente? & não sei & $\operatorname{sim}$ & não \\
\hline 13 & $\begin{array}{l}\text {...você se sentiu sem objetivos, como se tudo tivesse perdido o } \\
\text { sentido? }\end{array}$ & não sei & sim & não \\
\hline 14 & ...você perdeu o interesse na sua aparência? & não sei & $\operatorname{sim}$ & não \\
\hline 15 & ...nada que você vestisse parecia cair bem? & não sei & sim & não \\
\hline 16 & $\begin{array}{l}\text {...você ficou deprimido quando teve algum problema médico, } \\
\text { como gripe ou resfriado? }\end{array}$ & não sei & sim & não \\
\hline 17 & $\begin{array}{l}\text {...você ficou deprimido ao tomar medicações como antibióticos, } \\
\text { anticoncepcionais ou esteróides? } \\
\text { ( ) a pessoa nunca tomou estas medicações }\end{array}$ & não sei & $\operatorname{sim}$ & não \\
\hline 18 & $\begin{array}{l}\text {...você ficou deprimido ao usar muito álcool, pílulas para dormir, } \\
\text { remédios para ansiedade, maconha ou substâncias semelhantes? } \\
\text { ( ) a pessoa nunca tomou estas substâncias }\end{array}$ & não sei & $\operatorname{sim}$ & não \\
\hline 19 & $\begin{array}{l}\text {...você ficou deprimido um mês após ter parado de tomar alguma } \\
\text { dessas substâncias? } \\
\text { ( ) a pessoa nunca tomou estas substâncias }\end{array}$ & não sei & $\operatorname{sim}$ & não \\
\hline 20 & $\begin{array}{l}\text {...você ficou deprimido ao usar álcool, pílulas para dormir, } \\
\text { remédios para ansiedade, nicotina, cafeína, estimulantes ou } \\
\text { substâncias semelhantes, mesmo tomando essas substâncias } \\
\text { para se sentir bem? } \\
\text { ( ) a pessoa nunca tomou estas substâncias }\end{array}$ & não sei & $\operatorname{sim}$ & não \\
\hline 21 & $\begin{array}{l}\text {... você perdeu o interesse e o prazer na sua vida social e preferia } \\
\text { passar a maior parte do tempo sozinho(a), afastando-se de } \\
\text { família e amigos? }\end{array}$ & não sei & $\operatorname{sim}$ & não \\
\hline 22 & $\begin{array}{l}\text {...você perdeu o interesse em fazer novos amigos ou achava } \\
\text { difícil fazer novos amigos? }\end{array}$ & não sei & $\operatorname{sim}$ & não \\
\hline
\end{tabular}

Durante a sua vida, inclusive quando você era criança, você teve períodos de pelo menos 3 a 5 dias nos quais...

\begin{tabular}{|l|l|l|l|l|}
\hline 23 & ...você perdeu o interesse na sua vida afetiva? & não sei & sim & não \\
\hline 24 & Sua vida afetiva sempre foi muito limitada? & não sei & sim & não \\
\hline 25 & $\begin{array}{l}\text {..você perdeu o interesse nos hobbies, jogos ou esportes que } \\
\text { praticava? }\end{array}$ & não sei & sim & não \\
\hline 26 & $\begin{array}{l}\text {...você se sentiu indiferente a respeito de tudo (seja positivo ou } \\
\text { negativo) que aconteceu com você ou sua família? }\end{array}$ & não sei & sim & não \\
\hline 27 & $\begin{array}{l}\text {.. você perdeu o interesse ou o prazer em todas ou quase todas } \\
\text { as coisas de que você costumava gostar? }\end{array}$ & não sei & sim & não \\
\hline 28 & Se você respondeu SIM a qualquer uma das questões de 1 a 27, & não sei & sim & não \\
\hline
\end{tabular}


você se sentiu muito prejudicado(a), preocupado(a) ou perturbado(a) pelo que estava acontecendo com você?

Durante a sua vida, inclusive quando você era criança, você teve períodos de pelo menos 3 a 5 dias nos quais...

\begin{tabular}{|c|c|c|c|c|}
\hline 29 & ...você se sentiu bem ou eufórico por longos períodos? & não sei & sim & não \\
\hline 30 & $\begin{array}{l}\text {...você achou (ou outros acharam) que seu senso de humor ou } \\
\text { ironia estava muito afiado(a)? }\end{array}$ & não sei & $\operatorname{sim}$ & não \\
\hline 31 & ...mesmo a menor coisa deixava você muito entusiasmado(a)? & não sei & sim & não \\
\hline 32 & ...você gostava de fazer trocadilhos ou brincar com as palavras? & não sei & $\operatorname{sim}$ & não \\
\hline 33 & $\begin{array}{l}\text {...você gostava de fazer muitas piadas (mesmo aquelas que } \\
\text { poderiam ser impróprias ou inadequadas)? }\end{array}$ & não sei & $\operatorname{sim}$ & não \\
\hline 34 & $\begin{array}{l}\text {...você foi intrometido(a), agressivo(a), inoportuno(a) ou outros } \\
\text { acharam que você foi? }\end{array}$ & não sei & $\operatorname{sim}$ & não \\
\hline 35 & $\begin{array}{l}\text {...você achou muito agradável e fácil comprar coisas, mesmo } \\
\text { aquelas de que você não precisava? }\end{array}$ & não sei & sim & não \\
\hline 36 & $\begin{array}{l}\text {...você deu muitos presentes, mesmo quando não estava em } \\
\text { condições de pagá-los? }\end{array}$ & não sei & sim & não \\
\hline
\end{tabular}

Durante a sua vida, inclusive quando você era criança, você teve períodos de pelo menos 3 a 5 dias nos quais...

\begin{tabular}{|c|c|c|c|c|}
\hline 37 & $\begin{array}{l}\text {...você ficou eufórico(a), extrovertido(a) e sociável e era muito fácil } \\
\text { se apresentar a outros e fazer novos amigos? }\end{array}$ & não sei & $\operatorname{sim}$ & não \\
\hline 38 & $\begin{array}{l}\text {...você foi o tipo de pessoa que atraía os outros por causa de sua } \\
\text { confiança, energia e entusiasmo? }\end{array}$ & não sei & $\operatorname{sim}$ & não \\
\hline 39 & ...você era muito divertido(a) em casa ou restaurantes? & não sei & $\operatorname{sim}$ & não \\
\hline 40 & $\begin{array}{l}\text {... você se divertiu sendo o centro das atenções ou foi } \\
\text { particularmente sedutor(a) ou namorador(a), como se estivesse } \\
\text { desempenhando um papel? }\end{array}$ & não sei & $\operatorname{sim}$ & não \\
\hline 41 & ...você teve uma vida afetiva particularmente intensa? & não sei & $\operatorname{sim}$ & não \\
\hline 42 & Você é uma pessoa que sempre teve uma vida afetiva intensa? & não sei & $\operatorname{sim}$ & não \\
\hline
\end{tabular}

Durante a sua vida, inclusive quando você era criança, você teve períodos de pelo menos 3 a 5 dias nos quais...

\begin{tabular}{|c|c|c|c|c|}
\hline 43 & $\begin{array}{l}\text {...você se vestiu ou usou um penteado que era chamativo, } \\
\text { extravagante, muito na moda ou incomum? }\end{array}$ & não sei & sim & não \\
\hline 44 & $\begin{array}{l}\text {...você ficou cheio(a) de planos ou se envolveu em muitos } \\
\text { projetos, pulando de uma atividade para outra? }\end{array}$ & não sei & $\operatorname{sim}$ & não \\
\hline 45 & $\begin{array}{l}\text {...você teve dificuldade de dizer "não" para oportunidades sociais } \\
\text { ou de negócios, mesmo quando sabia que não tinha tempo para } \\
\text { elas? }\end{array}$ & não sei & sim & não \\
\hline 46 & $\begin{array}{l}\text {...você freqüentemente mudou (mais freqüentemente que o usual } \\
\text { para seus amigos e conhecidos): } \\
\text { a) de emprego? } \\
\text { b) de endereço? } \\
\text { c) de amigos? } \\
\text { d) de esportes e hobbies favoritos? }\end{array}$ & $\begin{array}{l}\text { não sei } \\
\text { não sei } \\
\text { não sei } \\
\text { não sei }\end{array}$ & $\begin{array}{l}\text { sim } \\
\text { sim } \\
\text { sim } \\
\text { sim }\end{array}$ & $\begin{array}{l}\text { não } \\
\text { não } \\
\text { não } \\
\text { não }\end{array}$ \\
\hline 47 & $\begin{array}{l}\text {...você achou muito prazeroso e excitante envolver-se em } \\
\text { atividades perigosas, arriscadas, desafiadoras } \\
\text { emocionalmente intensas? }\end{array}$ & não sei & $\operatorname{sim}$ & não \\
\hline 48 & $\begin{array}{l}\text {...você ficou inclinado a fazer o contrário do que as pessoas } \\
\text { queriam que você fizesse ou agiu como advogado(a) do diabo? }\end{array}$ & não sei & $\operatorname{sim}$ & não \\
\hline
\end{tabular}

Durante a sua vida, inclusive quando você era criança, você teve períodos de pelo menos 3 a 5 dias nos quais... 


\begin{tabular}{|c|c|c|c|c|}
\hline 49 & $\begin{array}{l}\text {...seu humor mudou rapidamente de alegre para triste e voltou a } \\
\text { alegre? }\end{array}$ & não sei & $\operatorname{sim}$ & não \\
\hline 50 & ...você percebeu que ria e chorava ao mesmo tempo? & não sei & $\operatorname{sim}$ & não \\
\hline 51 & $\begin{array}{l}\text {..você ficava muito irritado? Por exemplo: } \\
\text { a) mesmo a menor coisa o(a) deixava muito irritado(a)? } \\
\text { b) você achou que estava particularmente crítico(a) ou } \\
\text { sarcástico(a)? } \\
\text { c) você tinha grande dificuldade de aceitar os pontos de vista dos } \\
\text { outros? } \\
\text { d) você foi contestador(a) ou hostil de um jeito que não } \\
\text { costumava ser? }\end{array}$ & $\begin{array}{l}\text { não sei } \\
\text { não sei } \\
\text { não sei } \\
\text { não sei }\end{array}$ & $\begin{array}{l}\operatorname{sim} \\
\operatorname{sim} \\
\operatorname{sim} \\
\operatorname{sim}\end{array}$ & $\begin{array}{l}\text { não } \\
\text { não } \\
\text { não } \\
\text { não }\end{array}$ \\
\hline 52 & $\begin{array}{l}\text {...você teve dificuldade de controlar seu temperamento? Por } \\
\text { exemplo: } \\
\text { a) você sentiu que realmente precisava dar o troco? } \\
\text { b) você se viu gritando com os outros ou começando discussões } \\
\text { ou brigas mesmo sobre assuntos sem nenhuma importância? }\end{array}$ & $\begin{array}{l}\text { não sei } \\
\text { não sei }\end{array}$ & $\begin{array}{l}\operatorname{sim} \\
\operatorname{sim}\end{array}$ & $\begin{array}{l}\text { não } \\
\text { não }\end{array}$ \\
\hline 53 & $\begin{array}{l}\text {...você ficou irritado(a) ou exaltado(a) quando teve um problema } \\
\text { médico, como uma gripe ou resfriado? }\end{array}$ & não sei & $\operatorname{sim}$ & não \\
\hline 54 & $\begin{array}{l}\text {...você ficou irritado(a) ou exaltado(a) quando tomou medicações } \\
\text { (que não foram prescritas para alterar o humor), como } \\
\text { antibióticos, anticoncepcionais e esteróides? } \\
\text { () a pessoa nunca tomou estas medicações }\end{array}$ & não sei & $\operatorname{sim}$ & não \\
\hline 55 & $\begin{array}{l}\text {... você ficou irritado(a) ou exaltado(a) quando claramente abusou } \\
\text { de álcool, sedativos, hipnóticos, ansiolíticos ou outras substâncias } \\
\text { ou em um mês de abstinência? } \\
\text { ( ) a pessoa nunca tomou estas substâncias }\end{array}$ & não sei & $\operatorname{sim}$ & não \\
\hline 56 & $\begin{array}{l}\text {...você ficou realmente mais irritado(a) ou exaltado(a) quando } \\
\text { aumentou seu consumo de álcool, sedativos, nicotina, cafeína, } \\
\text { estimulantes e substâncias similares e você já estava irritado(a) } \\
\text { ou exaltado(a)? } \\
\text { () a pessoa nunca tomou estas substâncias }\end{array}$ & não sei & $\operatorname{sim}$ & não \\
\hline 57 & $\begin{array}{l}\text { Se você respondeu SIM às questões de } 29 \text { a } 56 \text {, você se sentiu } \\
\text { muito prejudicado(a), preocupado(a) ou perturbado(a) pelo que } \\
\text { estava acontecendo com você? } \\
\text { () a pessoa não respondeu SIM a nenhuma questão acima }\end{array}$ & não sei & $\operatorname{sim}$ & não \\
\hline
\end{tabular}

\section{DOMÍNIO II ENERGIA}

O próximo grupo de questões refere-se à sua energia e ao seu nível de atividade.

Durante a sua vida, inclusive quando você era criança, você teve períodos de pelo menos 3 a 5 dias nos quais...

\begin{tabular}{|c|c|c|c|c|}
\hline 58 & ...você tinha dificuldade de fazer qualquer coisa? & não sei & $\operatorname{sim}$ & não \\
\hline 59 & $\begin{array}{l}\text {...você se sentia lento(a), como se todos os seus movimentos } \\
\text { fossem em câmera lenta? }\end{array}$ & não sei & $\operatorname{sim}$ & não \\
\hline 60 & ...sua fala e/ou pensamento parecia $(\mathrm{m})$ lento $(\mathrm{a})(\mathrm{s}) ?$ & não sei & $\operatorname{sim}$ & não \\
\hline 61 & $\begin{array}{l}\text {...você percebia o tempo passar muito lentamente e se sentia } \\
\text { pesado(a)? }\end{array}$ & não sei & $\operatorname{sim}$ & não \\
\hline 62 & $\begin{array}{l}\text {...você se sentia apático(a), preguiçoso(a) e não conseguia } \\
\text { cumprir seus compromissos e responsabilidades habituais? }\end{array}$ & não sei & $\operatorname{sim}$ & não \\
\hline 63 & ...você sentia dificuldade de levantar da cama pela manhã? & não sei & $\operatorname{sim}$ & não \\
\hline 64 & $\begin{array}{l}\text {...você tinha dificuldade de se cuidar (por exemplo, tomava menos } \\
\text { banho, usava as mesmas roupas, não se maquiava ou } \\
\text { barbeava?) }\end{array}$ & não sei & sim & não \\
\hline 65 & ...você se sentia cansado(a), fraco(a) ou fatigado(a), como se a & não sei & sim & não \\
\hline
\end{tabular}


menor tarefa (por exemplo, lavar o rosto ou encher o açucareiro) fosse um esforço que exigisse muita energia? sentado(a) ou precisava andar pelo quarto ou ficar constantemente em movimento?

67 Se você respondeu SIM a qualquer das questões de 58 a 66, você se sentiu muito prejudicado(a), preocupado(a) ou perturbado(a) pelo que estava acontecendo com você? () a pessoa não respondeu SIM a nenhuma questão acima

As questões a seguir referem-se a períodos nos quais você pode ter estado com mais energia que o habitual.

Durante a sua vida, inclusive quando você era criança, você teve períodos de pelo menos 3 a 5 dias nos quais...

\begin{tabular}{|c|c|c|c|c|}
\hline 68 & $\begin{array}{l}\text {...você sentiu uma necessidade irresistível de se comunicar por } \\
\text { telefonemas, cartas, e-mails ou faxes? }\end{array}$ & não sei & $\operatorname{sim}$ & não \\
\hline 69 & $\begin{array}{l}\text {...você sentiu um forte desejo de voltar a entrar em contato com } \\
\text { pessoas que não via ou falava há bastante tempo? }\end{array}$ & não sei & $\operatorname{sim}$ & não \\
\hline 70 & $\begin{array}{l}\text {...você ficava muito falante, falava alto e rapidamente ou não } \\
\text { deixava interrompê-lo(a) ou dava pouca importância ao desejo de } \\
\text { outros falarem? }\end{array}$ & não sei & $\operatorname{sim}$ & não \\
\hline 71 & $\begin{array}{l}\text {...você era tão barulhento(a) que outros reclamavam (por } \\
\text { exemplo, mantinha seu rádio ou televisão muito altos)? }\end{array}$ & não sei & $\operatorname{sim}$ & não \\
\hline 72 & $\begin{array}{l}\text {...você sentia que suas idéias iam e vinham com facilidade de um } \\
\text { jeito fora do comum, como se seus pensamentos estivessem } \\
\text { correndo? }\end{array}$ & não sei & $\operatorname{sim}$ & não \\
\hline 73 & $\begin{array}{l}\text {...você tinha tantos pensamentos e idéias ao mesmo tempo que } \\
\text { achava difícil expressá-los? }\end{array}$ & não sei & $\operatorname{sim}$ & não \\
\hline 74 & $\begin{array}{l}\text {.. seus interesses mudavam constantemente e você se distraía } \\
\text { facilmente, a ponto de ser difícil terminar de ler um artigo de jornal } \\
\text { ou revista ou assistir a um programa de televisão do início ao fim? }\end{array}$ & não sei & sim & não \\
\hline 75 & $\begin{array}{l}\text {...você gastou bastante tempo envolvido em causas políticas, } \\
\text { sociais ou religiosas? }\end{array}$ & não sei & $\operatorname{sim}$ & não \\
\hline 76 & $\begin{array}{l}\text {...você fazia afirmações sem se importar com o que os outros iam } \\
\text { pensar? }\end{array}$ & não sei & $\operatorname{sim}$ & não \\
\hline 77 & $\begin{array}{l}\text {...você se sentiu cheio de vigor e mais cheio(a) de vida que o } \\
\text { habitual e cheio(a) de energia? }\end{array}$ & não sei & $\operatorname{sim}$ & não \\
\hline 78 & ...você ficava muito impaciente? & não sei & $\operatorname{sim}$ & não \\
\hline 79 & $\begin{array}{l}\text {...você ficava em constante atividade e tinha a sensação } \\
\text { agradável de nunca se cansar e sua energia era tanta que } \\
\text { cansava ou irritava os outros? }\end{array}$ & não sei & sim & não \\
\hline 80 & $\begin{array}{l}\text { Se você respondeu SIM a qualquer das questões de } 68 \text { a } 79 \text {, } \\
\text { você se sentiu muito prejudicado(a), preocupado(a) ou } \\
\text { perturbado(a) pelo que estava acontecendo com você? } \\
\text { () a pessoa não respondeu SIM a nenhuma questão acima }\end{array}$ & não sei & $\operatorname{sim}$ & não \\
\hline
\end{tabular}

\section{DOMíNIO III FUNÇÃO COGNITIVA}

As questões a seguir referem-se aos seus pensamentos.

Durante a sua vida, inclusive quando você era criança, você teve períodos de pelo menos 3 a 5 dias nos quais... 


\begin{tabular}{|c|c|c|c|c|}
\hline 81 & $\begin{array}{l}\text {...você ficou hipercrítico(a) ou cético(a) em relação ao que as } \\
\text { pessoas em geral valorizam na vida? }\end{array}$ & não sei & $\operatorname{sim}$ & não \\
\hline 82 & $\begin{array}{l}\text {...você ficou preocupado(a) consigo mesmo(a) e } \\
\text { problemas, pensamentos ou sentimentos? }\end{array}$ & não sei & $\operatorname{sim}$ & não \\
\hline 83 & $\begin{array}{l}\text {...você ficou muito vulnerável ou teve constantemente medo de } \\
\text { fazer alguma coisa de errado? }\end{array}$ & não sei & $\operatorname{sim}$ & não \\
\hline 84 & $\begin{array}{l}\text {...você ficou desapontado(a) consigo mesmo(a), sentiu-se inútil, } \\
\text { como se não tivesse nenhum talento e não pudesse fazer nada } \\
\text { certo? }\end{array}$ & não sei & sim & não \\
\hline 85 & $\begin{array}{l}\text {...você se sentiu como se seu corpo estivesse doente ou de } \\
\text { alguma forma transformado? }\end{array}$ & não sei & sim & não \\
\hline 86 & $\begin{array}{l}\text {...você ficou muito preocupado(a) com dinheiro, mesmo que não } \\
\text { tivesse nenhum problema financeiro? }\end{array}$ & não sei & sim & não \\
\hline 87 & $\begin{array}{l}\text {...você sentiu uma forte necessidade de buscar ajuda em oração } \\
\text { ou religião? }\end{array}$ & não sei & sim & não \\
\hline 88 & $\begin{array}{l}\text {...você teve problemas com sua memória, como dificuldade para } \\
\text { encontrar a palavra certa ou para se lembrar de coisas que } \\
\text { deveria facilmente se lembrar? } \\
\text { Nota: não devido a medicações ou doenças físicas }\end{array}$ & não sei & sim & não \\
\hline 89 & $\begin{array}{l}\text {...seu desempenho piorou no trabalho doméstico, no cuidado das } \\
\text { crianças, na escola, nos esportes ou nos hobbies? } \\
\text { Nota: não devido a medicações ou doenças físicas }\end{array}$ & não sei & sim & não \\
\hline 90 & $\begin{array}{l}\text {...você teve dificuldade de tomar decisões, por menores que } \\
\text { fossem (como que roupas usar, que trabalho doméstico fazer } \\
\text { primeiro)? }\end{array}$ & não sei & sim & não \\
\hline 91 & $\begin{array}{l}\text {...você teve muita dificuldade de pensar e se concentrar, como } \\
\text { problema em participar de uma discussão, leitura, escrever, fazer } \\
\text { contas ou acompanhar um programa de televisão, artigo de } \\
\text { jornal ou revista? } \\
\text { Nota: não devido a medicações ou doenças físicas }\end{array}$ & não sei & $\operatorname{sim}$ & não \\
\hline 92 & $\begin{array}{l}\text {...você se sentiu mentalmente entorpecido(a) ou confuso(a)? } \\
\text { Nota: não devido a medicações ou doenças físicas }\end{array}$ & não sei & $\operatorname{sim}$ & não \\
\hline
\end{tabular}

Durante a sua vida, inclusive quando você era criança, você teve períodos de pelo menos 3 a 5 dias nos quais...

\begin{tabular}{|c|c|c|c|c|}
\hline 93 & $\begin{array}{l}\text {...você se sentiu culpado(a) ou com remorso, por exemplo: } \\
\text { a) pensou que deveria ser culpado(a) até mesmo por problemas } \\
\text { que outros estavam vivendo? } \\
\text { b) sentiu que você não poderia fazer o suficiente pela sua } \\
\text { família, patrão, colegas de trabalho? } \\
\text { c) pensou muito sobre coisas do passado que gostaria de ter } \\
\text { feito diferente? } \\
\text { d) achou que deveria ser punido(a) por todas as coisas ruins que } \\
\text { fez? }\end{array}$ & $\begin{array}{l}\text { não sei } \\
\text { não sei } \\
\text { não sei } \\
\text { não sei }\end{array}$ & $\begin{array}{l}\text { sim } \\
\text { sim } \\
\text { sim } \\
\text { sim }\end{array}$ & $\begin{array}{l}\text { não } \\
\text { não } \\
\text { não } \\
\text { não }\end{array}$ \\
\hline 94 & $\begin{array}{l}\text {...você sentiu como se outras pessoas estivessem causando } \\
\text { todos os seus problemas? }\end{array}$ & não sei & $\operatorname{sim}$ & não \\
\hline 95 & $\begin{array}{l}\text {...você se sentiu rodeado(a) de hostilidade, como se todos } \\
\text { fossem contra você. Por exemplo: } \\
\text { a) pensou que todo mundo o(a) acusava e odiava? } \\
\text { b) sentiu como se todo mundo estivesse o(a) observando? } \\
\text { c) sentiu que estava sendo perseguido(a) ou que era } \\
\text { procurado(a) pela polícia? }\end{array}$ & $\begin{array}{l}\text { não sei } \\
\text { não sei } \\
\text { não sei }\end{array}$ & $\begin{array}{l}\text { sim } \\
\text { sim } \\
\text { sim }\end{array}$ & $\begin{array}{l}\text { não } \\
\text { não } \\
\text { não }\end{array}$ \\
\hline 96 & ...você sentiu como se todo mundo estivesse falando sobre & não sei & $\operatorname{sim}$ & não \\
\hline
\end{tabular}




\begin{tabular}{|l|l|l|l|l|} 
& você? & & & \\
\hline 97 & $\begin{array}{l}\text {...você ouviu vozes falando mal de você ou vozes que eram } \\
\text { hostis ou o(a) xingavam? }\end{array}$ & não sei & sim & não \\
\hline 98 & ...se você ouviu vozes, você ouviu essas vozes claramente? & não sei & sim & não \\
\hline
\end{tabular}

Durante a sua vida, inclusive quando você era criança, você teve períodos de pelo menos 3 a 5 dias nos quais...

\begin{tabular}{|l|l|l|l|l|}
\hline 99 & $\begin{array}{l}\text {..você pensou que não havia nada que pudesse fazer para } \\
\text { mudar o jeito que as coisas iam ou viu o futuro como muito negro } \\
\text { ou difícil? }\end{array}$ & não sei & sim & não \\
\hline 100 & $\begin{array}{l}\text {..você sentiu como se quisesse desaparecer, por exemplo, } \\
\text { pegando o carro e indo para longe, ou pegando um ônibus ou } \\
\text { avião sem pensar para onde estava indo? }\end{array}$ & sim & não \\
\hline 101 & ...você usou o sono como fuga? & não sei & sim & não \\
\hline 102 & ...você pensou que a vida não valia a pena de ser vivida? & não sei & sim & não \\
\hline
\end{tabular}

Durante a sua vida, inclusive quando você era criança, você teve períodos de pelo menos 3 a 5 dias nos quais...

\begin{tabular}{|c|c|c|c|c|}
\hline 103 & $\begin{array}{l}\text {...você desejou não acordar pela manhã ou morrer em um } \\
\text { acidente ou de alguma doença, como um ataque cardíaco ou } \\
\text { derrame? }\end{array}$ & não sei & $\operatorname{sim}$ & não \\
\hline 104 & ...você quis morrer ou se machucar? & não sei & $\operatorname{sim}$ & não \\
\hline 105 & $\begin{array}{l}\text {... se você desejou morrer, você chegou a fazer um plano para } \\
\text { se machucar ou se matar? } \\
\text { () a pessoa nunca quis morrer }\end{array}$ & não sei & $\operatorname{sim}$ & não \\
\hline 106 & ...você tentou realmente se matar? & não sei & $\operatorname{sim}$ & não \\
\hline 107 & $\begin{array}{l}\text {...se você tentou se matar, você precisou de atendimento } \\
\text { médico? } \\
\text { () a pessoa nunca tentou se matar }\end{array}$ & não sei & sim & não \\
\hline 108 & $\begin{array}{l}\text { Se você respondeu SIM a qualquer das questões de } 81 \text { a } 107 \text {, } \\
\text { você se sentiu muito prejudicado(a), preocupado(a) ou } \\
\text { perturbado(a) pelo que estava acontecendo com você? } \\
\text { () a pessoa não respondeu SIM a nenhuma questão acima }\end{array}$ & não sei & sim & não \\
\hline
\end{tabular}

As questões a seguir referem-se a períodos quando seus pensamentos foram mais positivos.

Durante a sua vida, inclusive quando você era criança, você teve períodos de pelo menos 3 a 5 dias nos quais...

\begin{tabular}{|c|c|c|c|c|}
\hline 109 & $\begin{array}{l}\text {...você pensou (ou outros pensaram) que você tinha muito } \\
\text { talento para ser artista ou era criativo(a)? }\end{array}$ & não sei & $\operatorname{sim}$ & não \\
\hline 110 & $\begin{array}{l}\text {...você teve uma explosão de inspiração ou de criatividade (por } \\
\text { exemplo, escreveu poesias, textos, compôs músicas, pintou, } \\
\text { esculpiu ou fez outras obras com muita facilidade e rapidez)? }\end{array}$ & não sei & $\operatorname{sim}$ & não \\
\hline 111 & $\begin{array}{l}\text {...você esteve particularmente sensível às formas e à harmonia } \\
\text { na natureza? }\end{array}$ & não sei & $\operatorname{sim}$ & não \\
\hline 112 & $\begin{array}{l}\text {...você ficou muito curioso(a) e interessado(a) a respeito de } \\
\text { tudo e todos? }\end{array}$ & não sei & $\operatorname{sim}$ & não \\
\hline 113 & $\begin{array}{l}\text {...seu desempenho no serviço doméstico, no cuidado com as } \\
\text { crianças, na escola, no trabalho, nos hobbies e nos esportes } \\
\text { melhorou muito? }\end{array}$ & não sei & $\operatorname{sim}$ & não \\
\hline 114 & ...você se sentiu realmente bem com a sua aparência? & não sei & $\operatorname{sim}$ & não \\
\hline
\end{tabular}

Durante a sua vida, inclusive quando você era criança, você teve períodos de pelo menos 3 a 5 dias nos quais...

\begin{tabular}{|l|l|l|l|l|l|}
\hline 115 & ...você se sentiu muito inteligente, brilhante ou com raciocínio & não sei & sim & não \\
\hline
\end{tabular}




\begin{tabular}{|c|c|c|c|c|}
\hline & rápido? & & & \\
\hline 116 & $\begin{array}{l}\text {...você se sentiu seguro(a), carismático(a) ou quis assumir o } \\
\text { papel de líder? }\end{array}$ & não sei & $\operatorname{sim}$ & não \\
\hline 117 & $\begin{array}{l}\text {...você achou que estava sempre certo(a), era incapaz de } \\
\text { cometer erros e ficou indiferente a críticas? }\end{array}$ & não sei & $\operatorname{sim}$ & não \\
\hline 118 & $\begin{array}{l}\text {...você pensou que poderia decidir por outros porque conhecia } \\
\text { seus pensamentos, intenções ou desejos? }\end{array}$ & não sei & $\operatorname{sim}$ & não \\
\hline 119 & $\begin{array}{l}\text {...você não se sentiu apreciado(a) ou estimado porque os outros } \\
\text { não o(a) compreenderam ou compartilharam suas idéias } \\
\text { otimistas ou criativas? }\end{array}$ & não sei & $\operatorname{sim}$ & não \\
\hline 120 & $\begin{array}{l}\text {...você sentiu sua auto-estima incomumente alta, teve } \\
\text { sentimentos de superioridade ou idéias irreais de que você tinha } \\
\text { habilidades, talentos, conhecimentos ou poderes } \\
\text { extraordinários? }\end{array}$ & não sei & $\operatorname{sim}$ & não \\
\hline 121 & $\begin{array}{l}\text {...você se sentiu particularmente forte e invulnerável a doenças e } \\
\text { acidentes? }\end{array}$ & não sei & $\operatorname{sim}$ & não \\
\hline 122 & $\begin{array}{l}\text {...você ficou espiritualizado(a) ou místico(a) de um jeito fora do } \\
\text { comum? }\end{array}$ & não sei & sim & não \\
\hline 123 & $\begin{array}{l}\text {...você sentiu que conhecia a verdade, sabia como o mundo } \\
\text { funcionava e entendia o significado da existência? }\end{array}$ & não sei & $\operatorname{sim}$ & não \\
\hline 124 & ...você ouviu vozes que o(a) inspiravam ou elogiavam? & não sei & $\operatorname{sim}$ & não \\
\hline 125 & ...você foi (ou outras pessoas julgaram você) irresponsável? & não sei & sim & não \\
\hline 126 & $\begin{array}{l}\text {...você tomou decisões muito importantes (como comprar ou } \\
\text { vender uma casa ou um carro, ou mudar de emprego) de uma } \\
\text { hora para outra? }\end{array}$ & não sei & $\operatorname{sim}$ & não \\
\hline 127 & $\begin{array}{l}\text {...você fez coisas como: } \\
\text { a) gastar muito dinheiro? } \\
\text { b) dirigir muito rápido ou de forma inconseqüente? } \\
\text { c) tomar decisões absurdas nos negócios? }\end{array}$ & $\begin{array}{l}\text { não sei } \\
\text { não sei } \\
\text { não sei }\end{array}$ & $\begin{array}{l}\operatorname{sim} \\
\operatorname{sim} \\
\text { sim }\end{array}$ & $\begin{array}{l}\text { não } \\
\text { não } \\
\text { não }\end{array}$ \\
\hline
\end{tabular}

Durante a sua vida, inclusive quando você era criança, você teve períodos de pelo menos 3 a 5 dias nos quais...

\begin{tabular}{|l|l|l|l|l|}
\hline 128 & $\begin{array}{l}\text {...você estava inclinado a ignorar regras do dia-a-dia e a etiqueta } \\
\text { social ou se envolveu em atividades ilegais? }\end{array}$ & não sei & sim & não \\
\hline 129 & ...você teve experiências místicas ou visões? & não sei & sim & não \\
\hline 130 & ...você sentiu como se tivesse percepções extra-sensoriais? & não sei & sim & não \\
\hline 131 & $\begin{array}{l}\text {..se você respondeu SIM a qualquer das questões de 109 a } \\
130, \text { se sentiu muito prejudicado(a), preocupado(a) ou } \\
\text { perturbado(a) pelo que estava acontecendo com você? } \\
\text { () a pessoa não respondeu SIM a nenhuma questão acima }\end{array}$ & sim & não \\
\hline
\end{tabular}

\section{DOMÍNIO IV RITMICIDADE}

Muitas pessoas têm alguma variação no humor, energia, interesse e eficiência ao longo do ano ou até mesmo ao longo do dia

\begin{tabular}{|l|l|l|l|l|}
\hline 132 & $\begin{array}{l}\text { É difícil (isto é, mais difícil que o habitual para seus amigos ou } \\
\text { conhecidos) para você trabalhar ou ser produtivo(a) logo cedo? }\end{array}$ & não & sim & não \\
\hline 133 & $\begin{array}{l}\text { É difícil (isto é, mais difícil que o habitual para seus amigos ou } \\
\text { conhecidos) para você trabalhar ou ser produtivo(a) no final da } \\
\text { tarde ou à noite? }\end{array}$ & não sei & sim & não \\
\hline 134 & $\begin{array}{l}\text { Você fica irritado(a) ou tem dificuldade de funcionar se sua } \\
\text { rotina diária é perturbada (por exemplo, se você tem que } \\
\text { levantar, comer ou trabalhar fora de seus horários habituais)? }\end{array}$ & sim & não \\
\hline
\end{tabular}




\begin{tabular}{|c|c|c|c|c|}
\hline 135 & $\begin{array}{l}\text { Você acha que seu humor, energia, interesse e eficiência } \\
\text { melhoram se você se mantém dentro da sua rotina? }\end{array}$ & não sei & sim & não \\
\hline 136 & $\begin{array}{l}\text { Se, por alguma razão, você dorme muito menos que o normal } \\
\text { para o seu padrão de sono, você acha que tem mais energia em } \\
\text { vez de menos no dia seguinte? } \\
\text { Nota: não considere viagens com diferença de fuso horário de } 4 \\
\text { horas em resposta a esta questão }\end{array}$ & não sei & $\operatorname{sim}$ & não \\
\hline 137 & $\begin{array}{l}\text { Você é o tipo de pessoa em que o humor, energia e bem-estar } \\
\text { físico mudam: } \\
\text { a) de acordo com o clima (por exemplo, quando está } \\
\text { ensolarado, chuvoso, úmido ou frio)? } \\
\text { b) em uma estação do ano específica ou com a mudança das } \\
\text { estações? } \\
\text { c) quando você viaja com uma mudança de mais que } 4 \text { fusos } \\
\text { horários? } \\
\text { () a pessoa nunca fez uma viagem com diferença de mais de } 4 \\
\text { fusos horários } \\
\text { d) durante seu ciclo menstrual? } \\
\text { () a pessoa nunca teve ciclos menstruais }\end{array}$ & $\begin{array}{l}\text { não sei } \\
\text { não sei } \\
\text { não sei }\end{array}$ & $\begin{array}{l}\text { sim } \\
\text { sim }\end{array}$ & $\begin{array}{l}\text { não } \\
\text { não }\end{array}$ \\
\hline
\end{tabular}

As questões a seguir referem-se a mudanças no seu sono que ocorreram em outros períodos em que você estava doente, tomando medicações que afetam o sono ou (se mulher) quando você estava grávida

Durante a sua vida, inclusive quando você era criança, você teve períodos de pelo menos 3 a 5 dias nos quais...

\begin{tabular}{|c|c|c|c|c|}
\hline 138 & $\begin{array}{l}\text {...você se sentiu sonolento(a) o tempo todo? } \\
\text { Nota: não devido a horários de trabalho }\end{array}$ & não sei & sim & não \\
\hline 139 & $\begin{array}{l}\text {...você tinha dificuldade de adormecer? } \\
\text { Nota: não devido a horários de trabalho }\end{array}$ & não sei & $\operatorname{sim}$ & não \\
\hline 140 & $\begin{array}{l}\text {...você acordava no meio da noite e tinha dificuldade para voltar } \\
\text { a dormir? } \\
\text { Nota: não devido a horários de trabalho }\end{array}$ & não sei & $\operatorname{sim}$ & não \\
\hline 141 & $\begin{array}{l}\text {...você acordava muito mais cedo do que queria e não } \\
\text { conseguia voltar a dormir? } \\
\text { Nota: não devido a horários de trabalho }\end{array}$ & não sei & $\operatorname{sim}$ & não \\
\hline 142 & $\begin{array}{l}\text {...você precisou de muito mais sono que o habitual durante o dia } \\
\text { ou à noite? } \\
\text { Nota: não devido a horários de trabalho }\end{array}$ & não sei & sim & não \\
\hline 143 & $\begin{array}{l}\text {...você passou dias sem dormir ou com muito menos sono que o } \\
\text { habitual, mas não se sentiu cansado(a)? }\end{array}$ & não sei & $\operatorname{sim}$ & não \\
\hline 144 & $\begin{array}{l}\text { Você tem muita dificuldade em dormir antes ou depois de } \\
\text { atividades estimulantes físicas, sociais ou profissionais (como } \\
\text { em férias ou uma viagem, ou ao começar um novo ano escolar } \\
\text { ou um novo projeto no trabalho)? }\end{array}$ & não sei & $\operatorname{sim}$ & não \\
\hline
\end{tabular}

Algumas pessoas acreditam que seu sono muda muito em uma determinada estação do ano ou quando as estações mudam, ou (se mulher) durante o ciclo menstrual.

\begin{tabular}{|l|l|l|l|l|}
\hline 145 & $\begin{array}{l}\text { A qualidade de seu sono ou sua necessidade de sono aumenta } \\
\text { em uma determinada estação do ano ou durante a mudança de } \\
\text { estações? }\end{array}$ & não sei & sim & não \\
\hline 146 & $\begin{array}{l}\text { A qualidade de seu sono ou sua necessidade de sono aumenta } \\
\text { quando você faz uma viagem com diferença de pelo menos 4 } \\
\text { fusos horários? } \\
\text { ( ) a pessoa nunca fez uma viagem com diferença de 4 fusos }\end{array}$ & sim & não \\
\hline
\end{tabular}




\begin{tabular}{|l|l|l|l|l|} 
& horários & & & \\
\hline 147 & $\begin{array}{l}\text { A qualidade de seu sono ou sua necessidade de sono diminui } \\
\text { quando você viaja através de pelo menos 4 fusos horários? } \\
\text { () a pessoa nunca fez uma viagem com diferença de mais de 4 } \\
\text { fusos horários }\end{array}$ & não sei & não \\
\hline 148 & $\begin{array}{l}\text { A qualidade de seu sono ou sua necessidade de sono aumenta } \\
\text { durante o seu ciclo menstrual ? } \\
\text { () a pessoa nunca teve ciclos menstruais }\end{array}$ & não sei & sim & não \\
\hline 149 & $\begin{array}{l}\text { A qualidade de seu sono ou sua necessidade de sono diminui } \\
\text { durante o seu ciclo menstrual ? } \\
\text { () a pessoa nunca teve ciclos menstruais }\end{array}$ & não sei & sim & não \\
\hline
\end{tabular}

As questões seguintes referem-se a mudanças no seu apetite, interesse sexual ou experiências, ou a sintomas físicos que você pode ter sentido. Nós estamos interessados apenas em mudanças que podem ter ocorrido em períodos em que você não estava grávida, amamentando, doente ou tomando medicações.

Durante a sua vida, inclusive quando você era criança, você teve períodos de pelo menos 3 a 5 dias nos quais...

\begin{tabular}{|l|l|l|l|l|}
\hline 150 & ...nenhuma comida era apetitosa ou saborosa para você? & não sei & sim & não \\
\hline 151 & $\begin{array}{l}\text {...você constantemente tinha necessidade de comer doces ou } \\
\text { carboidratos? }\end{array}$ & não sei & sim & não \\
\hline 152 & ...seu apetite e/ou peso aumentou(aram)? & não sei & sim & não \\
\hline 153 & ...seu apetite e/ou peso diminuiu(íram)? & não sei & sim & não \\
\hline
\end{tabular}

As questões a seguir são sobre mudanças no seu interesse sexual ou experiências.

Durante a sua vida você teve períodos de pelo menos 3 a 5 dias nos quais...

\begin{tabular}{|l|l|l|l|l|}
\hline 154 & ...você ficou menos ativo(a) no sexo do que normalmente? & não sei & sim & não \\
\hline 155 & ...você teve dificuldade de ser excitado(a) sexualmente? & não sei & sim & não \\
\hline 156 & ...você teve dificuldade em atingir o orgasmo? & não sei & sim & não \\
\hline 157 & ...você ficou mais interessado(a) em sexo? & não sei & sim & não \\
\hline 158 & ...você freqüentemente mudava de parceiros sexuais? & não sei & sim & não \\
\hline
\end{tabular}

As questões a seguir são sobre alguns sintomas físicos que você pode ter experimentado.

Durante a sua vida, inclusive quando você era criança, você teve períodos de pelo menos 3 a 5 dias nos quais...

\begin{tabular}{|c|c|c|c|c|}
\hline 159 & $\begin{array}{l}\text {...você teve sintomas físicos perturbadores com freqüência, } \\
\text { como, por exemplo: } \\
\text { a) dores de cabeça freqüentes? } \\
\text { b) sua boca ficava seca? } \\
\text { c) você ficava constipado(a)? } \\
\text { d) você tinha náuseas ou outros problemas estomacais ou } \\
\text { intestinais? }\end{array}$ & $\begin{array}{l}\text { não sei } \\
\text { não sei } \\
\text { não sei } \\
\text { não sei }\end{array}$ & $\begin{array}{l}\operatorname{sim} \\
\operatorname{sim} \\
\operatorname{sim} \\
\operatorname{sim}\end{array}$ & $\begin{array}{l}\text { não } \\
\text { não } \\
\text { não } \\
\text { não }\end{array}$ \\
\hline 160 & $\begin{array}{l}\text {...você ficou mais ou menos sensível que o habitual para calor, } \\
\text { frio ou dor? }\end{array}$ & não sei & sim & não \\
\hline 161 & $\begin{array}{l}\text {.....se você respondeu SIM a qualquer das questões de } 132 \text { a } \\
160 \text {, você se sentiu muito prejudicado(a), preocupado(a) ou } \\
\text { perturbado(a) pelo que estava preocupado(a) ou perturbado(a) } \\
\text { pelo que estava acontecendo com você? } \\
\text { () a pessoa não respondeu SIM a nenhuma questão acima }\end{array}$ & não sei & $\operatorname{sim}$ & não \\
\hline
\end{tabular}




\section{7) REFERÊNCIAS}

Akiskal HS, Mallya G. Criteria for the "soft" bipolar spectrum: treatment implications. Psychopharmacol Bull. 1987;23(1):68-73.

Akiskal HS, Pinto O. The evolving bipolar spectrum. Prototypes I, II, III, and IV. Psychiatr Clin North Am. 1999 Sep;22(3):517-34, vii.

Akiskal HS, Bourgeois ML, Angst J, Post R, Moller H, Hirschfeld R. Reevaluating the prevalence of and diagnostic composition within the broad clinical spectrum of bipolar disorders. J Affect Disord. 2000 Sep;59 Suppl 1:S5-S30.

Akiskal HS, Mendlowicz MV, Jean-Louis G, Rapaport MH, Kelsoe JR, Gillin JC et al. TEMPS-A: validation of a short version of a self-rated instrument designed to measure variations in temperament. J Affect Disord. 2005 Mar ;85(1-2):45-52.

American Psychiatric Association (APA). Diagnostic and statistical manual of mental disorders, fourth edition. Washington, DC: American Psychiatric Press; 1994.

Angst $\mathrm{J}$. The emerging epidemiology of hypomania and bipolar II disorder. J Affect Disord. 1998 Sep;50(2-3):143-51.

Angst J, Gamma A, Benazzi F, Ajdacic V, Eich D, Rossler W. Toward a redefinition of subthreshold bipolarity: epidemiology and proposed criteria for bipolar-II, minor bipolar disorders and hypomania. J Affect Disord. 2003a Jan;73(1-2):133-46.

Angst J, Gamma A, Sellaro R, Lavori PW, Zhang, H. Recurrence of bipolar disorders and major depressions. A life-long perspective. Eur Arch Clin Neurosci 2003b; 253:236-40. 
Angst J, Cassano G. The mood spectrum: improving the diagnosis of bipolar disorder. Bipolar Disord. 2005; 7 (Suppl 4):4-12.

Angst J, Adolfsson R, Benazzi F, Gamma A, Hantouche E, Meyer TD et al. The HCL-32: towards a self-assessment tool for hypomanic symptoms in outpatients. J Affect Disord. 2005 Oct;88(2):217-33.

Aurélio. Assertivo. Novo dicionário Aurélio da língua portuguesa. $3^{\mathrm{a}}$. ed. , $1^{\mathrm{a}}$. impr. Curitiba: Ed. Positivo; 2004.

Baldassano CF. Assessment tools for screening and monitoring bipolar disorder. Bipolar Disord. 2005;7 Suppl 1:8-15.

Balestrieri M, Rucci P, Sbrana A, Ravani L, Benvenuti A, Gonnelli C et al. Lifetime rhythmicity and mania as correlates of suicidal ideation and attempts in mood disorders. Compr Psychiatry. 2006 Sep-Oct;47(5):334-41.

Bech P, Malt UF, Dencker SJ, Ahlfors UG, Elgen K, Lewnder T et al. Scales for the assessment of diagnosis and severity of mental disorders. Acta Psychiatr Scand. Suppl. 1993; 87(372):1-87.

Benazzi F. Bipolar II disorder is common among depressed outpatients.

Psychiatry Clin Neurosci. 1999 Oct;53(5):607-9.

Benazzi F. Prevalence of bipolar II disorder in outpatient depression: a 203-case study in private practice. J Affect Disord. 1997 Apr;43(2):163-6.

Benazzi F, Akiskal HS. Refining the evaluation of bipolar II: beyond the strict SCID-CV guidelines for hypomania. J Affect Disord. 2003a Jan;73(1-2):33-8.

Benazzi F. Diagnosis of bipolar II disorder: a comparison of structured versus semistructured interviews. Prog Neuropsychopharmacol Biol Psychiatry. 2003b Sep;27(6):985-91.

Benazzi F. Melancholic outpatient depression in Bipolar-II vs. unipolar. Prog Neuropsychopharmacol Biol Psychiatry. 2004 May;28(3):481-5. 
Berk M, Malhi GS, Mitchell PB, Cahill CM, Carman AC, Hadzi-Pavlovic D et al. Scale matters: the need for a Bipolar Depression Rating Scale (BDRS). Acta Psychiatr Scand Suppl. 2004;(422):39-45.

Berk M, Dodd S. Bipolar II disorder: a review. Bipolar Disord. 2005 Feb;7(1):1121.

Berrocal C, Ruiz Moreno M, Merchan P, Mansukhani A, Rucci P, Cassano GB. The Mood Spectrum Self-Report: validation and adaptation into Spanish.

Depress Anxiety. 2006;23(4):220-35.

Bryant FB, Yarnold PR. Principal-components analysis and exploratory and confirmatory factor analysis. In: Grimm LG, Yarnold PR. Reading and understanding multivariate statistics. Washington, DC: American Psychological Association; 1995. p.99-136.

Bryant FB. Assessing the validity of measurement. In: Grimm LG, Yarnold PR. Reading and understanding more multivariate statistics. Washington, DC: American Psychological Association; 2000, p.99-147.

Calabrese JR, Hirschfeld RM, Reed M, Davies MA, Frye MA, Keck PE et al. Impact of bipolar disorder on a U.S. community sample. J Clin Psychiatry. 2003 Apr;64(4):425-32.

Calil HM, Pires MLN. Aspectos gerais das escalas de avaliação de depressão.In: Gorenstein C, Andrade LHSG, Zuardi AW. Escalas de avaliação clínica em psiquiatria e psicofarmacologia., São Paulo: Ed. Lemos; 2000, p.65-9.

Cassano GB, Michelini S, Shear MK, Coli E, Maser JD, Frank E. The panicagoraphobic spectrum: a descriptive approach to the assessment and treatment of subtle symptoms. Am J Psychiatry. 1997 Jun;154(6 Suppl):27-38.

Cassano GB, Banti S, Mauri M, Dell'Osso L, Miniati M, Maser JD et al. Internal consistency and discriminant validity of the Structured Clinical Interview for Panic-Agoraphobic Spectrum (SCI-PAS). Int J Meth Psych Res. 1999a; 8:13845. 
Cassano GB, Dell'Osso L, Frank E, Miniati M, Fagiolini A, Shear K et al. The bipolar spectrum: a clinical reality in search of diagnostic criteria and an assessment methodology. J Affect Disord. 1999b Aug;54(3):319-28.

Cassano GB, Frank E, Miniati M, Rucci P, Fagiolini A, Pini S et al. Conceptual underpinnings and empirical support for the mood spectrum. Psychiatr Clin North Am. 2002 Dec;25(4):699-712, v.

Cassano GB, Rucci P, Frank E, Fagiolini A, Dell'Osso L, Shear MK et al. The mood spectrum in unipolar and bipolar disorder: arguments for a unitary approach. Am J Psychiatry. 2004 Jul;161(7):1264-9.

Cassano GB. Mood Spectrum. Algorithm (Online). Available: http://www.spectrum-project.net/us/moods/moods.asp ( cited Jul. 23, 2006).

Cassidy F, Ahearn E, Murry E, Forest K, Carroll BJ. Diagnostic depressive symptoms of the mixed bipolar episode. Psychol Med. 2000 Mar;30(2):403-11.

Chengappa KR, Williams $P$. Barriers to the effective management of bipolar disorder: a survey of psychiatrists based in the UK and USA. Bipolar Disord. 2005;7 Suppl 1:38-42.

Clark LA, Watson D. Tripartite model of anxiety and depression: psychometric evidence and taxonomic implications. J Abnorm Psychol. 1991 Aug;100(3):31636 .

Cloninger CR, Svrakic DM, Przybeck TR. A psychobiological model of temperament and character. Arch Gen Psychiatry. 1993 Dec;50(12):975-90.

Coryell W. Bipolar II disorder: the importance of hypomania. In: Goldberg JEF, Harrow M. Bipolar disorders: clinical course and outcome. Washington,DC: American Psychiatric Press; 1999. p.219-37.

Cronbach LJ, Meehl PE. Construct validity in psychological tests. Psychological Bulletin 1955; 52:281-302. 
Cyranowski JM, Shear MK, Rucci P, Fagiolini A, Frank E, Grochocinski VJ et al. Adult separation anxiety: psychometric properties of a new structured clinical interview. J Psychiatr Res. 2002 Mar-Apr;36(2):77-86.

DATASUS. Informações de saúde. Epidemiológicas e morbidade. Morbidade hospitalar(Online). Available: http://w3.datasus.gov.br/datasus/datasus.php (cited Jan. 10, 2007).

Dell'Osso L, Cassano GB, Sarno N, Millanfranchi A, Pfanner C, Gemignani A et al. Validity and reliability of the Structured Clinical Interview for ObsessiveCompulsive Spectrum (SCI-OBS) and of the Structured Clinical Interview for Social Phobia Spectrum (SCl-SHY). Int J Meth Psych Res. 2000; 9:11-24.

Dell'Osso L, Armani A, Rucci P, Frank E, Fagiolini A, Corretti G et al. Measuring mood spectrum: comparison of interview (SCl-MOODS) and self-report (MOODS-SR) instruments. Compr Psychiatry. 2002a Jan-Feb;43(1):69-73.

Dell'Osso L, Rucci P, Cassano GB, Maser JD, Endicott J, Shear MK et al. Measuring social anxiety and obsessive-compulsive spectra: comparison of interviews and self-report instruments. Compr Psychiatry. 2002b MarApr;43(2):81-7.

Demyttenaere K, Bruffaerts R, Posada-Villa J, Gasquet I, Kovess V, Lepine JP et al. Prevalence, severity, and unmet need for treatment of mental disorders in the World Health Organization World Mental Health Surveys. JAMA. 2004 Jun 2;291(21):2581-90.

Depue RA, Monroe SM. The unipolar--bipolar distinction in the depressive disorders. Psychol Bull. 1978 Sep;85(5):1001-29.

Dratcu L, da Costa Ribeiro L, Calil HM. Depression assessment in Brazil. The first application of the Montgomery-Asberg Depression Rating Scale.

Br J Psychiatry. 1987 Jun;150:797-800. 
Duarte Silva AP, Stam A. Discriminant analysis. In: Grimm LG, Yarnold PR. Reading and understanding multivariate statistics. Washington, DC: American Psychological Association; 1995. p. 277-319.

Dunner DL, Gershon ES, Goodwin FK. Heritable factors in the severity of affective illness. Biol Psychiatry. 1976 Feb;11(1):31-42.

Endicott J, Spitzer RL. A diagnostic interview: the schedule for affective disorders and schizophrenia. Arch Gen Psychiatry. 1978 Jul;35(7):837-44.

Fagiolini A, Dell 'Osso L, Pini S, Armani A, Bouanani S, Rucci P et al. Validity and reliability of a new instrument for assessing mood symptomatology: the Structured Clinical Interview for Mood Spectrum (SCI-MOODS). Int J of Methods in Psych Research. 1999;8(2):71-82.

First MB, Spitzer RL, Gibbon M, Williams JBW. Structured Clinical Interview for DSM-IV Axis I Disorders - Patient edition, Version 2.0 (SCID - I / P). New York: Biometrics Research Department, 1995.

Frank E, Shear MK, Rucci P, Cyranowski JM, Endicott J, Fagiolini A et al. Influence of panic-agoraphobic spectrum symptoms on treatment response in patients with recurrent major depression. Am J Psychiatry. 2000 Jul;157(7):11017.

Frank E, Cyranowski JM, Rucci P, Shear MK, Fagiolini A, Thase ME et al. Clinical significance of lifetime panic spectrum symptoms in the treatment of patients with bipolar I disorder. Arch Gen Psychiatry. 2002 Oct;59(10):905-11.

Fuentes D, Tavares H, Camargo CHP, Gorenstein C. Inventário de Temperamento e de Caráter de Cloninger - Validação da versão em português. In: Gorenstein C, Andrade LHSG, Zuardi AW. Escalas de Avaliação Clínica em Psiquiatria e Psicofarmacologia, São Paulo: Lemos Editorial; 2000. p. 363-76.

Ghaemi SN, Sachs GS, Chiou AM, Pandurangi AK, Goodwin K. Is bipolar disorder still underdiagnosed? Are antidepressants overutilized? J Affect Disord. 1999 Jan-Mar;52(1-3):135-44. 
Ghaemi SN, Ko JY, Goodwin FK. The bipolar spectrum and the antidepressant view of the world. J Psychiatr Pract. 2001 Sep;7(5):287-97.

Ghaemi SN, Ko JY, Goodwin FK. "Cade's disease" and beyond: misdiagnosis, antidepressant use, and a proposed definition for bipolar spectrum disorder. Can J Psychiatry. 2002 Mar;47(2):125-34.

Ghaemi SN, Miller CJ, Berv DA, Klugman J, Rosenquist KJ, Pies RW. Sensitivity and specificity of a new bipolar spectrum diagnostic scale. J Affect Disord. 2005 Feb;84(2-3):273-7.

Gitlin MJ, Swendsen J, Heller TL, Hammen C. Relapse and impairment in bipolar disorder. Am J Psychiatry. 1995 Nov;152(11):1635-40.

Goodwin FK, Ghaemi SN. An introduction to and historical review of mood disorders. In: Gelder MG, Lopez-lbor JJ, Andreasen N. New Oxford Textbook of Psychiatry. London: Oxford University Press, 2003.

Goodwin FK, Jamison KR. Manic-Depressive Illness. New York: Oxford University Press, 1990.

Goldberg JF, Harrow M. Consistency of remission and outcome in bipolar and unipolar mood disorders: a 10-year prospective follow-up. J Affect Disord. 2004 Aug;81(2):123-31.

Goldstein JM, Simpson JC. Validity: definitions and applications to psychiatric research. In: Tsuang MT, Tohen M. Textbook in psychiatric epidemiology. $2^{\text {nd }}$. ed. New York (USA): Wiley-Liss; 2002, p. 149-65.

Gorenstein C, Andrade L. Validation of a Portuguese version of the Beck Depression Inventory and the State-Trait Anxiety Inventory in Brazilian subjects. Braz J Med Biol Res. 1996 Apr;29(4):453-7.

Grant BF, Stinson FS, Hasin DS, Dawson DA, Chou SP, Ruan WJ et al. Prevalence, correlates, and comorbidity of bipolar I disorder and axis I and II disorders: results from the National Epidemiologic Survey on Alcohol and Related Conditions. J Clin Psychiatry. 2005 Oct;66(10):1205-15. 
Hamilton M. A rating scale for depression. J Neurol Neurosurg Psychiatry. 1960 Feb;23:56-62.

Hantouche EG, Akiskal HS. Bipolar II vs. unipolar depression: psychopathologic differentiation by dimensional measures. J Affect Disord. 2005 Feb;84(2-3):12732.

Harding TW, de Arango MV, Baltazar J, Climent CE, Ibrahim HH, Ladrido-Ignacio $L$ et al. Mental disorders in primary health care: a study of their frequency and diagnosis in four developing countries. Psychol Med. 1980 May;10(2):231-41.

Hirschfeld RM, Williams JB, Spitzer RL, Calabrese JR, Flynn L, Keck PE Jr et al. Development and validation of a screening instrument for bipolar spectrum disorder: the Mood Disorder Questionnaire. Am J Psychiatry. 2000 Nov;157(11):1873-5.

Hirschfeld RM, Lewis L, Vornik LA. Perceptions and impact of bipolar disorder: how far have we really come? Results of the national depressive and manicdepressive association 2000 survey of individuals with bipolar disorder. J Clin Psychiatry. 2003 Feb;64(2):161-74.

Hirschfeld RM, Cass AR, Holt DC, Carlson CA. Screening for bipolar disorder in patients treated for depression in a family medicine clinic. J Am Board Fam Pract. 2005 Jul-Aug;18(4):233-9.

Judd LL, Akiskal HS, Schettler PJ, Endicott J, Maser J, Solomon DA et al. The long-term natural history of the weekly symptomatic status of bipolar I disorder. Arch Gen Psychiatry. 2002 Jun;59(6):530-7.

Judd LL, Schettler PJ, Akiskal HS. The prevalence, clinical relevance, and public health significance of subthreshold depressions. Psychiatr Clin North Am. 2002 Dec;25(4):685-98.

Judd LL, Akiskal HS, Schettler PJ, Coryell W, Maser J, Rice JA et al. The comparative clinical phenotype and long term longitudinal episode course of bipolar I and II: a clinical spectrum or distinct disorders? J Affect Disord. 2003 Jan;73(1-2):19-32. 
Judd LL, Akiskal HS. The prevalence and disability of bipolar spectrum disorders in the US population: re-analysis of the ECA database taking into account subthreshold cases. J Affect Disord. 2003 Jan;73(1-2):123-31.

Judd LL, Akiskal HS, Schettler PJ, Coryell W, Endicott J, Maser JD et al. A prospective investigation of the natural history of the long-term weekly symptomatic status of bipolar II disorder. Arch Gen Psychiatry. 2003 Mar;60(3):261-9.

Kessler RC, McGonagle KA, Zhao S, Nelson CB, Hughes M, Eshleman S et al. Lifetime and 12-month prevalence of DSM-III-R psychiatric disorders in the United States. Results from the National Comorbidity Survey. Arch Gen Psychiatry. 1994 Jan;51(1):8-19.

Kim SW, Kim SJ, Yoon BH, Kim JM, Shin IS, Hwang MY et al. Diagnostic validity of assessment scales for depression in patients with schizophrenia. Psychiatry Res. 2006 Sep 30;144(1):57-63

Klerman GL. The spectrum of mania. Compr Psychiatry. 1981 Jan-Feb;22(1):1120.

Kogan JN, Otto MW, Bauer MS, Dennehy EB, Miklowitz DJ, Zhang HW et al. Demographic and diagnostic characteristics of the first 1000 patients enrolled in the Systematic Treatment Enhancement Program for Bipolar Disorder (STEPBD). Bipolar Disord. 2004 Dec;6(6):460-9.

Koukopoulos A, Koukopoulos A. Agitated depression as a mixed state and the problem of melancholia. Psychiatr Clin North Am. 1999 Sep; 22(3), 547-64.

Kraepelin E. Clinical Psychiatry, 7a. ed (1921). New York: Scholar's Facsimiles e Reprints, 1981.

Kupfer DJ, Frank E, Grochocinski VJ, Cluss PA, Houck PR, Stapf DA. Demographic and clinical characteristics of individuals in a bipolar disorder case registry. J Clin Psychiatry. 2002 Feb;63(2):120-5. 
Leverich GS, Altshuler LL, Frye MA, Suppes T, Keck PE Jr, McElroy SL et al. Factors associated with suicide attempts in 648 patients with bipolar disorder in the Stanley Foundation Bipolar Network. J Clin Psychiatry. 2003 May;64(5):50615.

Manning JS, Haykal RF, Connor PD, Akiskal HS.On the nature of depressive and anxious states in a family practice setting: the high prevalence of bipolar II and related disorders in a cohort followed longitudinally. Compr Psychiatry. 1997 MarApr;38(2):102-8.

Mari JJ, Williams P. A validity study of a psychiatric screening questionnaire (SRQ-20) in primary care in the city of Sao Paulo. $\mathrm{Br} J$ Psychiatry. 1986 Jan;148:23-6.

Marneros A. Expanding the group of bipolar disorders. J Affect Disord. 2001 Jan;62(1-2):39-44.

Mauri M, Borri C, Baldassari S, Benvenuti A, Rucci P, Cassano GB, et al. Acceptability and psychometric properties of the Structured Clinical Interview for Anorexic - Bulimic Spectrum (SCl-ABS). Int J Meth Psych Res. 2000;9 :68-78.

McElroy SL, Keck PE Jr, Pope HG Jr, Hudson JI, Faedda GL, Swann AC. Clinical and research implications of the diagnosis of dysphoric or mixed mania or hypomania. Am J Psychiatry. 1992 Dec;149(12):1633-44.

McIntyre RS, Konarski JZ, Wilkins K, Bouffard B, Soczynska JK, Kennedy SH. The prevalence and impact of migraine headache in bipolar disorder: results from the Canadian Community Health Survey. Headache. 2006 Jun;46(6):973-82.

Menezes PR, Nascimento AF. Validade e confiabilidade das escalas de avaliação em psiquiatria. . In: Gorenstein C, Andrade LHSG, Zuardi AW. Escalas de Avaliação Clínica em Psiquiatria e Psicofarmacologia, São Paulo: Lemos Editorial; 2000, p. 23-9.

Miller CJ, Klugman J, Berv DA, Rosenquist KJ, Ghaemi SN. Sensitivity and specificity of the Mood Disorder Questionnaire for detecting bipolar disorder. J Affect Disord. 2004 Aug;81(2):167-71. 
Mitchell P, Parker G, Jamieson K, Wilhelm K, Hickie I, Brodaty $\mathrm{H}$ et al. Are there any differences between bipolar and unipolar melancholia? J Affect Disord. 1992 Jun;25 :97-105.

Mitchell PB, Wilhelm K, Parker G, Austin MP, Rutgers P, Malhi GS. The clinical features of bipolar depression: a comparison with matched major depressive disorder patients. J Clin Psychiatry. 2001 Mar;62(3):212-6.

Moreno $\mathrm{DH}$, Andrade $\mathrm{LH}$. The lifetime prevalence, health services utilization and risk of suicide of bipolar spectrum subjects, including subthreshold categories in the Sao Paulo ECA study. J Affect Disord. 2005 Aug;87(2-3):231-41.

Moreno DH, Almeida KM. Quadro clínico dos subtipos do espectro bipolar. In: Moreno RA, Moreno DH. Da psicose maníaco-depressiva ao espectro bipolar. São Paulo: Ed. Segmento Farma; 2005. p. 141-69.

Muntaner C, Eaton WW, Miech R, O'Campo P. Socioeconomic position and major mental disorders. Epidemiol Rev. 2004;26: 53-62.

Olfson M, Das AK, Gameroff MJ, Pilowsky D, Feder A, Gross R et al. Lantigua R. Bipolar depression in a low-income primary care clinic. Am J Psychiatry. 2005 Nov;162(11):2146-51.

Perlis RH, Brown E, Baker RW, Nierenberg AA. Clinical features of bipolar depression versus major depressive disorder in large multicenter trials. Am J Psychiatry. 2006 Feb;163(2):225-31.

Phelps JR, Ghaemi SN. Improving the diagnosis of bipolar disorder: predictive value of screening tests. J Affect Disord. 2006 Jun;92(2-3):141-8.

Pope HG Jr, Lipinski JF Jr. Diagnosis in schizophrenia and manic-depressive illness: a reassessment of the specificity of 'schizophrenic' symptoms in the light of current research. Arch Gen Psychiatry. 1978 Jul;35(7):811-28.

Regeer EJ, Krabbendam L, de Graaf R, ten Have M, Nolen WA, van Os J. A prospective study of the transition rates of subthreshold (hypo)mania and depression in the general population. Psychol Med. 2006 May;36(5):619-27. 
Rihmer Z, Pestality P. Bipolar II disorder and suicidal behavior. Psychiatr Clin North Am. 1999 Sep;22(3):667-73, ix-X.

Robins LN, Helzer JE, Croughan J, Ratcliff KS. National Institute of Mental Health Diagnostic Interview Schedule. Its history, characteristics, and validity. Arch Gen Psychiatry. 1981 Apr;38(4):381-9.

Robins LN, Wing J, Wittchen HU, Helzer JE, Babor TF, Burke J et al. The Composite International Diagnostic Interview. An epidemiologic Instrument suitable for use in conjunction with different diagnostic systems and in different cultures. Arch Gen Psychiatry. 1988 Dec;45(12):1069-77.

Rucci P, Maser JD. Instrument development in the Italy-USA Collaborative Spectrum Project. Epidemiol Psichiatr Soc. 2000 Oct-Dec;9(4):249-56.

Saha S, Chant D, Welham J, McGrath J. A systematic review of the prevalence of schizophrenia. PLoS Med. 2005 May;2(5):e141

Sajatovic M. Bipolar disorder: disease burden. Am J Manag Care. 2005 Jun;11(3 Suppl):S80-4.

Saraceno B, Levav I, Kohn R. The public mental health significance of research on socio-economic factors in schizophrenia and major depression. World Psychiatry. 2005 Oct;4(3):181-5.

Sbrana A, Dell'Osso L, Gonnelli C, Impagnatiello P, Doria MR, Spagnolli S et al. Acceptability, validity and reliability of the Structured Clinical Interview for the Spectrum of Substance Use (SCI-SUBS): a pilot study. Int J Methods Psychiatr Res. 2003;12(2):105-15.

Sbrana A, Dell'Osso L, Benvenuti A, Rucci P, Cassano P, Banti S et al.The psychotic spectrum: validity and reliability of the Structured Clinical Interview for the Psychotic Spectrum. Schizophr Res. 2005 Jun 15;75(2-3):375-87. 
Shansis F, Grevet E, Mattevi B, Berlim M, Maldonado G, Santin A et al. Development and application of the mania rating guide (MRG). Rev Bras Psiquiatr. 2003 Jun;25(2):91-5.

Shear MK, Greeno C, Kang J, Ludewig D, Frank E, Swartz HA et al. Diagnosis of nonpsychotic patients in community clinics. Am J Psychiatry. 2000 Apr;157(4):581-7.

Shear MK, Frank E, Rucci P, Fagiolini DA, Grochocinski VJ, Houck P et al. Panic-agoraphobic spectrum: reliability and validity of assessment instruments. J Psychiatr Res. 2001 Jan-Feb;35(1):59-66.

Sheehan DV, Lecrubier Y, Sheehan KH, Amorim P, Janavs J, Weiller E et al. The Mini-International Neuropsychiatric Interview (M.I.N.I.): the development and validation of a structured diagnostic psychiatric interview for DSM-IV and ICD-10. J Clin Psychiatry. 1998;59 Suppl 20:22-33.

Shrout PE. Reliability. In: Tsuang MT, Tohen M. Textbook in psychiatric epidemiology. $2^{\text {nd }}$. ed. New York (USA): Wiley-Liss; 2002. p. 131-49.

Simpson SG, McMahon FJ, McInnis MG, MacKinnon DF, Edwin D, Folstein SE et al. Diagnostic reliability of bipolar II disorder. Arch Gen Psychiatry. 2002 Aug;59(8):736-40.

Skyre I, Onstad S, Torgersen S, Kringlen E High interrater reliability for the Structured Clinical Interview for DSM-III-R Axis I (SCID-I). Acta Psychiatr Scand 1991 Aug;84(2):167-73.

Solomon DA, Leon AC, Maser JD, Truman CJ, Coryell W, Endicott $\mathrm{J}$ et al. Distinguishing bipolar major depression from unipolar major depression with the screening assessment of depression-polarity (SAD-P). J Clin Psychiatry. 2006 Mar;67(3):434-42.

Spitzer RL, Endicott J, Robins E. Research diagnostic criteria: rationale and reliability. Arch Gen Psychiatry. 1978 Jun; 35(6):773-82. 
Spitzer RL, Williams JBW, Gibbon M, First MB. Structured Clinical Interview for DSM-III-R, Patient Edition(SCID-P), Washington, D.C.: American Psychiatric Press, Inc., 1990.

SPSS. Statistical Package for Social Sciences for Windows, v. 12.0. 2002; Chicago: SPSS Inc.

Steiner JL, Tebes JK, Sledge WH, Walker ML. A comparison of the structured clinical interview for DSM-III-R and clinical diagnoses. J Nerv Ment Dis. 1995 Jun;183(6):365-9.

Strube MJ. Reliability and generalizability theory. In: Grimm LG, Yarnold PR. Reading and understanding more multivariate statistics. Washington, DC: American Psychological Association; 2000.p.23-67.

Swets JA, Dawes RM, Monahan J. Psychological science can improve diagnostic decisions. Psychological Science in the Public Interest. 2000 May; 1(1): 4-26.

Vieira S. Introdução à bioestatística. $2^{\mathrm{a}}$. Ed. Rio de Janeiro (RJ): Ed. Campus; 1991. p. 147.

Vilela JAA, Loureiro SR. Escala de Avaliação de Mania de Young- estudo das qualidades psicométricas da versão brasileira. In: Gorenstein C, Andrade LHSG, Zuardi AW. Escalas de Avaliação Clínica em Psiquiatria e Psicofarmacologia. São Paulo: Lemos Editorial; 2000. p.112-123.

Vilela JA, Crippa JA, Del-Ben CM, Loureiro SR. Reliability and validity of a Portuguese version of the Young Mania Rating Scale. Braz J Med Biol Res. 2005 Sep;38(9):1429-39.

Wang YP. Aspectos históricos da doença maníaco-depressiva. In: Moreno RA, Moreno DH. Da psicose maníaco-depressiva ao espectro bipolar. São Paulo: Ed. Segmento Farma; 2005.p.13-45.

Wang YP, Demetrio FN. Evolução da dicotomia unipolar/bipolar. In: Moreno RA, Moreno DH. Da psicose maníaco-depressiva ao espectro bipolar. São Paulo: Ed. Segmento Farma; 2005. p. 47-84. 
Wehr TA, Goodwin FK. Can antidepressants cause mania and worsen the course of affective illness? Am J Psychiatry. 1987 Nov;144(11):1403-11.

Weissman MM, Wickramaratne P, Adams P, Wolk S, Verdeli H, Olfson M. Brief screening for family psychiatric history: the family history screen. Arch Gen Psychiatry. 2000 Jul; 57(7):675-82.

Williams JBW, Gibbon M, First MB, Spitzer RL, Davis M, Borus J, et al. The Structured Clinical Interview for DSM-III-R (SCID) II. Multi-site test-retest reliability. Arch Gen Psychiatry,1992; 49:630-636.

Wing JK, Babor T, Brugha T, Burke J, Cooper JE, Giel R et al. SCAN. Schedules for Clinical Assessment in Neuropsychiatry. Arch Gen Psychiatry. 1990 Jun; 47(6):589-93.

Woods SW. The economic burden of bipolar disease. J Clin Psychiatry. 2000; 61 Supp 13:38-41.

World Health Organization (WHO). The ICD-10 classification of mental and behavioral disorders clinical descriptions and diagnostic guidelines. Genéve: World Health Organization. 1992.

World Health Organization (WHO). The ICD-10 classification of mental and behavioral disorders diagnostic criteria for research. Genéve: World Health Organization. 1993.

World Health Organization (WHO). Process of translation and adaptation of instruments (Online). Available: http://www.who.int/substance_abuse/research_tools/translation/en/print.html (cited Jul.23, 2006).

Wuensch K. Two Group Discriminant Function Analysis (Online). Available: http: // core.ecu.edu/psyc/wuenschk/MV/DFA/DFA2.doc ( cited Jul.23, 2006). 
Zimmerman M, Posternak MA, Chelminski I, Solomon DA. Using questionnaires to screen for psychiatric disorders: a comment on a study of screening for bipolar disorder in the community. J Clin Psychiatry. 2004 May;65(5):605-10; 